\title{
Process Heat Exchanger Options for Fluoride Salt High Temperature Reactor
}

Piyush Sabharwall

Eung Soo Kim

Michael McKellar

Nolan Anderson

The INL is a

U.S. Department of Energy

National Laboratory

operated by

Battelle Energy Alliance

April 2011

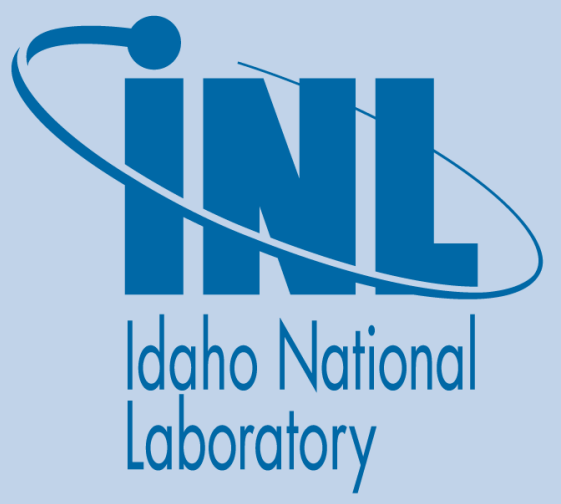




\section{DISCLAIMER}

This information was prepared as an account of work sponsored by an agency of the U.S. Government. Neither the U.S. Government nor any agency thereof, nor any of their employees, makes any warranty, expressed or implied, or assumes any legal liability or responsibility for the accuracy, completeness, or usefulness, of any information, apparatus, product, or process disclosed, or represents that its use would not infringe privately owned rights. References herein to any specific commercial product, process, or service by trade name, trade mark, manufacturer, or otherwise, does not necessarily constitute or imply its endorsement, recommendation, or favoring by the U.S. Government or any agency thereof. The views and opinions of authors expressed herein do not necessarily state or reflect those of the U.S. Government or any agency thereof. 


\title{
Process Heat Exchanger Options for Fluoride Salt High Temperature Reactor
}

\author{
Piyush Sabharwall \\ Eung Soo Kim \\ Michael McKellar \\ Nolan Anderson
}

April 2011

Idaho National Laboratory

Next Generation Nuclear Plant Project

Idaho Falls, Idaho 83415

Prepared for the

U.S. Department of Energy

Office of Nuclear Energy

Under DOE Idaho Operations Office

Contract DE-AC07-05ID14517 



\section{Process Heat Exchanger Options for Fluoride Salt High Temperature Reactor}

INL/EXT-11-21584

April 2011

Approved by:

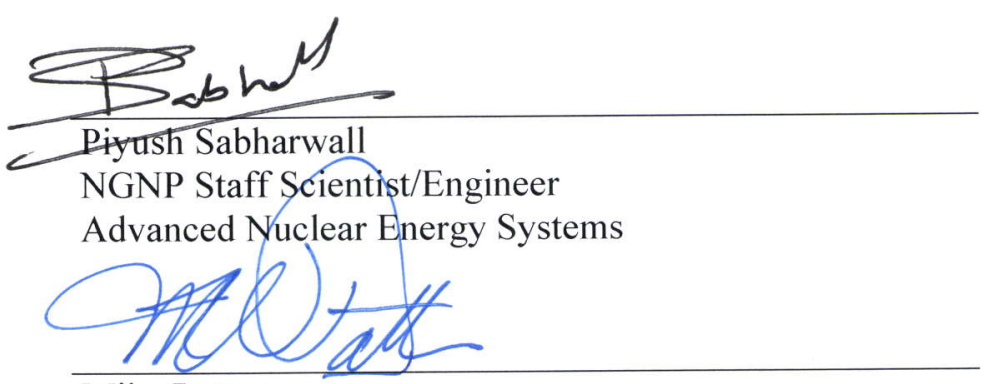

Mike Patterson

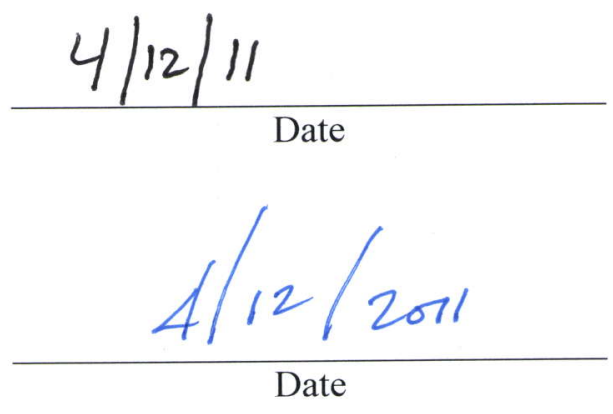

Project Manager

NGNP Process Heat Applications
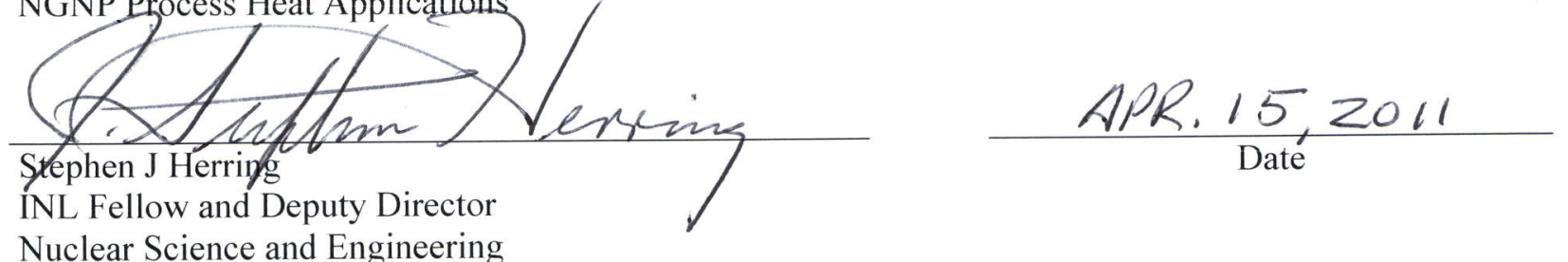

Nuclear Science and Engineering 



\begin{abstract}
The work reported herein is a significant intermediate step in reaching the final goal of commercial-scale deployment and usage of molten salt as the heat transport medium for process heat applications. The primary purpose of this study is to aid in the development and selection of a heat exchanger for power production and/or process heat application, which would support large-scale deployment.
\end{abstract}




\section{SUMMARY}

The strategic goal of the Advanced Reactor Concept Program for the fluoride high temperature reactor (FHR) is to broaden the environmental and economic benefits of nuclear energy in the U.S. economy by producing power to meet growing energy demands and demonstrating the FHRs applicability to market sectors not being served by light water reactors.

The primary purpose of this study is to aid in the development and selection of a heat exchanger for power production and/or process heat applications for the Fluoride High Temperature Reactor (FHR), which would support large-scale deployment. Of primary importance is the transfer of heat from the reactor to the power generation and/or process heat application. Heat in the FHR is transferred from the reactor core by the primary liquid-salt coolant to an intermediate heattransfer loop through an intermediate heat exchanger. The intermediate heattransfer loop uses a secondary liquid-salt coolant through a secondary heat exchanger to move the heat to a power conversion system or a process heat industrial application.

Three molten salt coolants were considered for use in the secondary coolant loop: $\mathrm{LiF}-\mathrm{NaF}-\mathrm{KF}$ (FLiNaK), $\mathrm{KF}-\mathrm{ZrF}_{4}$, and $\mathrm{KCl}-\mathrm{MgCl}_{2}$. The potential power conversion cycles identified are a super-critical Rankine steam cycle, a supercritical $\mathrm{CO}_{2}$ cycle, a subcritical Rankine steam cycle, and a helium Brayton cycle. Each of these cycles achieves different values of thermal efficiency along with diverse operating conditions. The choice of the heat exchanger type will largely depend on the operating conditions of the power conversion cycle.

Potential process heat applications were evaluated considering a maximum available temperature of $650^{\circ} \mathrm{C}$ for use by the process heat applications. The current FHR design could provide process heat for the following applications in the near term:

- Power production cycles (steam Rankine cycles, helium Brayton cycle, $\mathrm{SCO}_{2}$ cycle)

- Oil shale (in situ)

- Oil shale (ex situ)

- Oil sands.

The characteristics of candidate molten salt coolants were extensively investigated in three different aspects: coolant thermal performance, coolant cost, and coolant chemistry (corrosion). Details of these characteristics, presented in Appendix A, are summarized as follows:

- Thermal Performance: Six Figures of merit (FOMs) were developed in this study by an analytical approach to compare the thermal characteristics of various coolants. The FOMs were mathematically derived and the sensitivity of each property on the FOMs was also estimated. Overall, FLiNaK (LiF$\mathrm{NaF}-\mathrm{KF}$ ) showed superior thermal performance compared to the other candidate coolants, although it requires additional considerations for heat loss and insulation.

- Coolant Cost: The cost of the coolant in the intermediate loop was estimated. According to the comparisons, $\mathrm{KCl}-\mathrm{MgCl}_{2}$ had the lowest cost followed by 
$\mathrm{NaCl}-\mathrm{MgCl}_{2}$. All other molten salt costs are about two orders of magnitude greater. Among the fluoride based salts, $\mathrm{KF}-\mathrm{KBF}_{4}$ had the lowest cost, followed by NaF-NaBF 4 and then LiF-NaF-KF. However, entire system economics need to be considered because component sizes will be different for each coolant.

- Coolant Chemistry (Corrosion): Corrosion of process equipment is an essential issue for molten salt coolants. Careful alloy design and saltchemistry control will be necessary to operate fluoride salt coolants with a tolerable level of corrosion. A large degree of uncertainty is expected when using chloride and fluoroborate salts in a high temperature system because of a lack of experimental data. Investigations will be required with respect to the coolant corrosion of the secondary heat exchanger metallic material fabricated components (diffusion welded compact heat exchangers and welded structural components).

Of the 11 candidates compared, the molten salt FLiNaK (LiF-NaF-KF) is considered the best for use as the coolant in the FHR intermediate loop. It exhibits the best thermal performance, a reasonable coolant cost among the fluoride salts, with the most controllable corrosion effect by careful alloy selection (Hastelloy $\mathrm{N}$ is one of the suitable alloys) and chemistry control.

The basic setup for the selection of the secondary heat exchanger has been established with evaluation goals, alternatives, and criteria. Feasibility studies will be conducted to provide sufficient information for the evaluation and decision making process. Development of the integration methodology is an ongoing task. 


\section{CONTENTS}

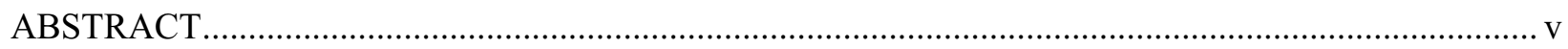

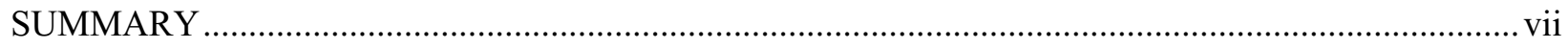

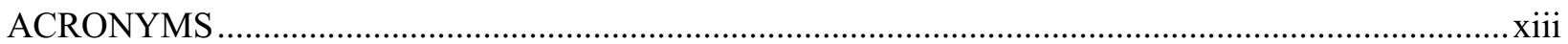

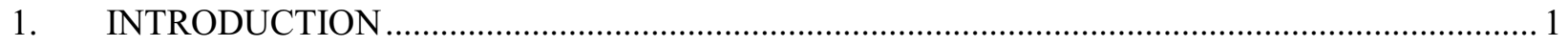

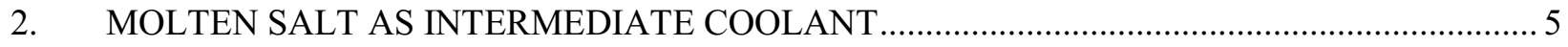

2.1 Molten Salt Key Characteristics........................................................................................ 5

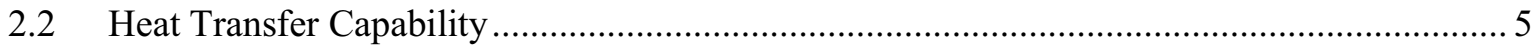

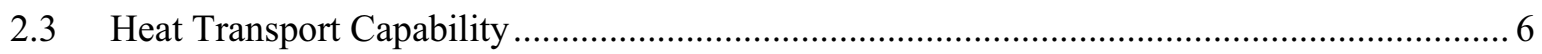

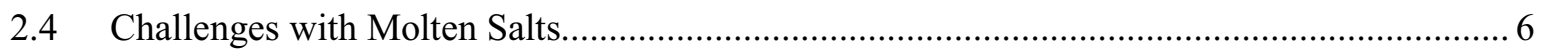

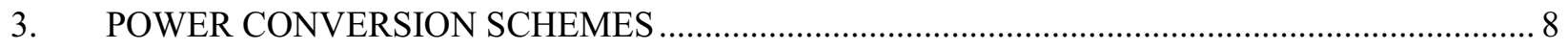

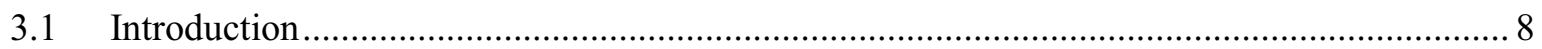

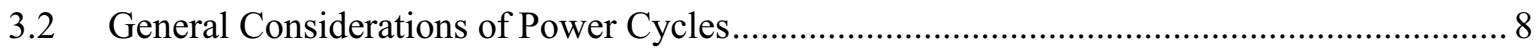

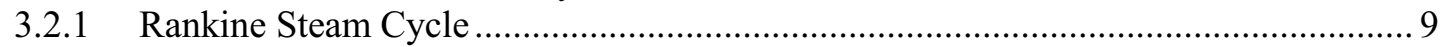

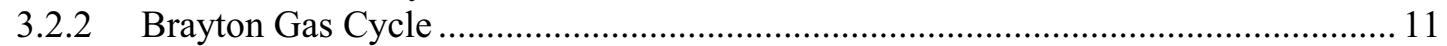

3.2.3 Supercritical Carbon Dioxide Recompression Brayton Cycle ................................... 13

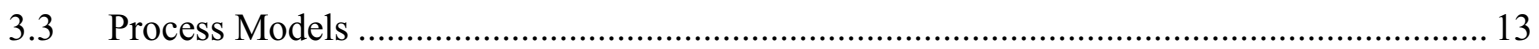

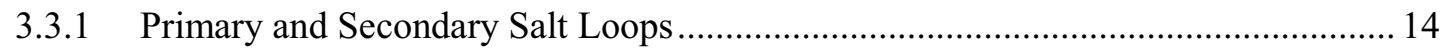

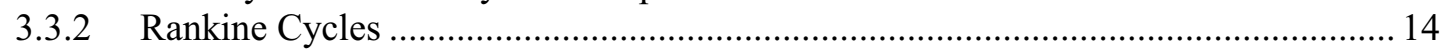

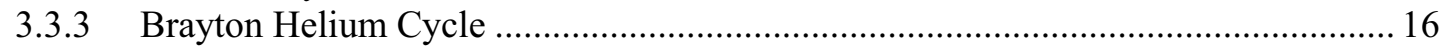

3.3.4 Supercritical Carbon Dioxide Recompression Brayton Cycle ................................. 16

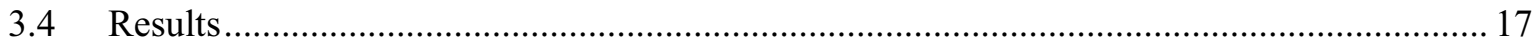

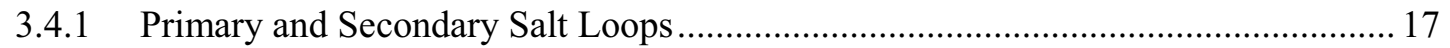

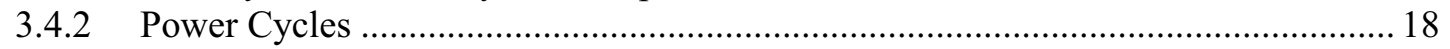

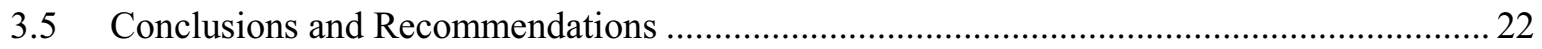

4. APPLICABILITY OF HEAT EXCHANGER TO PROCESS HEAT APPLICATIONS ................ 23

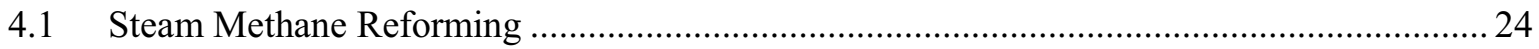

4.2 Substitute Natural Gas Production Analysis ................................................................25

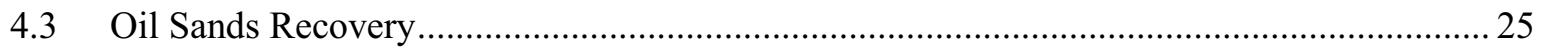

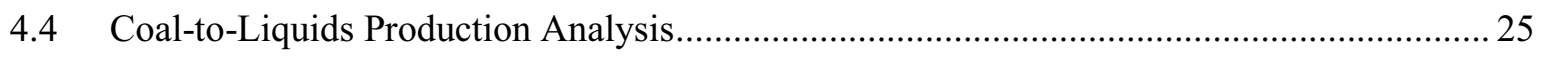

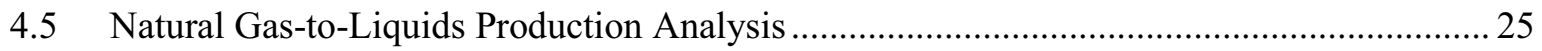

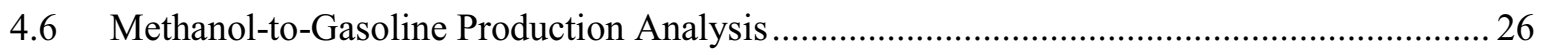

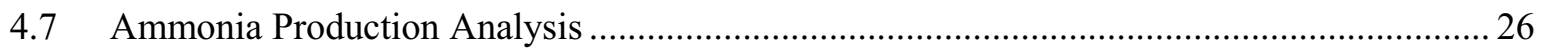

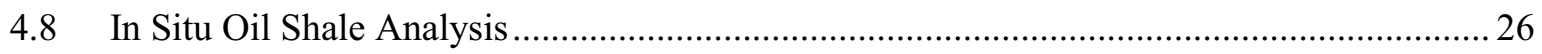

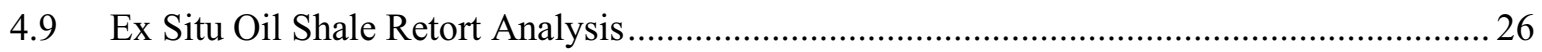

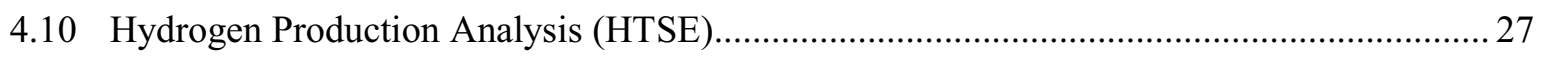

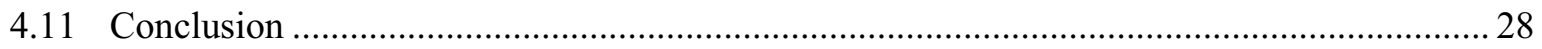

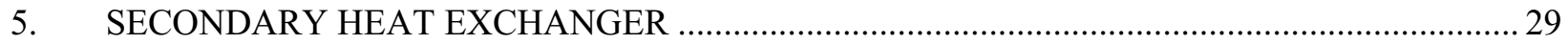




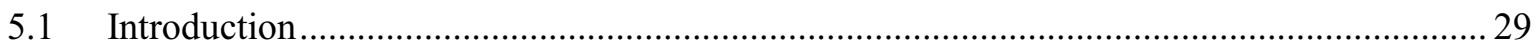

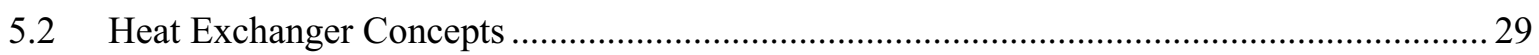

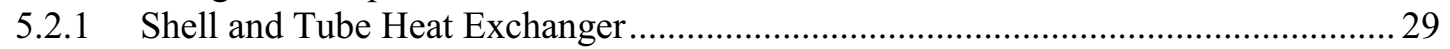

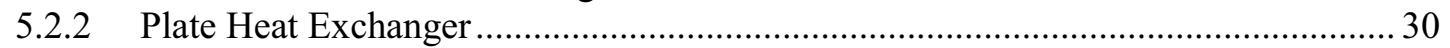

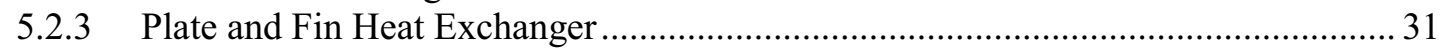

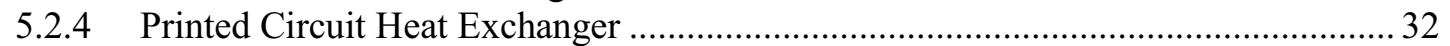

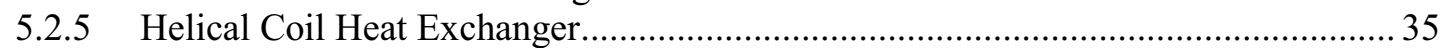

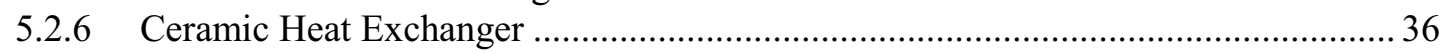

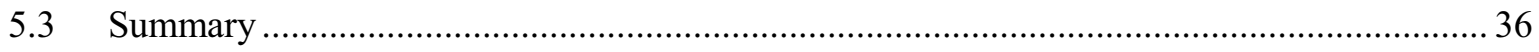

6. COMPARISONS OF FHR COOLANT PROPERTIES AND SELECTION ............................... 37

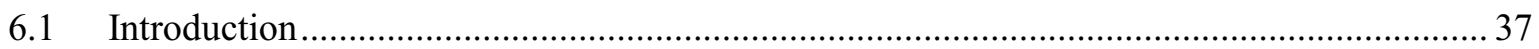

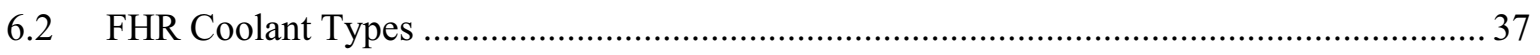

6.3 Key Parameters for the FHR Heat Exchanger Coolant Thermal Performance...................... 39

6.4 Comparisons of Coolant Thermal-Hydraulic Performance ............................................... 39

6.4.1 Comparisons of Coolant Thermal-Hydraulic Performance ....................................... 43

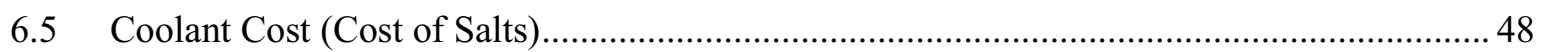

6.6 Coolant Chemical (Corrosion) Considerations .............................................................. 49

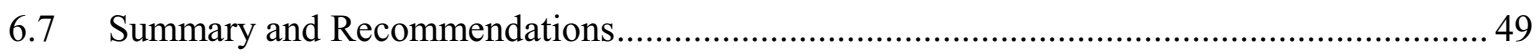

7. HEAT EXCHANGER EVALUATION AND SELECTION METHOD........................................... 51

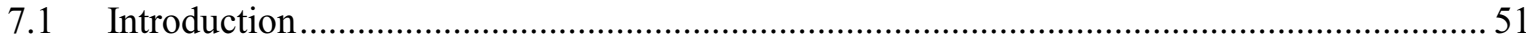

7.2 Initial Screening of Heat Exchanger Type Based on Operating Parameters........................ 51

7.3 Evaluation Method and Plan for Selection of FHR Heat Exchanger ................................... 54

7.3.1 Evaluation Method: Analytical Hierarchy Process .................................................... 54

7.3.2 Goal, Alternatives, and Criteria for FHR Heat Exchanger Selection......................... 55

7.3.3 Modeling of the FHR Heat Exchanger Selection................................................... 59

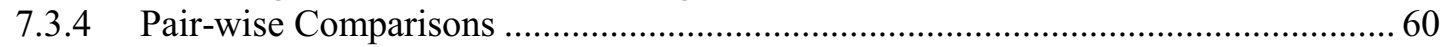

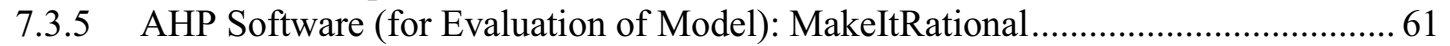

7.3.6 Plan for FHR Heat Exchanger Evaluation and Selection.......................................... 62

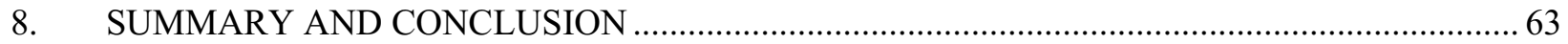

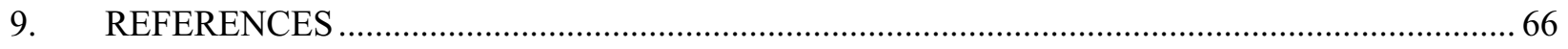

Appendix A Development of Figures of Merit for Coolant Thermal-Hydraulic Performance.................. 69

\section{FIGURES}

Figure 1-1. Conceptual design of pebble bed FHR with power generation cycle (Holcomb et al. 2009). 3

Figure 1-2. Thermal energy transfer in FHR for power or process application........................................ 4

Figure 3-1. Heat engine between hot source and cold sink ................................................................ 8

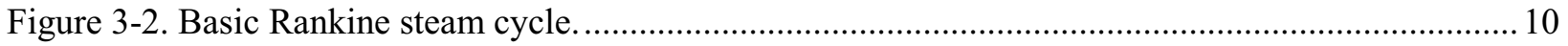

Figure 3-3. Rankine steam cycle with feed-water heaters. ................................................................... 11 


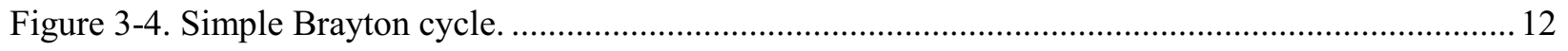

Figure 3-5. Helium Brayton cycle with reheat and recuperation. ...................................................... 12

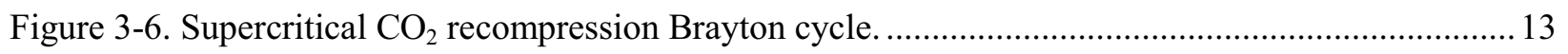

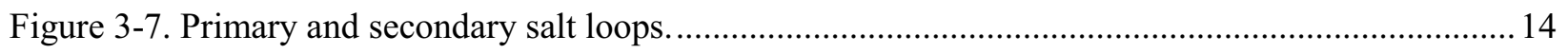

Figure 3-8. Process flow diagram of Rankine steam cycle ................................................................ 15

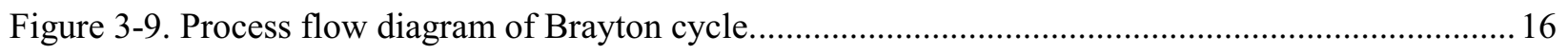

Figure 3-10. Process flow diagram of super-critical $\mathrm{CO}_{2}$ modified Brayton cycle. ................................. 17

Figure 4-1. Process applications for FHR versus required temperature. ................................................. 23

Figure 4-2. Thermal energy transfer in FHR for power or process application....................................... 24

Figure 4-3. Block flow diagram for an FHR-integrated ex situ oil shale retort operation........................ 27

Figure 5-1. Shell and tube heat exchanger with baffles (Sherman and Chen 2008) ................................. 30

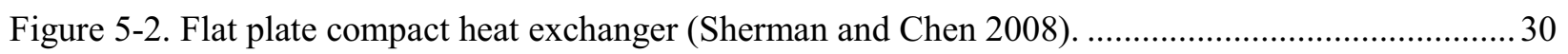

Figure 5-3. Bavex welded plate heat exchanger (Fisher and Sindelar 2008).......................................... 31

Figure 5-4. Elements of diffusion-bonded plate and fin heat exchanger (Fisher and Sindelar

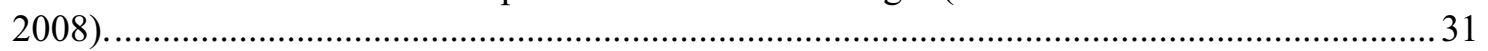

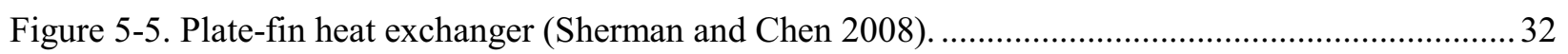

Figure 5-6. First step — plate passages (Heatric ${ }^{\mathrm{TM}}$ Homepage 2011) ..................................................... 32

Figure 5-7. Second step — diffusion bonding of plates (Heatric ${ }^{\text {TM }}$ Homepage 2011) ............................. 33

Figure 5-8. Diffusion-bonded PCHE section (Heatric ${ }^{\mathrm{TM}}$ Homepage 2011) . ............................................ 33

Figure 5-9. Third step — block composed of diffusion-bonded plates (Heatric ${ }^{\mathrm{TM}}$ Homepage 2011).......... 33

Figure 5-10. Cross sectional view of the semi-circular passages (Heatric ${ }^{\mathrm{TM}}$ Homepage 2011) ................ 34

Figure 5-11. Side view of passage shapes (Hesselgreaves 2001)........................................................ 34

Figure 5-12. Current operating experience of Heatric ${ }^{\mathrm{TM}}$ PCHEs (Gezelius 2004) .................................. 34

Figure 5-13. Simple cross flow (left) and cross-counterflow (right) configuration (Hesselgreaves

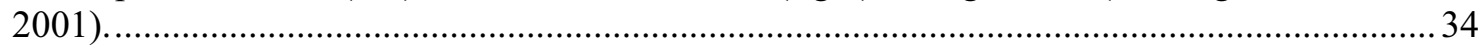

Figure 5-14. The Heatric ${ }^{\mathrm{TM}} \mathrm{H}^{2} \mathrm{X}$ heat exchanger-PCHE construction on the left side and plate

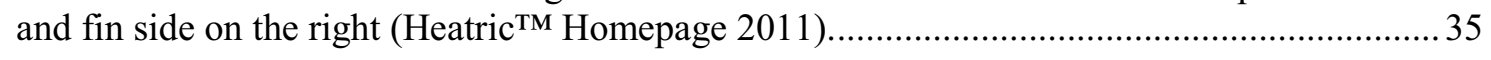

Figure 5-15. A helical-coil heat exchanger (Areva 2008).................................................................. 35

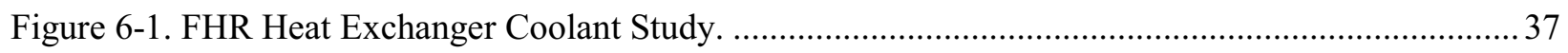

Figure 6-2. General thermal-hydraulic requirements for the intermediate coolant in the FHR

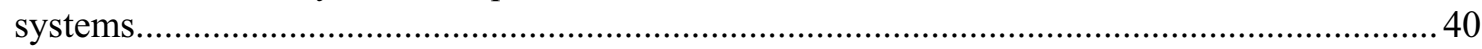

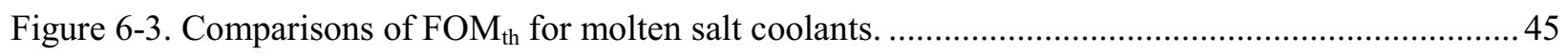

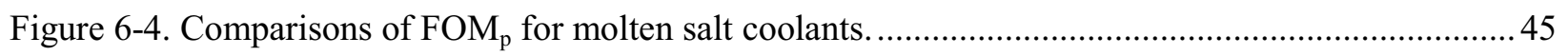

Figure 6-5. Comparisons of $\mathrm{FOM}_{\mathrm{cv}}$ for molten salt coolants............................................................... 46

Figure 6-6. Comparisons of $\mathrm{FOM}_{\mathrm{ccv}}$ for molten salt coolants................................................................ 46

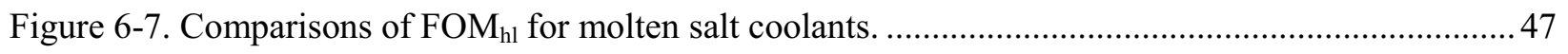




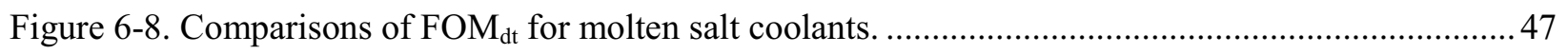

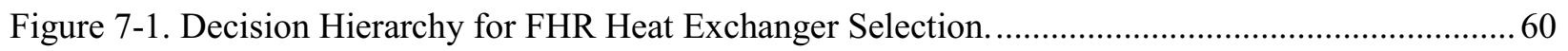

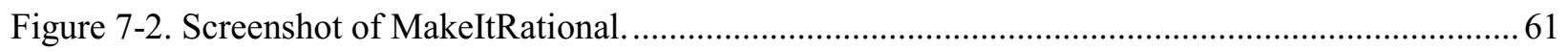

Figure A-1. General thermal-hydraulic requirements for the intermediate coolant in the FHR

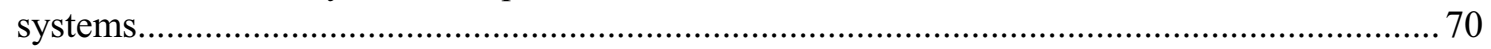

Figure A-2. General configuration of intermediate heat transfer loop............................................... 71

Figure A-3. Geometry and input parameters for FOM development (heat transfer performance)............ 72

\section{TABLES}

Table 1-1. Basic physical properties of molten salts [Williams 2006].................................................. 2

Table 3-1. Mass flow rates and IHX temperatures for the primary and secondary salt loops.................. 18

Table 3-2. Design data for IHX between primary and secondary salt loops. .......................................... 18

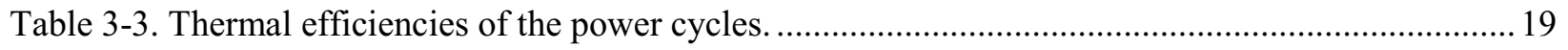

Table 3-4. Maximum pressure for each power cycle ............................................................................ 19

Table 3-5. Minimum pressure of each power cycle ................................................................................. 19

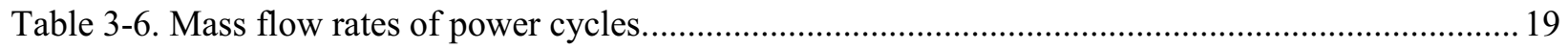

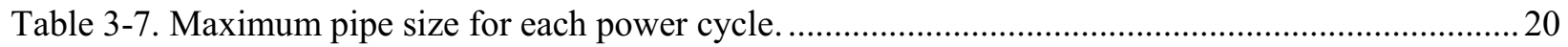

Table 3-8. Temperatures, mass flows, and pressures of heat exchangers between secondary loops

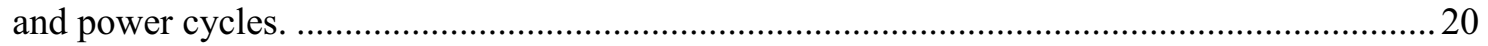

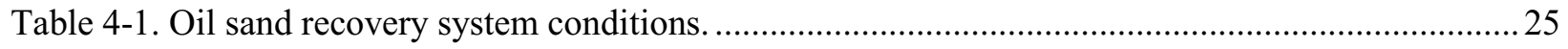

Table 4-2. Oil Shale (In Situ and Ex Situ) production system conditions............................................22

Table 6-1. Summary of the candidate molten salt properties for heat transfer loop (Williams et al.

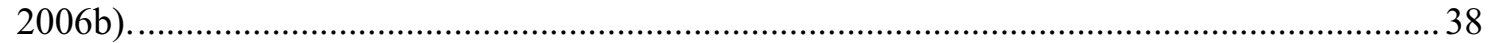

Table 6-2. Summary of FOMs for heat transfer coolant (refer Appendix A for details)......................... 42

Table 6-3. Summary of Reference Values in FOMs (Water at $25^{\circ} \mathrm{C}, 1 \mathrm{~atm}$ ) (SI unit).......................... 42

Table 6-4. Comparisons of FOMs for the Various Molten Salt Coolants................................................. 44

Table 6-5. Raw material costs for various salt mixtures and relative total cost estimations...................... 48

Table 7-1. Principal features of several types of heat exchangers (Shah 2003).......................................53

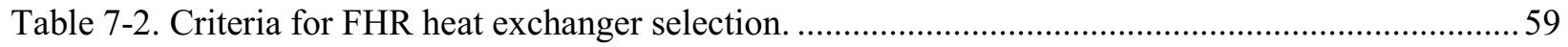

Table 7-3. Fundamental scale for pair-wise comparison in AHP (Forman 2001)...................................61

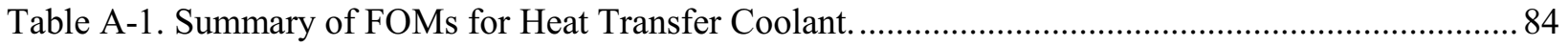




\section{ACRONYMS}

AHP Analytical Hierarchy Process

ARE Aircraft Reactor Experiment

ASME American Society of Mechanical Engineers

BPV Boiler and Pressure Vessel

FHR Fluoride High Temperature Reactor

FOM Figure of Merit

HTSE High Temperature Steam Electrolysis

IHX Intermediate Heat Exchanger

LMTD Log Mean Temperature Difference

LOC Loss of Coolant

MCD Multicriteria Decision Analysis

MSRE Molten Salt Reactor Experiment

ORNL Oak Ridge National Laboratory

PCS Power Conversion System

ROT Reactor Outlet Temperature

SAGD Steam Assisted Gravity Drainage

SHX Secondary Heat Exchanger 


\section{Process Heat Exchanger Options for Fluoride Salt High Temperature Reactor}

\section{OBJECTIVE}

The work reported herein is a significant intermediate step in reaching the final goal of large scale deployment and usage of molten salt as the heat transport medium for process heat applications. The primary purpose of this study is to aid in the development and selection of a heat exchanger for power production and/or process heat application, which would support large-scale deployment.

\section{INTRODUCTION}

Molten salt technology has been used for many decades in industrial process heat transfer, thermal storage, heat treatment, high-temperature electrochemical plating, and other materials processing applications. The potential utility of molten salts as heat transfer agents was also demonstrated for nuclear reactors, as the liquid fuel in the Aircraft Reactor Experiment (ARE) and the Molten Salt Reactor Experiment (MSRE) programs. The behavior and material compatibility of various molten salts was studied extensively by Oak Ridge National Laboratory (ORNL) from the 1950s through the 1970s in support of the MSRE and the Molten Salt Breeder Reactor programs (Sohal et al. 2010). Several types of molten salt, including LiF-NaF-KF $(46.5,11.5$, and $52 \mathrm{~mol} \%$, respectively; also known as FLiNaK), LiF$\mathrm{BeF}_{2}$ (67 and $33 \mathrm{~mol} \%$, respectively; also known as $\mathrm{FLiBe}$ ), and $\mathrm{KCl}-\mathrm{MgCl}_{2}$ (68 and $32 \mathrm{~mol} \%$, respectively) have been recently investigated by several Japanese and U.S. groups (FLiBe and FLiNaK), as well as the University of Wisconsin $\left(\mathrm{KCl}-\mathrm{MgCl}_{2}\right.$ and $\left.\mathrm{FLiNaK}\right)$ in support of fusion reactor and high temperature reactor concepts, respectively.

The characteristics essential for a high temperature reactor coolant are (Williams 2006; Sabharwall et al. 2010a):

- Chemical stability at high temperatures $\left(500\right.$ to $\left.800^{\circ} \mathrm{C}\right)$

- Freezing (melting) temperature as low as possible, preferably lower than $525^{\circ} \mathrm{C}$

- Large specific heat and thermal conductivity

- Low vapor pressures that are substantially less than one atmosphere at operating temperatures and are thus not volatile

- Compatible with high-temperature materials, alloys, graphite, and ceramics.

Molten salts appear to be excellent candidates, meeting most of these requirements. However, no single-component salt meets the requirement of low melting temperature; multicomponent eutectic mixtures are needed to meet the melting temperature requirement. Some multicomponent eutectic salt mixtures have melting temperatures less than $500^{\circ} \mathrm{C}$. The use of eutectic mixtures ensures compositional and phase stability, and therefore, uniform thermophysical properties in the operating temperature range (Grimes et al. 1972; Ingersoll et al. 2007). A primary advantage of molten salt technology is that the molten salt can be heated to $\sim 560^{\circ} \mathrm{C}$, which allows high energy steam to be generated at utility-standard temperatures of $11.4 \mathrm{MPa}$ and $550^{\circ} \mathrm{C}$, thus achieving high thermodynamic cycle efficiencies of approximately $40 \%$ in modern steam turbine systems.

Molten salts are excellent coolants, with a $25 \%$ higher volumetric heat capacity than pressurized water and nearly five times that of liquid sodium as indicated by LeBlanc 2010b. The greater heat capacity of molten salts results in more compact primary loop components like pumps and heat 
exchangers. Since liquid salts are not as pressurized in the system (loop), the leak in the system would not cause an extreme pressure difference in the plant.

The melting temperature of a salt mixture is one of, if not the most important criteria in the selection of a salt. The desired salt mixture should have a melting temperature as low as possible while maintaining thermal stability of the salt at temperatures up to $1000^{\circ} \mathrm{C}$. One way to lower the melting point of a salt is to combine multiple salts together to form a salt of eutectic composition, which has a lower melting temperature than the individual salt components and are characterized by a single melting point. However, most ternary and higher-order systems of salt mixtures do not have much experimental data available for the determination of density, viscosity, and thermal conductivity as shown by Sohal et al. (2010).

Liquid salts offer two potential advantages: smaller equipment size because of the higher volumetric heat capacity, and no gross chemical exothermal reactions between the reactor, intermediate loop, and power cycle coolants as explained by Renault et al. (2009). After studying a variety of individual molten salt mixtures, chlorides and fluorides have been given the most serious consideration. However, the neutron cross section of molten chlorides eliminates their use in the primary loop of the thermal reactors. The University of Wisconsin is presently considering them for use as potential heat transport fluids (Anderson et al. 2010).

Three heat transfer molten salts have been identified as possible candidates for use in the secondary or tertiary side: $\mathrm{LiF}-\mathrm{NaF}-\mathrm{KF}$ (FLiNaK), $\mathrm{KCl}-\mathrm{MgCl}_{2}$ and $\mathrm{KF}^{-} \mathrm{ZrF}_{4}$. Their physical properties are shown in Table 1.

Table 1-1. Basic physical properties of molten salts [Williams 2006].

\begin{tabular}{|l|c|c|c|c|}
\hline \multicolumn{1}{|c|}{ Salt } & $\begin{array}{c}\text { Composition } \\
(\mathrm{mol} \%)\end{array}$ & $\begin{array}{c}\text { Molecular Weight } \\
(\mathrm{g} / \mathrm{mol})\end{array}$ & $\begin{array}{c}\text { Melting Point } \\
\left({ }^{\circ} \mathrm{C}\right)\end{array}$ & $\begin{array}{c}\text { Boiling Point } \\
\left({ }^{\circ} \mathrm{C}\right)\end{array}$ \\
\hline $\mathrm{LiF}-\mathrm{NaF}-\mathrm{KF}$ & $(46.5-11.5-42)$ & 41.3 & 454 & 1570 \\
\hline $\mathrm{KF}_{\mathrm{ZrF}} \mathrm{Z}$ & $(58-42)$ & 103.9 & 390 & $\sim 1450$ \\
\hline $\mathrm{KCl}-\mathrm{MgCl}_{2}$ & $(68-32)$ & 81.4 & 426 & $>1418$ \\
\hline
\end{tabular}

The use of a liquid salt provides the potential for improved heat transfer and reduced pumping power, but also introduces materials compatibility issues. Fluoride salt is a leading candidate as a fluid to transfer heat from the fluoride high-temperature Reactor (FHR) to the process application plant because of its better heat transfer capabilities. It is also chemically stable across a wide range of temperatures, with boiling temperatures around $1400^{\circ} \mathrm{C}$.

The emerging class of FHRs is part of the advanced reactor concept program. FHRs produce high outlet temperature $\left(704^{\circ} \mathrm{C}\right)$ using coated particle fuel and can potentially improve upon the attributes of existing light water reactors. An FHR reactor core consists of coated particle fuel embedded within graphite fuel elements. Graphite reflectors provide additional moderation and core structure. Heat removed from the reactor is transferred to a secondary salt that, in turn, is transferred to a tertiary side for power production or process heat application. The various scenarios under consideration for power production are described later in this report. The first FHR is still in the early development stage, but will, of necessity, be a test-scale reactor sized about the same as the MSRE in order to validate the system attributes before proceeding to larger-scale systems (Holcomb et al. 2009). So far, molten salt reactors have focused mainly on power production, but new concepts such as FHRs are looking into process heat applications, making them more attractive to industry. 
The pebble bed type reactor design is currently being considered for the FHR, but does not imply that this reactor type is superior to a prismatic design. The moving fuel in the form of pebbles is advantageous for FHRs when compared with other advance reactor concepts because the FHR has higher power density and consequently more rapid fuel burnup. Maintaining a high power density along with an adequately long refueling interval is a challenging problem for core design. A conceptual drawing of a pebble bed FHR as proposed by the University of California at Berkeley is shown in Figure 1-1.

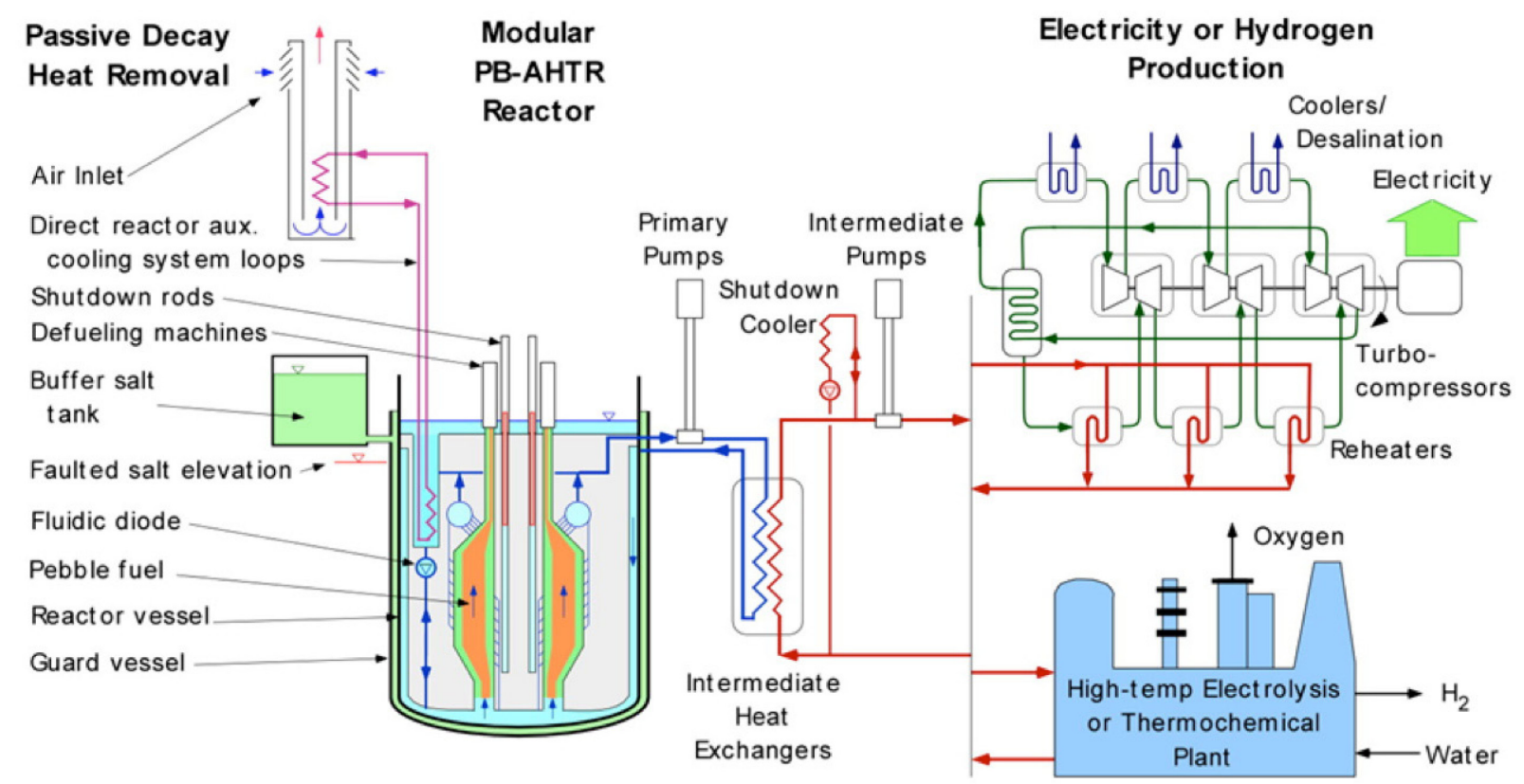

Figure 1-1. Conceptual design of pebble bed FHR with power generation cycle (Holcomb et al. 2009).

The increased FHR core outlet temperature also increases the thermal efficiency of the reactor, lowering the amounts of both waste heat and spent fuel produced per unit energy. It also, enables FHRs to serve as a source of industrial process heat (Holcomb et al. 2009). The effective natural circulation heat transfer provided by liquid salts enables passive heat rejection to ambient air using a direct reactor auxiliary cooling system. The effective passive heat removal allows large flexibility in reactor design. The reactor's low pressure, combined with the modular nature of its direct reactor auxiliary cooling system, enables FHRs to be developed to almost any power scale (Holcomb et al. 2009).

As shown in Figure 1-1, the FHR uses several heat exchangers in order to transfer heat from the reactor primary to the power conversion system or industrial plants. An intermediate heat exchanger (IHX) transfers heat from the reactor primary to the intermediate heat transfer loop.

Heat in the FHR is transferred from the reactor core by the primary liquid-salt coolant to an intermediate heat-transfer loop through an IHX. The intermediate heat-transfer loop uses a secondary liquid-salt coolant through a secondary heat exchanger (SHX) to move the heat to a power conversion system or a process heat industrial application as shown in Figure 1-2. The FHR is in the early developmental stage. The reactor outlet temperature (ROT) is currently $704^{\circ} \mathrm{C}$, but will possibly increase to 900 to $1000^{\circ} \mathrm{C}$ for the $\mathrm{n}^{\text {th }}$-of-a-kind. With its ability to provide higher ROT, the process heat application becomes an attractive option and its development is independent of the reactor design such that the process application component design should be a continuous, simultaneous, and parallel effort along with the development of the FHR. In the FHR, these heat exchangers are considered key components that 
need to be extensively investigated, because they are operated under a severe environment and their performance is directly related to the overall system efficiency and safety.

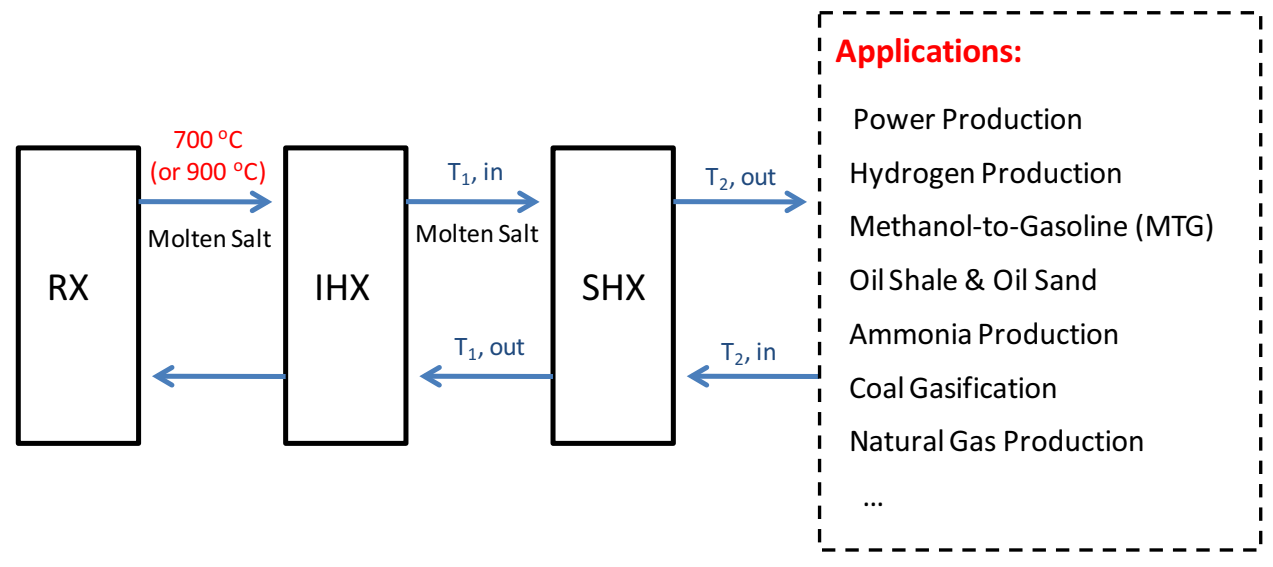

Figure 1-2. Thermal energy transfer in FHR for power or process application

The process plant will likely be separated from the nuclear plant because of safety, contamination, and licensing requirements (Sabharwall and Gunnerson 2009). Therefore the heat transfer fluid will likely have to travel significant distances without much, if any, temperature drop as most of the process heat applications are temperature driven. Several fluids could potentially be used to transfer the thermal energy, including alkali metals, helium, and molten salts. Alkali metals generally have lower melting temperatures and boiling points, which could lead to significant enthalpy gain when compared to singlephase heat transfer fluids, but they also have some material compatibility issues (Sabharwall 2009). This work focuses on liquid salts as the potential heat transfer fluids, which have been discussed previously (refer Table 1-1).

In this study different power conversion schemes are mentioned with their respective efficiencies for power production, followed by list of various near term or long term process heat applications that could potentially be met by the FHR. In order to transfer the thermal energy from the reactor to the process industry various heat exchangers would be employed. A list of potential secondary heat exchanger concepts are described with the explanation of evaluation and selection methodology. Development of the integration methodology and feasibility study is an ongoing task and will be covered in the later reports as the work progresses. 


\section{MOLTEN SALT AS INTERMEDIATE COOLANT}

The two main aspects in determining the effectiveness of a coolant are heat transfer and transport capability. Heat transfer capability can be defined by the heat transfer coefficient, while heat transport capability is defined by the ratio of thermal power removed to the pumping power required (Latzko 1970). A coolant could pose good heat transfer capability but not have good heat transport capability. For example, sodium and lithium pose superior heat transfer capability because of larger thermal conductivity, but liquid salts have a much higher value for density compared to both lithium and sodium, so are better coolants in heat transport capability (Latzko 1970; Sabharwall et al. 2010b).

\subsection{Molten Salt Key Characteristics}

Four key characteristics can be further divided into different characteristics (Benes et al. 2009):

- Thermophysical characteristics

- Large heat capacity

- $\quad$ Low melting point

- High boiling point

- Low vapor pressure

- High density at low pressure

- Safety characteristics

- Optical transparency

- In-service inspection

- Economics characteristics

- Low cost of salt as compared to liquid metal coolants

- Good resource availability

- Compatibility with cheap materials

- Chemistry characteristics

- Chemical stability

- Corrosiveness

- Chemical reactivity (water, air)

- $\quad$ Salt cleanup (with ease).

\subsection{Heat Transfer Capability}

Molten salts:

- Have a high volumetric expansion with temperature, providing strong natural circulation cooling in the event of loss-of-forced convection (Holcomb et al. 2009)

- Have a high heat capacity and other excellent qualities that lower pumping requirements, resulting in smaller heat exchangers (LeBlanc 2010a)

- Have low vapor pressures, which reduce the stress requirements in the piping 
- Allow for efficient thermal transport at relatively low pressure

- Have lower vapor pressure at the heat exchanger temperatures required for process heat transfer, enabling the heat exchanger to have thinner walls, which is more desirable for heat transfer.

\subsection{Heat Transport Capability}

Molten salts:

- Have good chemical stability and compatibility (if oxidation potential is under check in the loop) at higher temperatures

- Are reasonably compatible with high-temperature alloys (such as Hastelloy-N, and Alloys $800 \mathrm{H}$ and 617)

- Have acceptable safety characteristics under normal and off-normal conditions

- Have a higher volumetric heat capacity; i.e. the amount of molten salt required to transfer the heat is reduced, making it a more economically viable option that requires lower specific pumping power.

\subsection{Challenges with Molten Salts}

The following are key issues with molten salts:

- The use of molten salts requires the qualification of a new structural alloy, although the MSRE experience with Hastelloy $\mathrm{N}$ should limit the extent of risks and costs if the design temperature is maintained within the limits of previous material qualification $\left(704^{\circ} \mathrm{C}\right)$.

- Validation of salt compatibility with structural materials for all components is required under operating conditions (temperature and flow), including specific components such as joints, welds, valves, flanges, etc. Available knowledge of corrosion processes and qualification data is limited, and available for a few material combinations only (Sohal et al. (2010)). If active chemistry control is envisioned as part of the design for corrosion control, validation of long-term operation and effect on materials compatibility is also required.

- Physical properties for most of the fluoride salts, such as thermal conductivity, heat capacity and infrared absorptions, are not known with the desired precision (for example, thermo-physical and thermo-chemical properties database for $\mathrm{KF}^{-} \mathrm{ZrF}_{4}$ has not been validated). Validation of heat transport correlations with uncertainty analysis is also required.

- Some salt elements (most noticeably, beryllium) and materials required in handling processes (for example, fluoride gas) are toxic, creating safety challenges in particular for accident scenarios related to loss of coolant events and when evaluating cost of development activities (Holcomb et al. 2009).

- The relatively high melting point of most candidate salts makes thermal control of the coolant a challenge, in particular with respect to potential freezing during transient events. This issue is particularly challenging when considering process heat applications that are separated from the nuclear island because of safety, contamination, and licensing requirements (Sabharwall and Gunnerson 2009), when the heat transfer fluid must travel significant distance within insulated pipes. Effects of salt properties variations with temperature on structural and components materials must also be considered for long term operation and reliability (Holcomb et al. 2009)

- Instrumentation and inspection techniques for molten salt components require development and validation. 
- Assessment of compatibility between coolant salts and selected power cycle and process heat fluid requires analysis and experimental validation.

- Development and validation of salt handling processes at an industrial level is required, from preparation and purification to composition and chemistry control during operation. 


\section{POWER CONVERSION SCHEMES}

\subsection{Introduction}

The purpose of this section is to compare secondary heat loops using a variety of salts and their effects on a variety of power cycles. The salts analyzed for this study are FLiNaK (a tertiary salt), and $\mathrm{KCl}-\mathrm{MgCl}_{2}$, and $\mathrm{KF}-\mathrm{ZrF}_{4}$ (two binary salts). The primary reactor loop fluid is FLiBe (a binary salt). The power cycles analyzed are super-critical and sub-critical Rankine steam cycles, super-critical carbon dioxide, $\mathrm{CO}_{2}$, modified Brayton cycle, and a standard helium Brayton cycle.

\subsection{General Considerations of Power Cycles}

This section describes several power cycles that are used to generate electricity. The major difference between nuclear and non-nuclear power cycles is the heat source. Fossil fuels are the heat source for conventional plants, whereas nuclear fission is the heat source for a nuclear plant. A secondary difference is the type of cycle. Some fossil fuel power cycles are open cycles in which the reacted gases are exhausted to the atmosphere. Nuclear power cycles are closed cycles.

One of the primary functions of a nuclear reactor is to produce electricity. A power cycle generally consists of four stages: heat addition, power generation through expansion, heat rejection, and compression. When the working fluid of the power cycle directly cools the core of the nuclear plant, it is called a direct cycle. If the working fluid of the power cycle and the primary cooling loop of the reactor core are separate, it is called an indirect cycle. In an indirect cycle, heat from the core is provided to the power cycle by means of a steam generator or IHX. Direct power cycles can provide more electrical power from heat generated by the core but the power cycle components are contaminated with radioactive materials.

Optimal thermodynamic performance of a cycle is measured by its thermal efficiency. The thermal efficiency is defined as the electrical power output divided by the heat input, or

$\eta_{t h}=\frac{\dot{W}_{\text {elec }}}{\dot{Q}_{\text {in }}}$

A power cycle is thus based on the thermodynamic concept of a heat engine. Power may be produced from a heat engine that is placed between a high-temperature source and a low-temperature sink as shown in Figure 3-1. The work of the heat engine is defined as:

$\dot{W}=\dot{Q}_{H}-\dot{Q}_{L}$

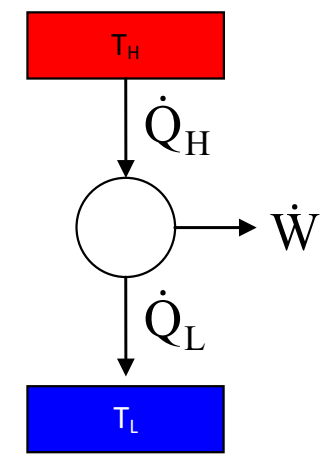

Figure 3-1. Heat engine between hot source and cold sink. 
Heat is transferred from the high-temperature source to the heat engine and heat is rejected from the heat engine to the low temperature sink. The thermal efficiency of a heat engine can be shown as:

$$
\eta_{t h}=\frac{\dot{Q}_{H}-\dot{Q}_{L}}{\dot{Q}_{H}}
$$

In real situations, a temperature difference is needed to transfer the heat from the source to the heat engine and from the heat engine to the heat sink. However, if those differences were made to go to zero, an ideal or maximum efficiency could be determined. The maximum efficiency is called the Carnot efficiency and is a function of source and sink temperatures only, as in:

$\eta_{\text {Carnot }}=\frac{T_{H}-T_{L}}{T_{H}}$

In this report, four power cycles were analyzed: Rankine super-critical and sub-critical steam cycles, helium Brayton gas cycle, and a modified super-critical carbon dioxide Brayton cycle. The following assumptions were made for all of the cycles analyzed:

- Reactor heat output is $20 \mathrm{MW}(\mathrm{t})$

- Outlet temperature of the reactor is $704^{\circ} \mathrm{C}$

- Inlet temperature of the reactor is $600^{\circ} \mathrm{C}$

- Turbines and compressors of the Brayton cycles have $90 \%$ isentropic efficiencies

- Circulators and pumps have $75 \%$ isentropic efficiencies

- IHX and steam generators have minimum approach temperatures of $25^{\circ} \mathrm{C}$

- All other heat exchangers in the Brayton cycles have minimum approach temperatures of $20^{\circ} \mathrm{C}$

- The feed water heaters in the Rankine cycles have minimum approach temperatures of $5.6^{\circ} \mathrm{C}$

- Pressure drops across the components are $2 \%$ of the inlet pressure to the component.

The assumptions for the reactor are based on a fluoride salt cooled reactor concept developed at ORNL (Holcomb et al. 2009).

\subsubsection{Rankine Steam Cycle}

The Rankine steam cycle is the most basic thermodynamic power cycle. The simplest cycle consists of a steam generator, a turbine, a condenser, and a pump as shown in Figure 3-2. The working fluid is water. Low-pressure water is pumped to a high pressure. Heat is transferred to the water through a steam generator to produce high-pressure steam. The steam expands through the turbine to produce flow work or power, which is then converted to electricity in a generator. The low-pressure saturated steam/water is condensed to liquid water in the condenser (Van Wylen and Sonntag 1973).

The efficiency for this cycle is defined as the power difference between the turbine and the pump divided by the heat input from the steam generator as in

$$
\eta_{\text {th }}=\frac{\dot{W}_{\text {Turbine }}-\dot{W}_{\text {Pump }}}{\dot{Q}_{\text {SteamGenerator }}} .
$$




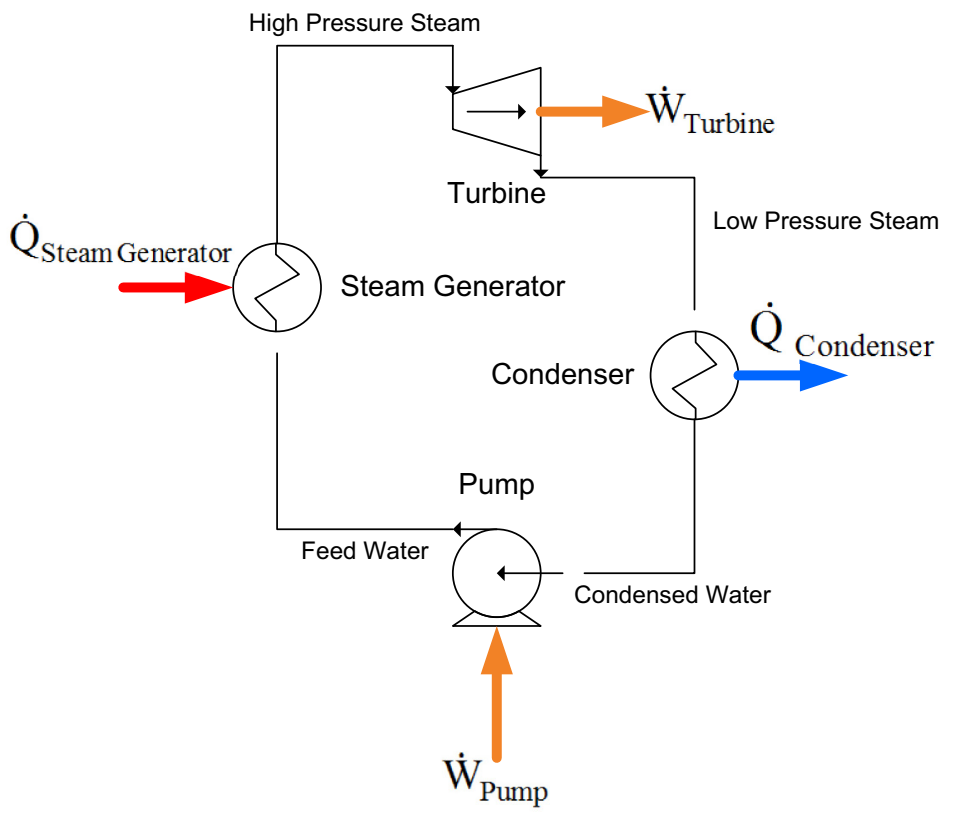

Figure 3-2. Basic Rankine steam cycle.

The cycle efficiency can be improved through heat recuperation in which partially expanded streams from the turbine exchange heat with the stream exiting the pump or feed water stream using exchangers labeled as feed water heaters. The efficiency can also be improved by reheating the partially expanded stream in the steam generator before it is further expanded in the turbine. Figure 3-3 shows a Rankine steam cycle with feed water heaters and a set of turbines. The partially expanded streams are split from the primary turbine stream to supply heat to the steam generator's feed water. These streams are mixed with the exit stream of the low-pressure turbine before the condenser. The power cycle is separated from the heat of the reactor through one circulation loop: the secondary salt loop. The purpose of the separation is to prevent tritium migration to the components of the power cycle. The thermal efficiency of the Rankine cycle for this work is defined as:

$\eta_{\text {th }}=\frac{\sum \dot{W}_{\text {turbines }}-\sum \dot{W}_{\text {pumps }}}{\dot{Q}_{\text {reactor }}}$ 


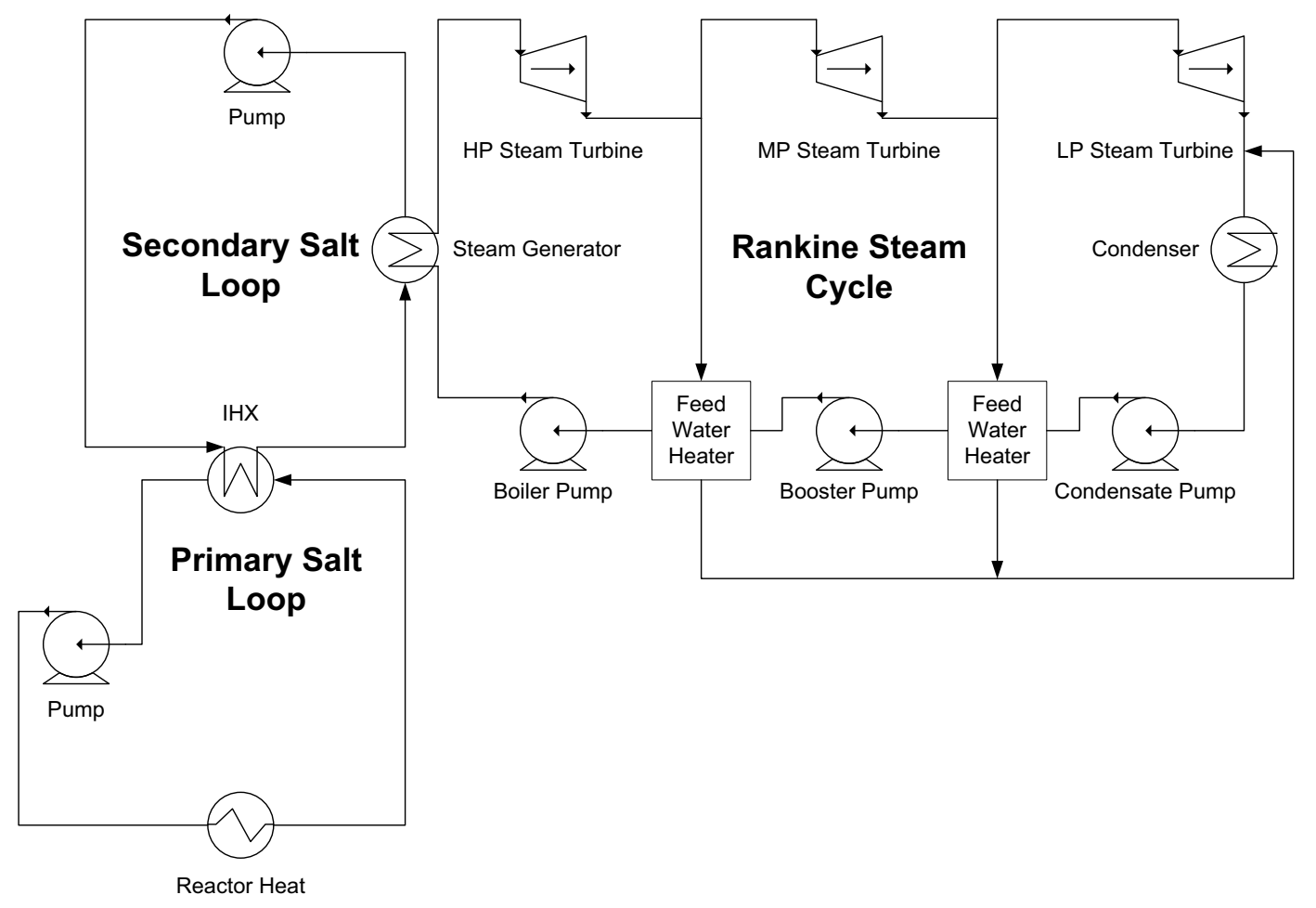

Figure 3-3. Rankine steam cycle with feed-water heaters.

\subsubsection{Brayton Gas Cycle}

The basic Brayton gas cycle is shown in Figure 3-4. The high-pressure working gas is expanded in a turbine to produce power. The low-pressure warm gas is cooled in an ambient cooler, which reduces the power of compression. The low-pressure cold gas is compressed to the high-pressure of the system. Often the turbine and the compressor are mechanically connected through a single shaft. The thermal efficiency of the cycle is presented as

$\eta_{\text {th }}=\frac{\dot{W}_{\text {Turbine }}-\dot{W}_{\text {Compressor }}}{\dot{Q}_{\text {Gas Heater }}}$.

As with the Rankine steam cycle, the thermal efficiency may be improved through partial expansion with reheat and recuperation. For an indirect cycle, the gas heater is the heat from the reactor, and not only is the compression in the Brayton cycle considered, but also the compression of the pump within the primary and secondary salt loops. Figure 3-5 shows the cycle analyzed for this report, which includes both reheat and recuperation (Van Wylen and Sonntag 1973). The reactor outlet flow is split into two streams, one going into a heater and the other into a reheater. Both gas turbines have the same high inlet temperature. The thermal efficiency for the Brayton cycle as shown in Figure 3-5:

$\eta_{\text {th }}=\frac{\sum \dot{W}_{\text {Turbines }}-\sum \dot{W}_{\text {Pumps }}}{\dot{Q}_{\text {Re actor }}}$ 


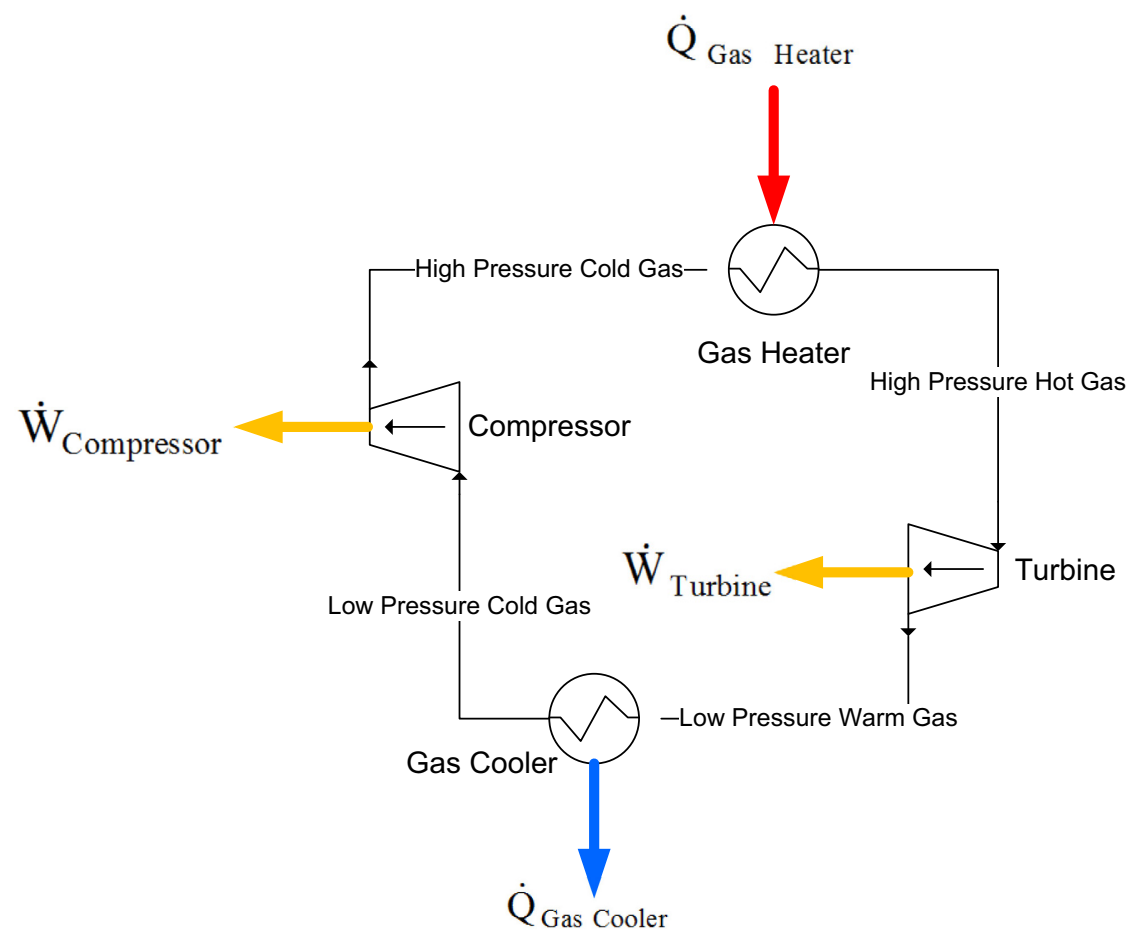

Figure 3-4. Simple Brayton cycle.

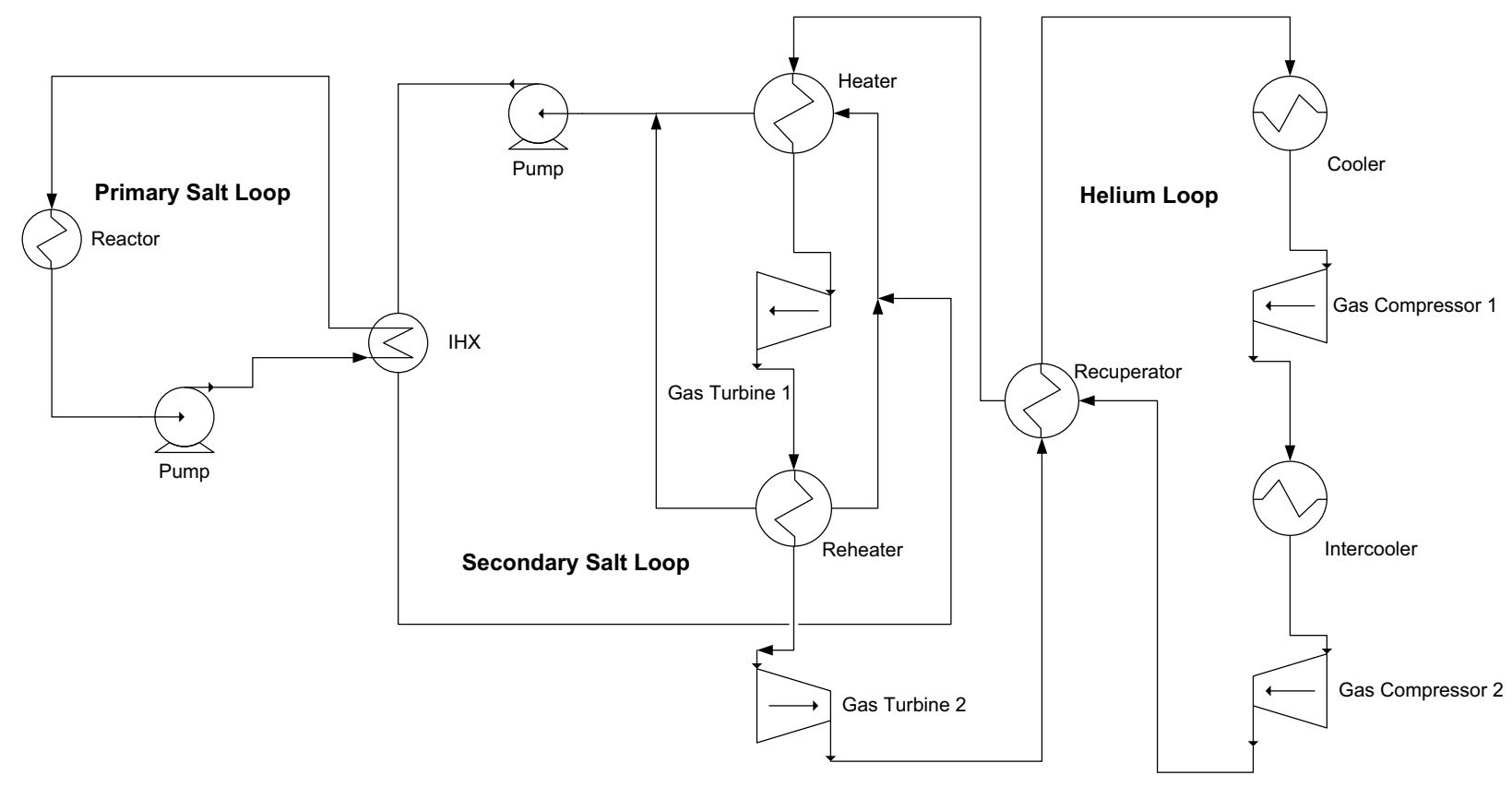

Figure 3-5. Helium Brayton cycle with reheat and recuperation. 


\subsubsection{Supercritical Carbon Dioxide Recompression Brayton Cycle}

The supercritical carbon dioxide recompression Brayton cycle is a cycle developed at the Massachusetts Institute of Technology (Dostal, Driscoll, and Heizlar 2004). Figure 3-6 shows a simplified process flow diagram of the cycle. The supercritical $\mathrm{CO}_{2}$ coolant is heated by the secondary salt loop and is expanded through the turbine to produce electric power. The coolant, at a lower temperature and pressure then passes through high-temperature and low-temperature recuperators, where it is further cooled. The coolant flow is then split into two streams (right side of Figure 3-6). One stream passes through a precooler that provides additional cooling to the working fluid before it enters Compressor 1. Compressor 1 provides the driving force to circulate the fluid back through the two recuperators where heat is recovered before the working fluid is returned to the reactor inlet to complete the cycle. The second split stream passes directly to Compressor 2 (the recompressor) without any additional cooling, where it is compressed and joined with the first split stream before passing through the high temperature recuperator and returning to the reactor inlet to complete the cycle.

The calculated power conversion cycle thermal efficiency $\left(\eta_{\text {pcs }}\right)$ is defined as:

$\eta_{\text {pcs }}=\left(\mathrm{P}_{\text {turbine }}-\mathrm{P}_{\text {compressors }}\right) / \mathrm{P}_{\text {reactor }}$

where

$\mathrm{P}_{\text {turbine }}=$ Power of the primary side turbine

$\mathrm{P}_{\text {compressors }}=$ Power of high and low pressure compressors

$\mathrm{P}_{\text {reactor }}=$ Reactor heat.

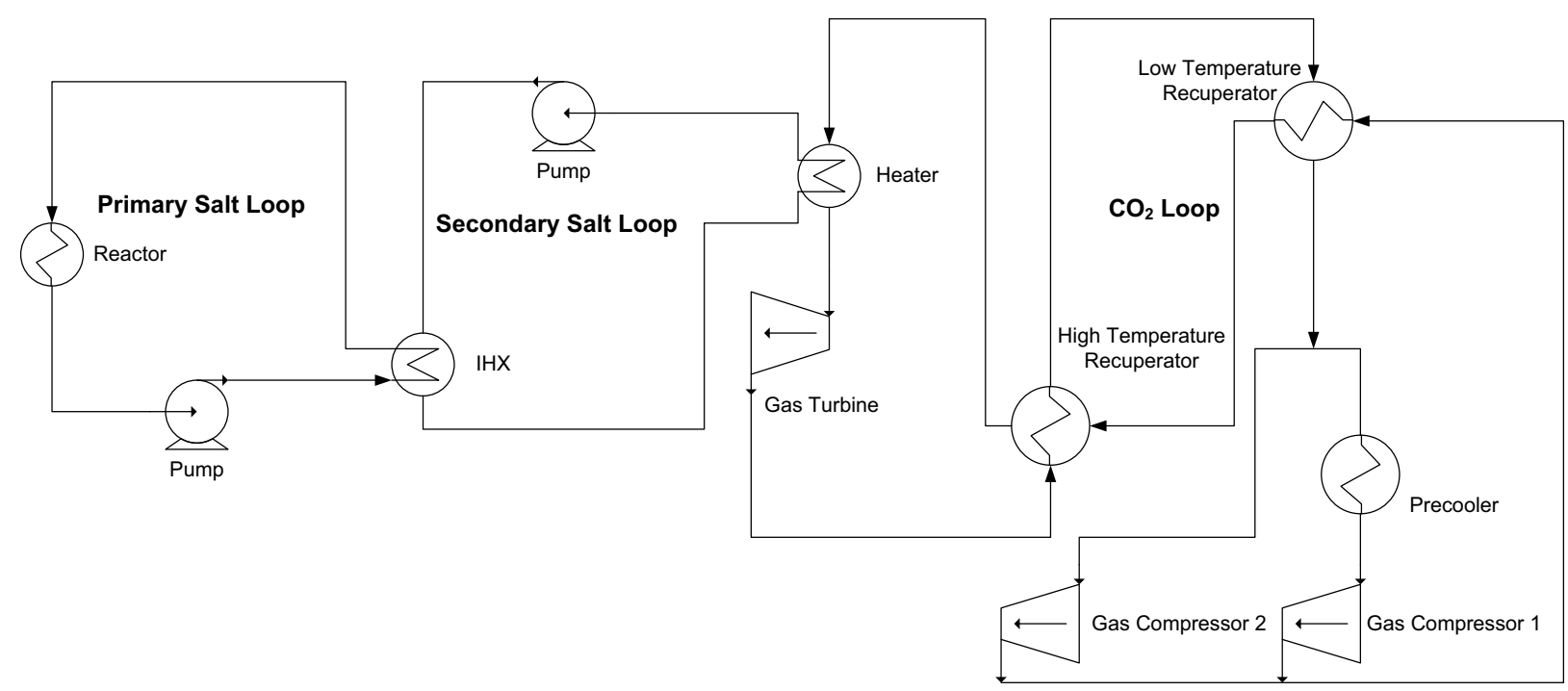

Figure 3-6. Supercritical $\mathrm{CO}_{2}$ recompression Brayton cycle.

\subsection{Process Models}

The process models for this mathematical analysis were developed using Honeywell's UniSim Design R390.1 (Build 15107) process modeling software. UniSim Design software inherently ensures mass and energy balances across all components, and it includes thermodynamic data for all chemical 
species. The software realistically models components such as pumps, compressors, turbines, and heat exchangers. It also models chemical equilibrium reactions. The models described in this report were developed assuming steady-state operation.

\subsubsection{Primary and Secondary Salt Loops}

Four salts were used in the process models of this study. The salt in the primary loop is a binary salt composed of FLiBe. Three salts were considered for the secondary heat transfer loop: a tertiary salt made of lithium fluoride, sodium fluoride, and potassium fluoride (or FLiNaK) and two binary salts: potassium chloride-magnesium chloride $\mathrm{KCl}-\mathrm{MgCl}_{2}$, and potassium fluoride-zirconium fluoride $\mathrm{KF}^{-} \mathrm{ZrF}_{4}$. These salts are not part of the properties found within the UniSim Design software and therefore were incorporated into the software as UniSim's hypothetical fluids routines. The properties of the salts used in the analyses are found in Sohal et al. (2010) and Anderson and Sabharwall (2010).

The process model of the salt loops is found in Figure 3-7. The pressure of the loop is near atmosphere $(0.156 \mathrm{MPa})$. The temperature into and out of the reactor is $600^{\circ} \mathrm{C}$ and $704^{\circ} \mathrm{C}$ respectively. The secondary loop provides heat to the power cycle.

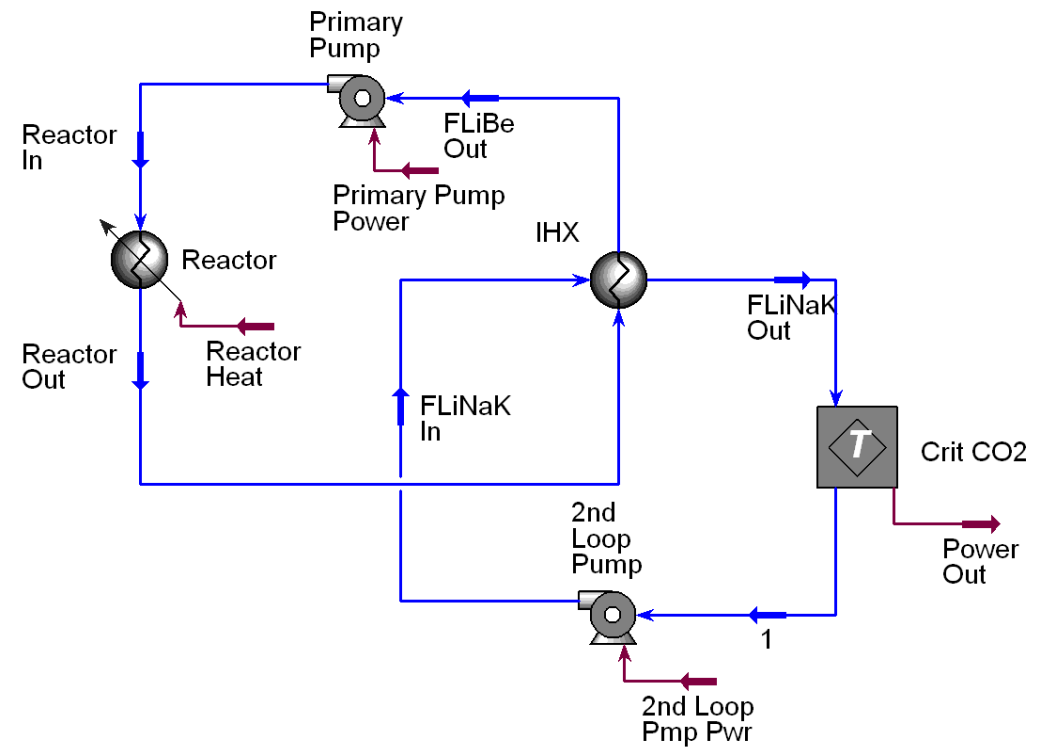

Figure 3-7. Primary and secondary salt loops.

\subsubsection{Rankine Cycles}

The Rankine cycle process model developed for this study is based on a super-critical steam cycle developed by Babcock and Wilcox, (Kitto and Stultz 2005). The cycle has seven feed-water heaters and a steam generator with reheating as shown in Figure 3-8. This same model is also used for the subcritical steam cycle. The high pressure turbine has an efficiency of $85 \%$, the two stage intermediate pressure turbine has an efficiency of $90 \%$, and the five stage low pressure turbine has an efficiency of $80 \%$. Each flow from the turbines to the feed-waters is $5 \%$ of the total flow. The turbine outlet pressures of the flows to the feed-water heaters are adjusted to ensure that the flows are condensed as they heat the water returning to the steam generator. The mass flow of the returning water is adjusted until the fluid entering the condensing pump is a saturated liquid. The pressure at the condenser is $1.5 \mathrm{psia}(0.010 \mathrm{MPa})$ which gives a condensing temperature of $46^{\circ} \mathrm{C}$, which should be suitable for water or air cooled condensing. For this model the water or air used to condense is not accounted. 


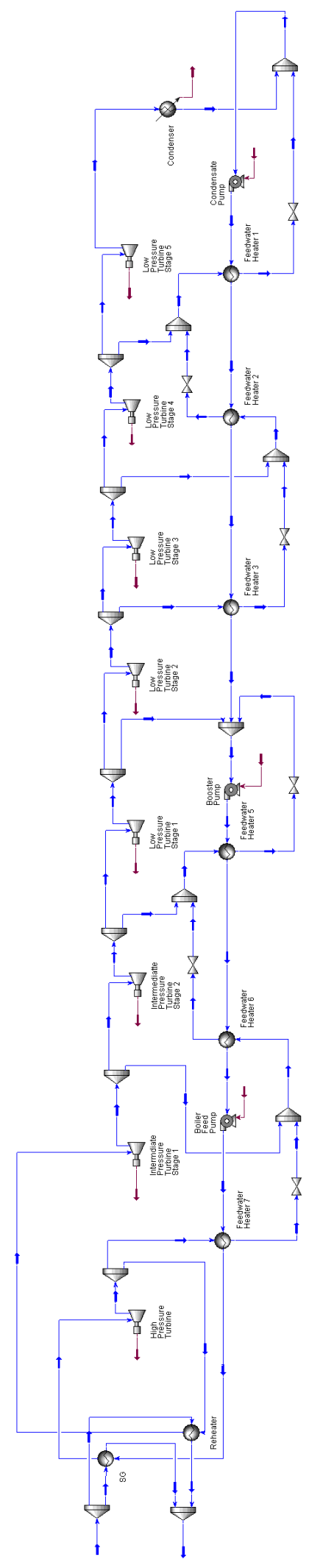

Figure 3-8. Process flow diagram of Rankine steam cycle. 


\subsubsection{Brayton Helium Cycle}

The Brayton cycle has a heater and a reheater that uses the heat from the salt to raise the temperature of the helium to the same high temperature for both turbines as shown in Figure 3-9. The incoming salt flow is split $50 \%$ each. The helium mass flow rate is determined by the temperature difference and flow of the incoming salt and by setting the heater and reheater to have $25^{\circ} \mathrm{C}$ minimum approach temperatures. The recuperative heat exchanger has a minimum approach temperature of $20^{\circ} \mathrm{C}$. Before each compressor, the helium gas is cooled to $36^{\circ} \mathrm{C}$. The compressors and turbines have isentropic efficiencies of $90 \%$. Outlet pressures of the compressors and turbines were adjusted until maximum thermal efficiency was achieved.

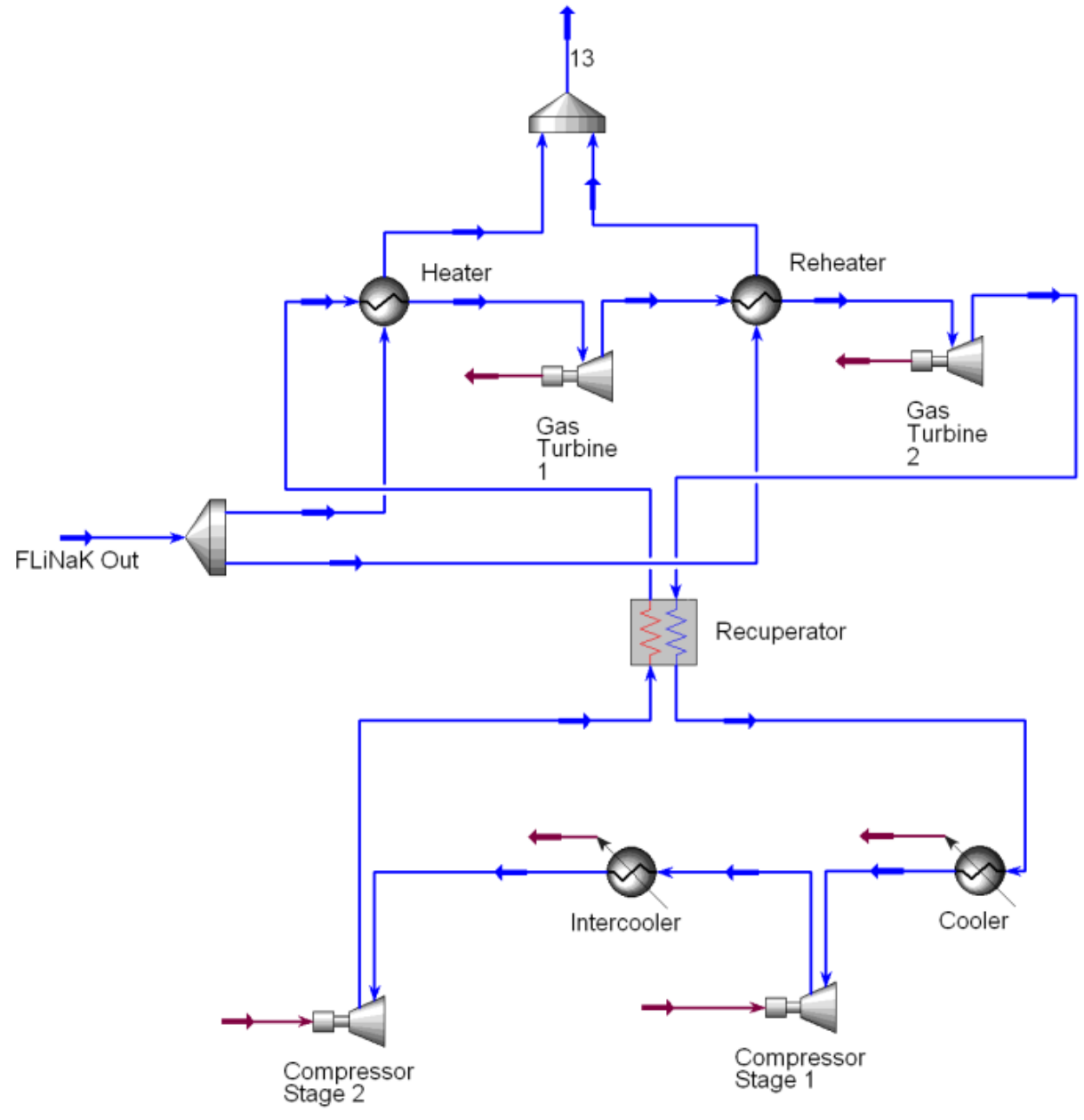

Figure 3-9. Process flow diagram of Brayton cycle.

\subsubsection{Supercritical Carbon Dioxide Recompression Brayton Cycle}

The super-critical $\mathrm{CO}_{2}$ uses the same conditions as the helium Brayton cycle except for pressures. The lower pressure of the cycle was adjusted near the critical point of carbon dioxide. The upper pressure, the pressure out of gas turbine 1, the outlet compressor pressure and the temperature of the carbon dioxide entering the heater were adjusted to maximize the thermal efficiency of the cycle. The split between the compressors was adjusted to ensure that the isentropic efficiency of compressor 2 was $90 \%$. 


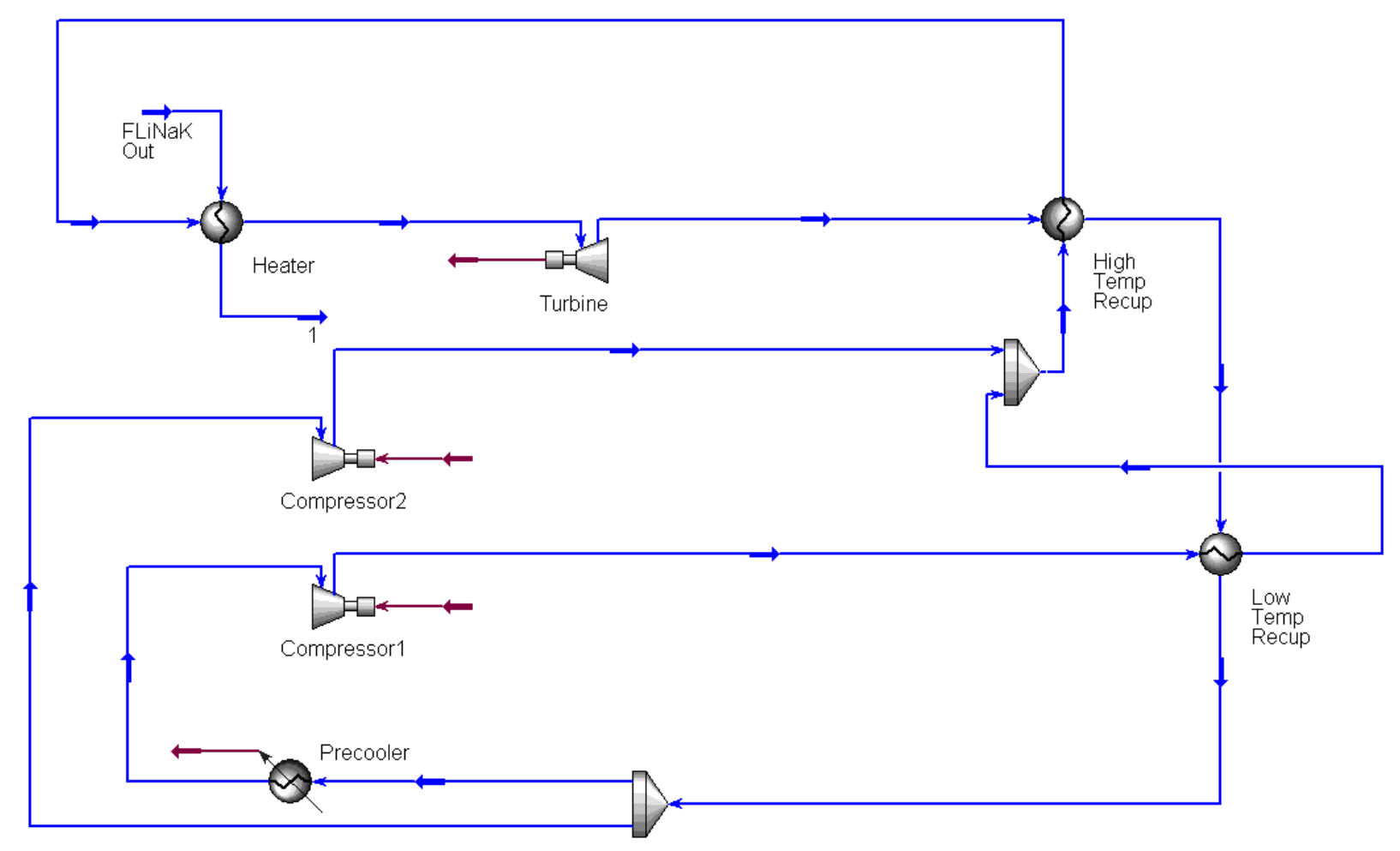

Figure 3-10. Process flow diagram of super-critical $\mathrm{CO}_{2}$ modified Brayton cycle.

\subsection{Results}

\subsubsection{Primary and Secondary Salt Loops}

The primary salt loop conditions did not change for all the cases studied. The mass flow rate of the salt loop is established by the inlet and outlet reactor temperatures of $600^{\circ} \mathrm{C}$ and $704^{\circ} \mathrm{C}$, respectively, and the reactor heat of $20 \mathrm{MW}(\mathrm{t})$. A nearly constant $25^{\circ} \mathrm{C}$ temperature difference was set for the IHX, between the primary and secondary salt loops. This difference established the mass flow rates of each of the salts in the secondary loop. The power cycles did not have an influence on the IHX and therefore the results will be presented for the different salts without regard to the power cycle used. Table 3-1 presents the mass flow rates and inlet and outlet temperatures for the IHX. Table 3-2 presents the design conditions for the IHX between the salt loops. The UA is the product of the overall heat transfer coefficient and heat transfer area. The magnitude of the UA indicates a relative size. The log mean temperature difference (LMTD) is a measure of the average temperature between the hot and cold sides of the heat exchanger. The product of the UA and LMTD is the duty of the heat exchanger. The duty is the amount of heat transferred from the hot side to the cold side of the heat exchanger. As can be seen in Tables 3-1 and 3-2, the intermediate heat exchangers for the binary salts are identical. The FLiNaK salt has a slightly smaller heat exchanger. The mass flow rate of the FLiNaK salt is the smallest as well. Based on the heat transfer and thermodynamic results, the FLiNaK salt has the best performance. However the difference is not enough to make a final conclusion. The corrosive and economic aspects of each salt needs to be accounted, which may favor a salt different than FLiNaK. 
Table 3-1. Mass flow rates and IHX temperatures for the primary and secondary salt loops.

\begin{tabular}{|lcccc|}
\hline \multicolumn{1}{|c}{ Salt } & $\begin{array}{c}\text { Inlet IHX } \\
\text { Temperature }\left({ }^{\circ} \mathbf{C}\right)\end{array}$ & $\begin{array}{c}\text { Outlet IHX } \\
\text { Temperature }\left({ }^{\circ} \mathbf{C}\right)\end{array}$ & $\begin{array}{c}\text { Pressure } \\
(\mathbf{M P a})\end{array}$ & $\begin{array}{c}\text { Mass Flow Rate } \\
(\mathbf{k g} / \mathbf{s})\end{array}$ \\
\hline FLiBe & 704.0 & 600.0 & 0.156 & 79.6 \\
$\mathbf{F L i N a K}$ & 575.0 & 676.2 & 0.156 & 102.2 \\
$\mathbf{K C l}_{-}-\mathbf{M g C l}_{\mathbf{2}}$ & 575.0 & 679.0 & 0.156 & 166.4 \\
${\mathbf{K F}-\mathbf{Z r F}_{\mathbf{4}}}$ & 575.0 & 679.0 & 0.156 & 183.0 \\
\hline
\end{tabular}

Table 3-2. Design data for IHX between primary and secondary salt loops.

\begin{tabular}{|lccc|}
\hline \multicolumn{1}{|c}{ Salt } & Duty (MW) & UA $\left(\mathbf{M W} /{ }^{\circ} \mathbf{C}\right)$ & LMTD $\left({ }^{\circ} \mathbf{C}\right)$ \\
\hline FLiNaK & 20.0 & 0.773 & 25.9 \\
KCl-MgCl $_{2}$ & 20.0 & 0.800 & 25.0 \\
KF-ZrF $_{4}$ & 20.0 & 0.800 & 25.0 \\
\hline
\end{tabular}

\subsubsection{Power Cycles}

The overall thermal efficiencies of the power cycles are presented in Table 3-3. The maximum and minimum pressures of each cycle are presented in Table 3-4 and Table 3-5. The mass flow rates of the power cycles are shown in Table 3-6. The supercritical steam Rankine cycle has the highest thermal efficiency followed by the supercritical $\mathrm{CO}_{2}$. These cycles also have the highest pressures of 24.99 and 21.66 MPa respectively. The subcritical steam Rankine has an efficiency of $42 \%$ with a high pressure of 17.7 MPa. The helium Brayton cycle has the lowest efficiency with the lowest pressure. The power cycle efficiencies do not vary much with respect to the secondary loop salt used. The pressures and flows do not vary much when considering salt type. There is some variation in salt type when considering the helium Brayton cycle. The pressures of the cycles are set to get their specific performance except for the Brayton cycle. Helium is nearly an ideal gas. Assuming the ideal gas law and considering the first law of thermodynamics for the turbines and compressors, the following equation may be derived for turbine power:

$\dot{W}=P_{\text {in }} v_{\text {in }} A_{\text {in }} \eta_{\text {turbine }} \frac{\gamma}{\gamma-1}\left[\left(\frac{P_{\text {out }}}{P_{\text {in }}}\right)^{\frac{\gamma-1}{\gamma}}-1\right]$.

Where:

$\dot{W}=$ power of the turbine

$P_{\text {in }}=$ pressure into the turbine

$P_{\text {out }}=$ pressure out of the turbine

$A_{\text {in }}=$ cross sectional area into the turbine

$v_{\text {in }}=$ velocity into the turbine

$\eta_{\text {turbine }}=$ the isentropic efficiency of the turbine

$\gamma=$ the specific heat ratio. 
Table 3-3. Thermal efficiencies of the power cycles.

\begin{tabular}{|lcccc|}
\hline Salt/Power Cycle & $\begin{array}{c}\text { Helium } \\
\text { Brayton }\end{array}$ & $\begin{array}{c}\text { Critical CO } \\
\text { Modified Brayton }\end{array}$ & $\begin{array}{c}\text { Super Critical } \\
\text { Steam Rankine }\end{array}$ & $\begin{array}{c}\text { Sub-Critical } \\
\text { Steam Rankine }\end{array}$ \\
\hline FLiNaK & $40.3 \%$ & $43.7 \%$ & $44.0 \%$ & $41.9 \%$ \\
KCl-MgCl $_{2}$ & $40.4 \%$ & $43.9 \%$ & $44.0 \%$ & $42.0 \%$ \\
KF-ZrF $_{4}$ & $40.4 \%$ & $43.9 \%$ & $44.0 \%$ & $42.0 \%$ \\
\hline
\end{tabular}

Table 3-4. Maximum pressure for each power cycle.

\begin{tabular}{|lcccc|}
\hline Salt/Power Cycle & $\begin{array}{c}\text { Helium } \\
\text { Brayton }\end{array}$ & $\begin{array}{c}\text { Critical CO } \\
\text { Modified Brayton }\end{array}$ & $\begin{array}{c}\text { Super Critical } \\
\text { Steam Rankine }\end{array}$ & $\begin{array}{c}\text { Sub-Critical } \\
\text { Steam Rankine }\end{array}$ \\
\hline FLiNaK & 7.11 & 21.66 & 24.99 & 17.7 \\
KCl-MgCl $_{2}$ & 7.35 & 21.66 & 24.99 & 17.7 \\
KF-ZrF $_{4}$ & 7.49 & 21.66 & 24.99 & 17.7 \\
\hline
\end{tabular}

Table 3-5. Minimum pressure of each power cycle.

\begin{tabular}{|lcccc|}
\hline Salt/Power Cycle & $\begin{array}{c}\text { Helium } \\
\text { Brayton }\end{array}$ & $\begin{array}{c}\text { Critical CO } \\
\text { Modified Brayton }\end{array}$ & $\begin{array}{c}\text { Super Critical } \\
\text { Steam Rankine }\end{array}$ & $\begin{array}{c}\text { Sub-Critical } \\
\text { Steam Rankine }\end{array}$ \\
\hline FLiNaK & 2.69 & 8.27 & 0.01014 & 0.01014 \\
KCl-MgCl $_{2}$ & 2.79 & 8.38 & 0.01014 & 0.01014 \\
KF-ZrF $_{4}$ & 2.79 & 8.38 & 0.01014 & 0.01014 \\
\hline
\end{tabular}

Table 3-6. Mass flow rates of power cycles.

\begin{tabular}{|lcccc|}
\hline Salt/Power Cycle & $\begin{array}{c}\text { Helium } \\
\text { Brayton }\end{array}$ & $\begin{array}{c}\text { Critical CO } \mathbf{C}_{\mathbf{2}} \\
\text { Modified Brayton }\end{array}$ & $\begin{array}{c}\text { Super Critical } \\
\text { Steam Rankine }\end{array}$ & $\begin{array}{c}\text { Sub-Critical } \\
\text { Steam Rankine }\end{array}$ \\
\hline FLiNaK & 13.43 & 102.2 & 6.96 & 7.09 \\
KCl-MgCl $_{\mathbf{2}}$ & 13.42 & 102.3 & 6.96 & 7.11 \\
KF-ZrF $_{4}$ & 13.22 & 102.3 & 6.95 & 7.10 \\
\hline
\end{tabular}

The power of the compressor has an identical form except the left hand terms are divided by the efficiency instead of multiplied. The specific heat ratio is constant for an ideal gas. For a specific design point, the turbine and compressor efficiencies and areas are constant. Therefore the turbine and compressor powers are a function of inlet pressure, pressure ratio, and velocity. Equation (10) implies that the same power cycle efficiency may be found at lower pressures. With that in mind, another case was modeled in which the lowest pressure of the Brayton cycle were set at $20 \mathrm{psia}(0.137 \mathrm{MPa})$, the same pressure as the salt loops. In this analysis FLiNaK was used as the secondary salt. The thermal efficiency of this Brayton cycle in this analysis is $40.3 \%$, with a high pressure of $0.341 \mathrm{MPa}$ and a low pressure of $0.135 \mathrm{MPa}$. The mass flow rate through the power cycle is $13.8 \mathrm{~kg} / \mathrm{s}$. The helium Brayton cycle has the advantage over the other cycles in that the absolute pressures within the cycle may be adjusted and still produce the same power cycle efficiency.

However, there are consequences for running at the lower pressure: the equipment size must increase as the pressure goes down. The data from the FLiNaK cases were used to create Table 3-7 in which the 
largest pipe size was calculated for each cycle. The largest flows are found at the highest volume flow rates and lowest fluid densities of the power cycles. In each case, this location is at the outlet of the last turbine. The velocity was assumed to be $100 \mathrm{ft} / \mathrm{s}$ for each case and the density at those locations were used. Table 3-7 shows the results of this analysis. The low pressure helium gas has a pipe diameter that is 4.6 times greater than the higher pressure gas. The super critical $\mathrm{CO}_{2}$ cycle has the smallest pipe size due to the high density of the carbon dioxide near the critical point. The large pipe sizes of the Rankine cycles are due to the very low pressures in the condenser resulting in very low steam densities. The low pressure of the Brayton cycle may be adjusted to find an optimal pipe size and pressure ratio across the IHX. The mass flow rates of the Rankine cycles shown in Table 3-7 are different than those found in Table 3-6 because of the flows diverted for the feed water heaters. The flows in Table 3-6 are the flows through the steam generator.

Table 3-7. Maximum pipe size for each power cycle.

\begin{tabular}{|lccccc|}
\hline & $\begin{array}{c}\text { High } \\
\text { Pressure } \\
\text { Helium } \\
\text { Brayton }\end{array}$ & $\begin{array}{c}\text { Low Pressure } \\
\text { Helium } \\
\text { Brayton }\end{array}$ & $\begin{array}{c}\text { Critical CO } \\
\text { Modified } \\
\text { Brayton }\end{array}$ & $\begin{array}{c}\text { Super } \\
\text { Critical } \\
\text { Steam } \\
\text { Rankine }\end{array}$ & $\begin{array}{c}\text { Subcritical } \\
\text { Steam } \\
\text { Rankine }\end{array}$ \\
\hline Pressure (MPa) & 2.8 & 0.1379 & 8.79 & .0103 & .0103 \\
Temperature $\left({ }^{\circ} \mathbf{C}\right)$ & 519.3 & 522.8 & 542.8 & 46.48 & 46.48 \\
Mass Flow Rate (kg/s) & 13.4 & 13.8 & 102.2 & 4.92 & 5.01 \\
Density (kg/m3) & 1.699 & 0.0834 & 0.562 & 0.0744 & 0.0744 \\
Diameter (m) & 0.575 & 2.631 & 0.2756 & 1.662 & 1.676 \\
Diameter (inches) & 22.62 & 103.6 & 10.85 & 65.43 & 65.98 \\
\hline
\end{tabular}

Table 3-8. Temperatures, mass flows, and pressures of heat exchangers between secondary loops and power cycles.

\begin{tabular}{|c|c|c|c|c|}
\hline & $\begin{array}{c}\text { Inlet IHX } \\
\text { Temperature } \\
\left({ }^{\circ} \mathrm{C}\right)\end{array}$ & $\begin{array}{c}\text { Outlet IHX } \\
\text { Temperature } \\
\left({ }^{\circ} \mathrm{C}\right)\end{array}$ & $\begin{array}{c}\text { Pressure } \\
\text { (MPa) }\end{array}$ & $\begin{array}{c}\text { Mass Flow Rate } \\
(\mathrm{kg} / \mathrm{s})\end{array}$ \\
\hline \multicolumn{5}{|c|}{ Subcritical Rankine } \\
\hline \multicolumn{5}{|l|}{ Steam Generator } \\
\hline FLiNaK & 676.2 & 585.6 & 0.153 & 96.5 \\
\hline Water & 239.5 & 550.0 & 17.346 & 7.09 \\
\hline \multicolumn{5}{|l|}{ Reheater } \\
\hline FLiNaK & 676.2 & 384.3 & 0.153 & 5.72 \\
\hline Water & 359.3 & 550.0 & 4.62 & 6.74 \\
\hline \multicolumn{5}{|l|}{ Steam Generator } \\
\hline $\mathrm{KCl}-\mathrm{MgCl}_{2}$ & 679.0 & 586.0 & 0.153 & 157.4 \\
\hline Water & 241.6 & 550.0 & 17.346 & 7.11 \\
\hline \multicolumn{5}{|l|}{ Reheater } \\
\hline $\mathrm{KCl}-\mathrm{MgCl}_{2}$ & 679.0 & 383.5 & 0.153 & 9.00 \\
\hline Water & 358.5 & 550.0 & 4.59 & 6.75 \\
\hline \multicolumn{5}{|l|}{ Steam Generator } \\
\hline $\mathrm{KF}-\mathrm{ZrF}_{4}$ & 679.0 & 586.1 & 0.153 & 173.1 \\
\hline
\end{tabular}




\begin{tabular}{|c|c|c|c|c|}
\hline & $\begin{array}{c}\text { Inlet IHX } \\
\text { Temperature } \\
\left({ }^{\circ} \mathrm{C}\right)\end{array}$ & $\begin{array}{c}\text { Outlet IHX } \\
\text { Temperature } \\
\left({ }^{\circ} \mathrm{C}\right)\end{array}$ & $\begin{array}{c}\text { Pressure } \\
\text { (MPa) }\end{array}$ & $\begin{array}{c}\text { Mass Flow Rate } \\
(\mathrm{kg} / \mathrm{s})\end{array}$ \\
\hline Water & 241.7 & 550.0 & 17.346 & 7.10 \\
\hline \multicolumn{5}{|l|}{ Reheater } \\
\hline $\mathrm{KF}-\mathrm{ZrF}_{4}$ & 679.0 & 381.3 & 0.153 & 9.91 \\
\hline Water & 356.3 & 550.0 & 4.51 & 6.75 \\
\hline \multicolumn{5}{|c|}{ Supercritical Rankine } \\
\hline \multicolumn{5}{|l|}{ Steam Generator } \\
\hline FLiNaK & 676.2 & 586.5 & 0.153 & 95.4 \\
\hline Water & 251.6 & 593.0 & 24.49 & 6.96 \\
\hline \multicolumn{5}{|l|}{ Reheater } \\
\hline FLiNaK & 676.2 & 406.7 & 0.153 & 6.85 \\
\hline Water & 381.7 & 593.0 & 6.09 & 6.612 \\
\hline \multicolumn{5}{|l|}{ Steam Generator } \\
\hline $\mathrm{KCl}-\mathrm{MgCl}_{2}$ & 679.0 & 586.7 & 0.153 & 155.5 \\
\hline Water & 251.6 & 593.0 & 24.49 & 6.96 \\
\hline \multicolumn{5}{|l|}{ Reheater } \\
\hline $\mathrm{KCl}-\mathrm{MgCl}_{2}$ & 679.0 & 406.7 & 0.153 & 10.8 \\
\hline Water & 381.7 & 593.0 & 6.09 & 6.612 \\
\hline \multicolumn{5}{|l|}{ Steam Generator } \\
\hline $\mathrm{KF}-\mathrm{ZrF}_{4}$ & 679.0 & 586.8 & 0.153 & 171.1 \\
\hline Water & 251.4 & 593.0 & 24.49 & 6.95 \\
\hline \multicolumn{5}{|l|}{ Reheater } \\
\hline $\mathrm{KF}-\mathrm{ZrF}_{4}$ & 679.0 & 405.0 & 0.153 & 11.9 \\
\hline Water & 380.0 & 593.0 & 6.01 & 6.6025 \\
\hline \multicolumn{5}{|c|}{ Helium Brayton } \\
\hline \multicolumn{5}{|l|}{ Heater } \\
\hline FLiNaK & 676.2 & 568.3 & 0.153 & 51.1 \\
\hline Helium & 498.9 & 651.2 & 6.97 & 13.4 \\
\hline \multicolumn{5}{|l|}{ Reheater } \\
\hline FLiNaK & 676.2 & 581.6 & 0.153 & 51.1 \\
\hline Helium & 517.2 & 651.2 & 4.40 & 13.4 \\
\hline \multicolumn{5}{|l|}{ Heater } \\
\hline $\mathrm{KCl}-\mathrm{MgCl}_{2}$ & 679.0 & 568.9 & 0.153 & 83.2 \\
\hline Helium & 502.3 & 654.0 & 7.203 & 13.4 \\
\hline \multicolumn{5}{|l|}{ Reheater } \\
\hline $\mathrm{KCl}-\mathrm{MgCl}_{2}$ & 679.0 & 581.1 & 0.153 & 83.2 \\
\hline Helium & 519.0 & 654.0 & 4.54 & 13.4 \\
\hline \multicolumn{5}{|l|}{ Heater } \\
\hline $\mathrm{KF}-\mathrm{ZrF} \mathbf{F}_{4}$ & 679.0 & 568.2 & 0.153 & 91.5 \\
\hline Helium & 499.0 & 654.0 & 7.3402 & 13.2 \\
\hline Reheater & & & & \\
\hline
\end{tabular}




\begin{tabular}{|c|c|c|c|c|}
\hline & $\begin{array}{c}\text { Inlet IHX } \\
\text { Temperature } \\
\left({ }^{\circ} \mathrm{C}\right) \\
\end{array}$ & $\begin{array}{c}\text { Outlet IHX } \\
\text { Temperature } \\
\left({ }^{\circ} \mathrm{C}\right) \\
\end{array}$ & $\begin{array}{c}\text { Pressure } \\
\text { (MPa) }\end{array}$ & $\begin{array}{c}\text { Mass Flow Rate } \\
(\mathrm{kg} / \mathrm{s})\end{array}$ \\
\hline $\mathrm{KF}-\mathrm{ZrF}_{4}$ & 679.0 & 581.8 & 0.153 & 91.5 \\
\hline Helium & 518.0 & 654.0 & 4.61 & 13.2 \\
\hline \multicolumn{5}{|c|}{ Super-critical $\mathrm{CO}_{2}$ Brayton } \\
\hline \multicolumn{5}{|l|}{ Heater } \\
\hline FLiNaK & 676.2 & 575.0 & 0.153 & 102.2 \\
\hline $\mathrm{CO}_{2}$ & 494.0 & 651.2 & 20.8 & 102.2 \\
\hline \multicolumn{5}{|l|}{ Heater } \\
\hline $\mathrm{KCl}-\mathrm{MgCl}_{2}$ & 679.0 & 575.0 & 0.153 & 166.4 \\
\hline $\mathrm{CO}_{2}$ & 497.0 & 654.0 & 20.8 & 102.3 \\
\hline \multicolumn{5}{|l|}{ Heater } \\
\hline $\mathrm{KF}-\mathrm{ZrF}_{4}$ & 679.0 & 575.0 & 0.153 & 183.0 \\
\hline $\mathrm{CO}_{2}$ & 497.0 & 654.0 & 20.8 & 102.3 \\
\hline
\end{tabular}

\subsection{Conclusions and Recommendations}

The following conclusions are drawn:

- FLiNaK has the smallest heat exchanger size however the difference is not large enough to make a conclusive decision.

- The binary salts have identical results with respect to the IHX design.

- The super-critical Rankine steam cycle has the highest power cycle efficiency and also has the advantage of being a current commercial technology. The cycle has the disadvantage of the highest turbine inlet pressure.

- The super-critical $\mathrm{CO}_{2}$ cycle has a power cycle efficiency that is nearly the same as the super-critical Rankine steam cycle. It also has a maximum pipe diameter that is less than the other power cycles. The cycle also as the advantage of very few components. The disadvantage of the cycle is the high turbine inlet pressure and the cycle is in small scale testing and not available commercially.

- The subcritical Rankine steam cycle is currently used in commercial power plants. The power cycle efficiency is reasonable.

- The helium Brayton cycle has the advantage of adjustable pressures to reduce the pressure difference across the IHX. Brayton cycles have been developed for future gas reactors, however commercial cycles are not available.

The following recommendations should be considered:

- The corrosive nature of the salts needs to be considered for a final selection.

- The cost of each salt needs to be considered.

- The economics and technology development of the power cycles need to be developed and considered. 


\section{APPLICABILITY OF HEAT EXCHANGER TO PROCESS HEAT APPLICATIONS}

The strategic goal of the Advanced Reactor Concept Program for FHR is to broaden the environmental and economic benefits of nuclear energy in the U.S. economy from power production to meet the energy needs and also by demonstrating its applicability to market sectors not being served by light water reactors. This section has been prepared to evaluate integration of FHR technology with conventional chemical industrial processes. The process heat industrial applications being considered are: hydrogen production via steam methane reforming (SMR) of natural gas and high temperature steam electrolysis (HTSE), Substitute natural gas production, Oil Sands Recovery via steam assisted gravity drainage (SAGD), coal to liquid production, natural gas to liquids production, methanol to gasoline production, ammonia production, ex situ oil shale, and in situ oil shale. Shown below are long term $\left(>650^{\circ} \mathrm{C}\right)$ and near term goals $\left(<650^{\circ} \mathrm{C}\right)$ for FHR process applications.

Oil Shale (Ex Situ)
Oil Shale (In Situ)
Oil Sand Recovery
$\mathrm{H}_{2}$ Production Hybrid Sulfur
Hydrogen Production (SI)
Hydrogen Production (HTSE)
Steam Methane Reforming
Methanol to Gasoline (MTG)
Ammonia Production
Steam Rankine Cycle
Helium Brayton Cycle
$\mathrm{SCO}_{2}$ Cycle
\begin{tabular}{|l}
\hline Near Term \\
\hline
\end{tabular} Long Term

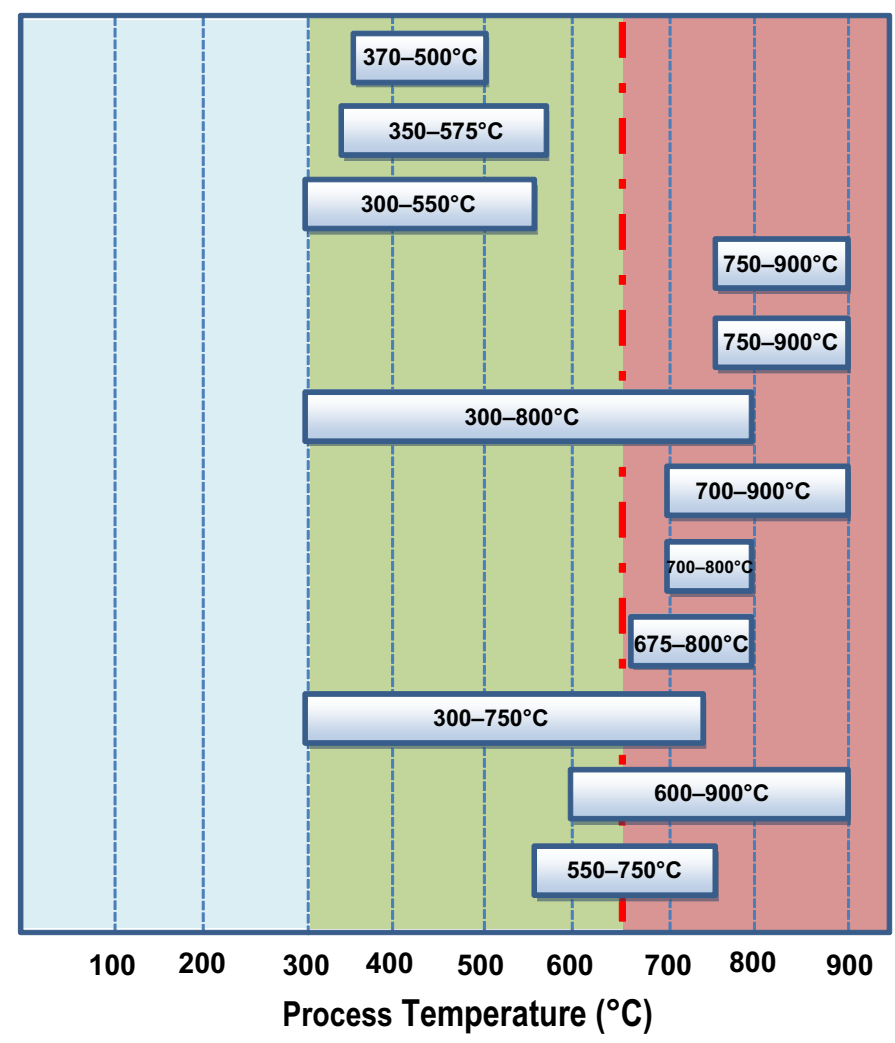

Figure 4-1. Process applications for FHR versus required temperature.

Heat in the FHR is transferred from the reactor core by the primary liquid-salt coolant to an intermediate heat-transfer loop through an IHX. The intermediate heat-transfer loop uses a secondary liquid-salt coolant through a SHX to move the heat to a power conversion system or for process industrial application as shown in Figure 4-2. FHR is in the early developmental stage. The ROT is currently $704^{\circ} \mathrm{C}$, but will possibly increase to 900 to $1000^{\circ} \mathrm{C}$ for the $\mathrm{n}^{\text {th }}$-of-a-kind. With its ability to provide higher ROT the process heat application becomes an attractive option. Though ROT for FHR is $700^{\circ} \mathrm{C}\left(\sim 704^{\circ} \mathrm{C}\right)$, the maximum available temperature for any process application is $650^{\circ} \mathrm{C}$ as shown by the dashed line in Figure 4-1. Process heat applications are briefly mentioned in this section. Details are given in TEV-1160, "FHR Technical Evaluation" (Sabharwall and Kim 2010). 


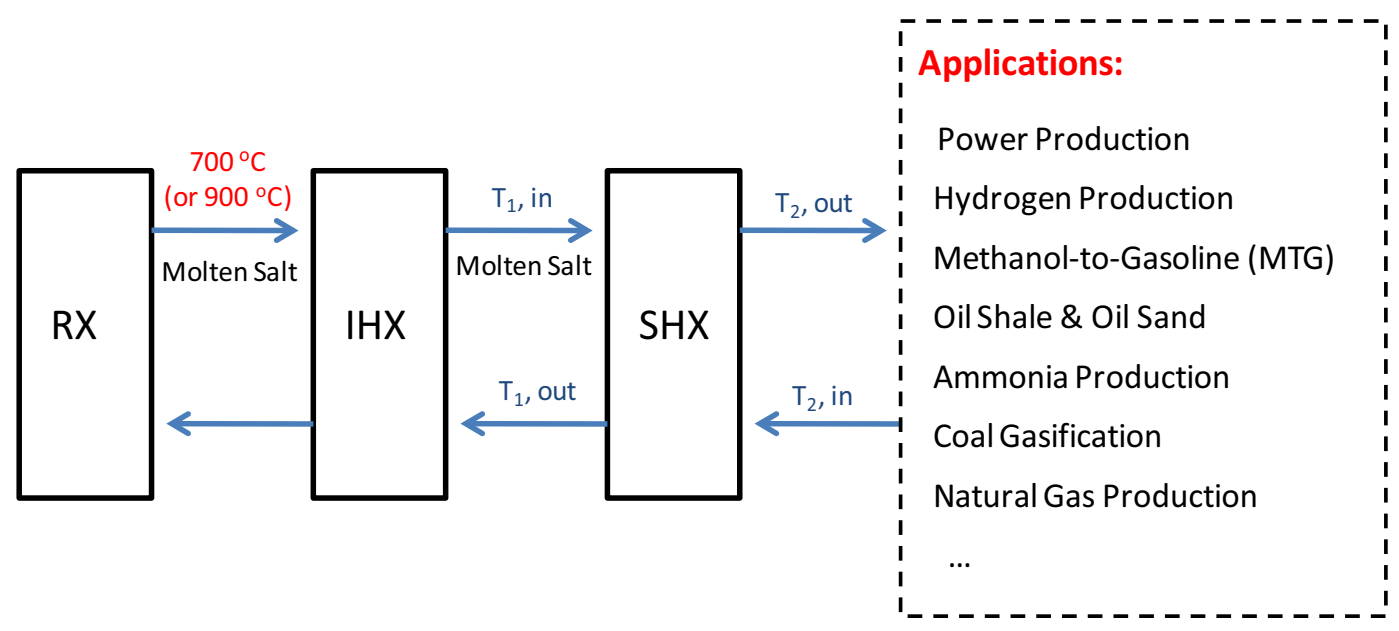

Figure 4-2. Thermal energy transfer in FHR for power or process application.

The following assumptions were made to carry out the analysis:

- The reactor outlet temperature for FHR is assumed to be $700^{\circ} \mathrm{C}$

- The FHR ROT should be sufficiently larger $\left(\sim 50^{\circ} \mathrm{C}\right)$ than the process application temperature requirement

- Any power production/industrial application requiring greater than $650^{\circ} \mathrm{C}$ is referred to as long term objective

- The FHR heat exchanger minimum temperature should be maintained high enough to avoid molten salt freezing (i.e. $>500^{\circ} \mathrm{C}$ ), which will provide about 50 and $65^{\circ} \mathrm{C}$ temperature threshold before fluoride salt such as LiF-NaF-KF (FLiNaK) and chloride salt such as $\mathrm{KCl}-\mathrm{MgCl}_{2}$ experiences freezing issues

- Heat exchanger tube material should have sufficient mechanical integrity to sustain pressure difference across the tube wall (will depend on application).

\subsection{Steam Methane Reforming}

Majority of the natural gas fed to the plant is first desulfurized. The desulfurized natural gas is mixed with steam and reformed in catalyst-filled tubes via the following endothermic reactions to produce hydrogen:

$$
\begin{aligned}
& \mathrm{CH}_{4}+\mathrm{H}_{2} \mathrm{O} \rightarrow 3 \mathrm{H}_{2}+\mathrm{CO} \\
& \mathrm{CH}_{4}+2 \mathrm{H}_{2} \mathrm{O} \rightarrow 4 \mathrm{H}_{2}+\mathrm{CO}
\end{aligned}
$$

Reformer temperatures between 800 and $870^{\circ} \mathrm{C}$ are typical (Baade 2001), although lower temperatures $\left(\sim 760^{\circ} \mathrm{C}\right)$ can be used to reduce the metallurgical requirements of the reforming tubes (Elshout 2010). Conversion of methane to hydrogen is improved by operating at higher temperatures. There is a slight temperature mismatch between what can be supplied by a first-generation $\mathrm{FHR}\left(650^{\circ} \mathrm{C}\right)$ and the optimal steam methane reformer operating temperature $\left(760\right.$ to $\left.880^{\circ} \mathrm{C}\right)$. This issue will be eliminated as future FHR designs are developed and are able to provide the temperature up to $1000^{\circ} \mathrm{C}$. 


\subsection{Substitute Natural Gas Production Analysis}

This proposed process includes the same unit operations as the conventional process with the following exceptions: the cryogenic air separation unit and water gas shift reactors are replaced by HTSE to provide oxygen and hydrogen for the process. The minimum temperature required for substitute natural gas production is higher than the available temperature $\left(650^{\circ} \mathrm{C}\right)$ from the current FHR for process heat applications.

\subsection{Oil Sands Recovery}

The integration point of the FHR is for steam production; the minimal amount of power required for the SAGD process is assumed to be purchased from the grid in order to minimize FHR cost by eliminating equipment associated with power production from the FHR. A single $600 \mathrm{MW}(\mathrm{t})$ FHR would be required to produce 56,000 barrels per day of bitumen. By substituting nuclear heat for natural gas combustion in the steam generator (heat exchanger), natural gas consumption is eliminated from the process. $\mathrm{CO}_{2}$ emissions are also eliminated from the process, although there are still $\mathrm{CO}_{2}$ emissions if imported power is used.

Table 4-1 shows typical oil sand recovery system conditions where the process heat is exchanged. Since the FHR maximum available temperature $\left(650^{\circ} \mathrm{C}\right)$ is above the required temperature, the heat requirement could be easily met. However, as shown in Table 4-1, the heat exchanger inlet temperature $\left(352^{\circ} \mathrm{C}\right)$ is lower than the candidate molten salt melting temperatures $\left(<500^{\circ} \mathrm{C}\right)$. Therefore, more study is needed with some lower melting temperature molten salts, such as nitrides or recuperative heating could be incorporated such that the salt does not freeze.

Table 4-1. Oil sand recovery system conditions.

\begin{tabular}{|c|c|c|c|c|}
\hline System Type & $\begin{array}{c}\text { HX Inlet } \\
\text { Temperature } \\
\left({ }^{\circ} \mathbf{C}\right)\end{array}$ & $\begin{array}{c}\text { HX Outlet } \\
\text { Temperature } \\
\left({ }^{\circ} \mathbf{C}\right)\end{array}$ & $\begin{array}{c}\text { Pressure } \\
(\mathbf{M P a})\end{array}$ & $\begin{array}{c}\text { Mass Flow } \\
(\mathbf{k g} / \mathbf{s}) / \mathbf{Q}(\mathbf{W})\end{array}$ \\
\hline Oil Sand Recovery & 352 & 540 & 17 & $7.10 \mathrm{E}-07$ \\
\hline
\end{tabular}

\subsection{Coal-to-Liquids Production Analysis}

This proposed process includes unit operations for the HTSE, coal milling and drying, coal gasification, syngas cleaning and conditioning, sulfur recovery, $\mathrm{CO}_{2}$ compression/liquefaction, FischerTropsch synthesis, product upgrading, and refining. This process requires much higher temperatures than the available temperature $\left(650^{\circ} \mathrm{C}\right)$ from the FHR, thus becoming a long-term goal for FHRs.

\subsection{Natural Gas-to-Liquids Production Analysis}

This proposed process includes the same unit operations as the conventional process except the nuclear heat is used for preheating in the reforming section and reboiler duty in the refining section rather than burning light gas. A full light-gas recycle would lead to unacceptable buildup of inert gases in the process, so it will be deemed practical to fire a small portion of the recycle to minimize inert gas buildup. System conditions of the gas-to-liquid production require temperatures above $700^{\circ} \mathrm{C}$, thus becoming a long-term goal for FHRs. 


\subsection{Methanol-to-Gasoline Production Analysis}

Nuclear integrated coal-to-MTG (methanol-to-gasoline) process includes the same unit operations as the conventional coal-to-MTG process with the following exceptions: the cryogenic air separation unit and water gas shift reactors are replaced by HTSE to provide oxygen and hydrogen for the process. System conditions of the gas-to-liquid production require temperature above $700^{\circ} \mathrm{C}$, thus becoming a long-term goal for FHRs.

\subsection{Ammonia Production Analysis}

Producing ammonia from natural gas and coal are fundamentally different. Natural gas is hydrogen rich with a carbon-to-hydrogen ratio of 1:4. Coal is hydrogen limited with a carbon-to-hydrogen ratio of $\sim 1: 0.8$. Coal requires significant capital to gasify and cleanup the resulting syngas of $\mathrm{CO}$ and $\mathrm{H}_{2} . \mathrm{CO}$ is then used to produce additional $\mathrm{H}_{2}$ via the water-gas shift reaction. The nuclear-integrated natural-gas-to-

ammonia process includes the same unit operations as the conventional natural gas process except nuclear heat is used in the primary reformer rather than burning natural gas. Nuclear heat could also be used to preheat all streams entering the primary reformer. Sufficient low-temperature heat produced elsewhere in the plant could meet the requirements for the urea synthesis and water treatment plants. Because higher temperature heat is desired $\left(700^{\circ} \mathrm{C}\right)$ for steam reforming of natural gas, and is higher than the current available temperature $\left(650^{\circ} \mathrm{C}\right)$ from FHR. The process application will be investigated further and is currently taken as a long term goal for FHRs.

\subsection{In Situ Oil Shale Analysis}

In this integrated case, produced natural gas is not used as fuel to produce the hot fluids used to pyrolyze the kerogen in the oil shale, thus eliminating the generation of flue gas, which contains a large portion of the $\mathrm{CO}_{2}$ emitted from the base case in situ oil shale retort operation. Further modeling will be required to quantify the benefits of the integration. The hydrocarbon product resulting from the pyrolysis of kerogen in oil shale depends on heating rate, pressure, and the ultimate temperature (Vinegar 2006). Conversion efficiency of an oil shale retort is defined as the barrel-of-oil-equivalent of hydrocarbon produced divided by the Fischer Assay oil amount. The heating of the oil shale retort zone is still in the developing stage and would require few years to reach maturity.

\subsection{Ex Situ Oil Shale Retort Analysis}

A block flow diagram for the FHR-integrated ex situ oil shale operation shown in Figure 4-3 has inputs of raw oil shale, electricity from the FHR, and hydrogen from the FHR via high temperature steam electrolysis. Outputs are water, natural gas, spent shale plus char, and refinery-ready stabilized shale oil.

In this evaluation, hydrogen and electricity used by the retort are assumed to be supplied by the HTGR but could be easily correlated to the FHR module, as shown in Figure 4-3. The process conditions are provided in Table 4-2. An HTGR-integrated case was modeled in the NGNP effort, which was composed of two heat transfer loops. The primary loop, containing helium, removes heat from the HTGR and transfers it to a secondary loop containing helium, steam, or other appropriate fluid. This secondary loop feeds into a modified ATP retort kiln where it transfers its heat to the oil shale ore such that it is pyrolyzed and forms oil, gas, and char. The HTGR-integrated case sells the conditioned gas and greatly reduces the $\mathrm{CO}_{2}$ emissions by supplying heat from the HTGR modules and eliminating fossil fuel combustion and carbonate mineral decomposition. In this evaluation, hydrogen and electricity used by the retort are assumed to be supplied by the HTGR modules. The process conditions could be correlated to the FHR and are provided in Table 4-2. 


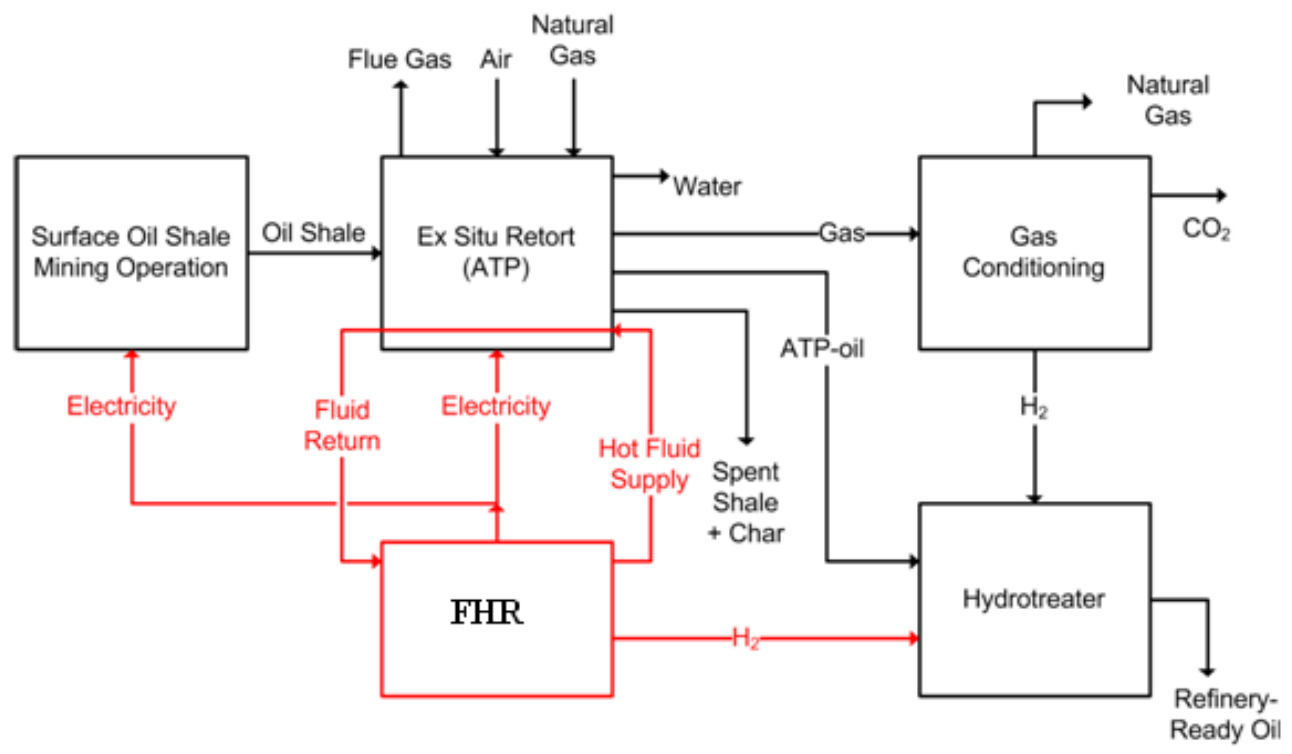

Figure 4-3. Block flow diagram for an FHR-integrated ex situ oil shale retort operation.

Table 4-2. Oil Shale (In Situ and Ex Situ) production system conditions.

\begin{tabular}{|c|c|c|c|c|c|}
\hline System Type & $\begin{array}{c}\text { Type of } \\
\text { Coolant }\end{array}$ & $\begin{array}{c}\text { HX Inlet } \\
\text { Temperature } \\
\left({ }^{\circ} \mathbf{C}\right)\end{array}$ & $\begin{array}{c}\text { HX Outlet } \\
\text { Temperature } \\
\left({ }^{\circ} \mathbf{C}\right)\end{array}$ & $\begin{array}{c}\text { Pressure } \\
(\mathbf{M P a})\end{array}$ & $\begin{array}{c}\text { Mass Flow } \\
(\mathbf{k g} / \mathbf{S} / \mathbf{Q} \text { (W) }\end{array}$ \\
\hline Oil Shale (In Situ) & Helium & 350 & 575 & 7 & $8.56678 \mathrm{E}-07$ \\
\hline Oil Shale (In Situ) & Steam & 350 & 575 & 5 & $1.8745 \mathrm{E}-06$ \\
\hline & & & & & \\
\hline Oil Shale (Ex Situ) & Helium & 60 & 500 & 7.9 & $4.38074 \mathrm{E}-07$ \\
\hline Oil Shale (Ex Situ) & Steam & 285 & 500 & 15.9 & $1.11298 \mathrm{E}-06$ \\
\hline Oil Shale (Ex Situ) & Nitrogen & 60 & 500 & 5.7 & $2.05305 \mathrm{E}-06$ \\
\hline
\end{tabular}

\subsection{Hydrogen Production Analysis (HTSE)}

Hydrogen can also be produced using FHR process heat by way of HTSE. The heat and electrical power from the reactor can be used to split water using solid oxide electrolysis cells to create hydrogen and oxygen. The process heat from the reactor reduces the amount of electricity needed to split the water, thus increasing the efficiency of the process when compared to low-temperature electrolysis. The HTSE process produces no carbon dioxide, but the process heat from the reactor is needed to create the steam $\left(700^{\circ} \mathrm{C}\right)$ necessary for the efficient electrolysis process. The minimum temperature required for efficient production of hydrogen is higher than the available temperature from the FHR without any recuperative heating or topping heat, thus becoming a long-term goal for FHRs. 


\subsection{Conclusion}

Process heat applications are briefly mentioned in this section and for detail refer FHR Technical Evaluation (Sabharwall and Kim, 2010, TEV-1160). With the ROT of $700^{\circ} \mathrm{C}$ and the maximum available temperature of $650^{\circ} \mathrm{C}$ for process heat applications, the current FHR could provide process heat for the following applications:

- Near-term integration $\left(<650^{\circ} \mathrm{C}\right)$ :

- $\quad$ Power production cycles (Steam Rankine Cycle, Helium Brayton Cycle, $\mathrm{SCO}_{2}$ cycle)

- $\quad$ Oil shale (in situ)

- $\quad$ Oil shale (ex situ)

- Oil sands.

- Long-term integration $\left(>650^{\circ} \mathrm{C}\right)$ :

- Hydrogen production via steam methane reforming

- Substitute natural gas production

- Coal to liquid production

- Natural gas to liquid production

- Methanol to gasoline production

- Ammonia production. 


\section{SECONDARY HEAT EXCHANGER}

\subsection{Introduction}

The fundamental objective of this project is the identification and evaluation of heat exchanger concepts for use as the secondary heat exchanger for FHR. The secondary heat exchanger provides the interface between the intermediate coolant and the power conversion system or process application. The identification of a viable secondary heat exchanger concept is based on the options for the power conversion scheme or the process heat application design needs.

The secondary heat exchanger serves as the coolant boundary and must be constructed to maintain system integrity under normal, off-normal, and accident conditions. To maintain high cycle efficiencies, it must also minimize temperature differences between the intermediate molten salt and the process working fluid, while minimizing the pressure drop. The difference in pressure required in the power conversion system and process heat applications imposes stringent requirements on the heat exchanger design.

Candidate materials of construction include Alloy N, 800H, and 617 which exhibit (in varying degrees) high temperature tensile and creep strength, and resistance to environmental degradation in molten salts. Longer-term research and development programs will evaluate ceramic and composite designs. Issues that must be addressed during the design process include materials compatibility with both the intermediate salt and the working fluid used in the power conversion system, high temperature strength, creep and creep-fatigue resistance, and the fabrication processes needed to manufacture an acceptable design (Holcomb et al. 2009).

\subsection{Heat Exchanger Concepts}

Some concepts identified as potential options for the secondary heat exchanger are: shell and tube, plate, plate and fin, printed circuit, helical coil, and ceramic. Each of these heat exchanger concepts are addressed below.

\subsubsection{Shell and Tube Heat Exchanger}

The shell and tube heat exchanger is the most common type found in industry. This exchanger is generally built of a bundle of round tubes mounted in a cylindrical shell with the tube axis parallel to that of the shell. One fluid flows inside the tubes and the other fluid flows across and along the tubes. The major components of this heat exchanger are the shell, tubes (or tube bundles), front-end head, rear-end head, baffles, and tube sheets (Shah and Sekulic 2003). In a shell and tube heat exchanger, the diameter of the outer shell is greatly increased, and a bank of tubes rather than a single central tube is used, as shown in Figure 5-1 (Sherman and Chen 2008). Fluid is distributed to the tubes through a manifold and tube sheet. To increase heat transfer efficiency, further modifications to the flow paths of the outer and inner fluids can be accomplished by adding baffles to the shell to increase fluid contact with the tubes, and by creating multiple flow paths or passes for the fluid flowing through the tubes (Sherman and Chen 2008). These heat exchangers are used for gas-liquid heat transfer applications primarily when the operating temperatures and/or pressures are very high (Shah and Sekulic 2003). 


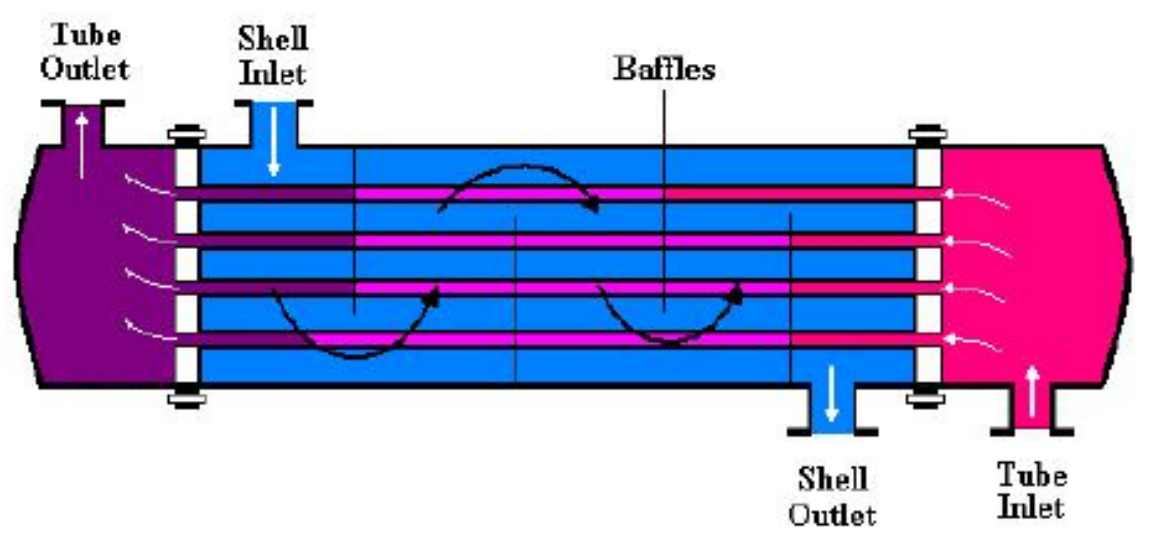

Figure 5-1. Shell and tube heat exchanger with baffles (Sherman and Chen 2008).

\subsubsection{Plate Heat Exchanger}

In a plate type heat exchanger, plate or planar surfaces are the fundamental heat transfer surfaces rather than tubes. Common plate heat exchangers deploy metal plates arranged in a stack-wise fashion and sealed with gaskets, welds, brazing, or diffusion welding (Figure 5-2). Counter flow, cross flow, and co-current flow can be arranged by altering the design of the supply manifolds to the heat exchanger (Sherman and Chen 2008). Plate type heat exchangers consists of a series of thin, corrugated alloy plates sealed and compressed together inside a carbon steel frame. Once compressed, the plate pack forms an arrangement of parallel flow channels. Each plate has a contoured surface that provides additional surface area, tortuous flow paths, and contact points with adjacent plates (Shah and Sekulic 2003). The two fluids (hot and cold) flow countercurrent to each other in alternate channels, as shown in Figure 5-2. Each plate is fitted with a gasket to direct the flow, seal the unit, and prevent fluid intermixing. The choice of gasket material is based on the application of the heat exchanger (Shah and Sekulic 2003). These plates act as primary heat transfer surfaces by conducting heat directly through metal plates from one fluid to another.

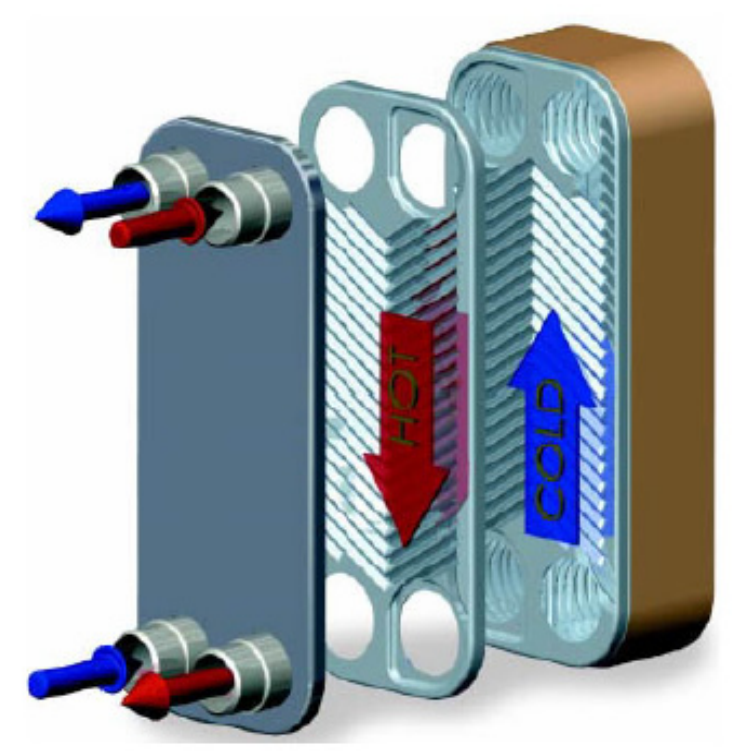

Figure 5-2. Flat plate compact heat exchanger (Sherman and Chen 2008). 
A hybrid welded-plate heat exchanger (Bavex heat exchanger; see Figure 5-3) is reported to be capable of operation at $900^{\circ} \mathrm{C}$ and pressures to $6 \mathrm{MPa}$ on the plate side. It is called a hybrid because one fluid is contained inside the plates while the other flows between the plates from baffled plenums inside a pressure boundary (Fisher and Sindelar 2008). It is reminiscent of a shell and tube arrangement with substantially greater surface area. Plates can be produced up to $0.35 \mathrm{~m}$ wide and $16 \mathrm{~m}$ long (Fisher and Sindelar 2008). Other variants of the welded plate type heat exchanger are produced, some of which do not require external shells. Service conditions range up to $700^{\circ} \mathrm{C}$ and $30 \mathrm{MPa}$ (in an external shell).

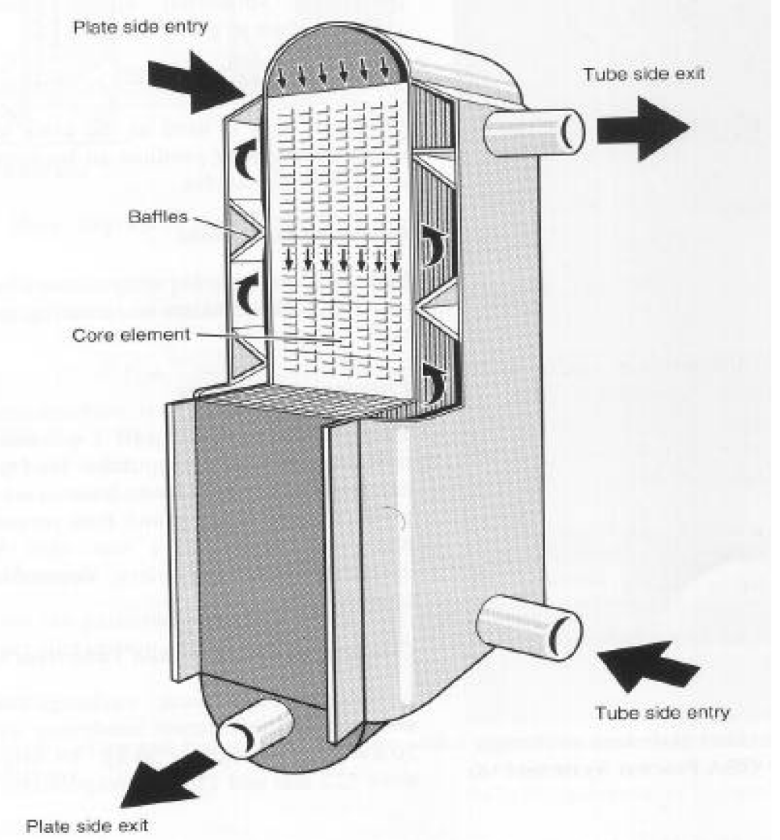

Figure 5-3. Bavex welded plate heat exchanger (Fisher and Sindelar 2008).

\subsubsection{Plate and Fin Heat Exchanger}

Plate and fin heat exchangers are formed by stacking flat metal plates alternately with corrugated metal plates (fins). Metal bars are placed around the perimeters between pairs of plates to support the stack and seal the edges, except for inlet and outlet passages (Sherman and Chen 2008). Heat transfer occurs as hot and cold fluids flow through the fins between alternate flat plates. Corrugated plates are secondary heat transfer surfaces, adding surface area and turbulence to the fluid flow (dependent on configuration) for greater heat transfer to the plates. Large numbers of plate and fin heat exchangers have been joined by brazing since the 1940 s, but more recently, manufacturers have also used diffusion welding for plate and fin models, as can be seen in Figure 5-4 (Fisher and Sindelar 2008). Both stainless steel and titanium plate and fin heat exchangers have been produced for service where conditions of higher temperature and/or pressure exist. A plate and fin heat exchanger with the arrangement of flat plates separated by corrugated

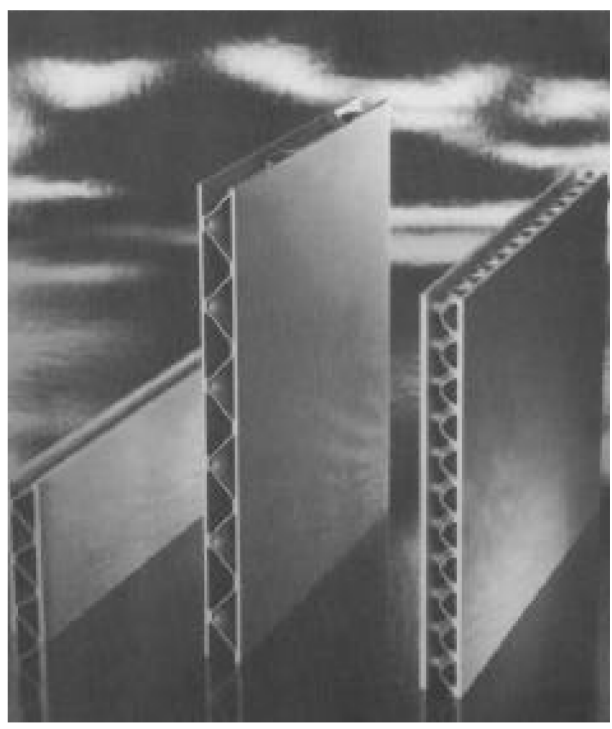

Figure 5-4. Elements of diffusion-bonded plate and fin heat exchanger (Fisher and Sindelar 2008). 
spacers in order to increase the contact surface area between the plates is shown in Figure 5-5.

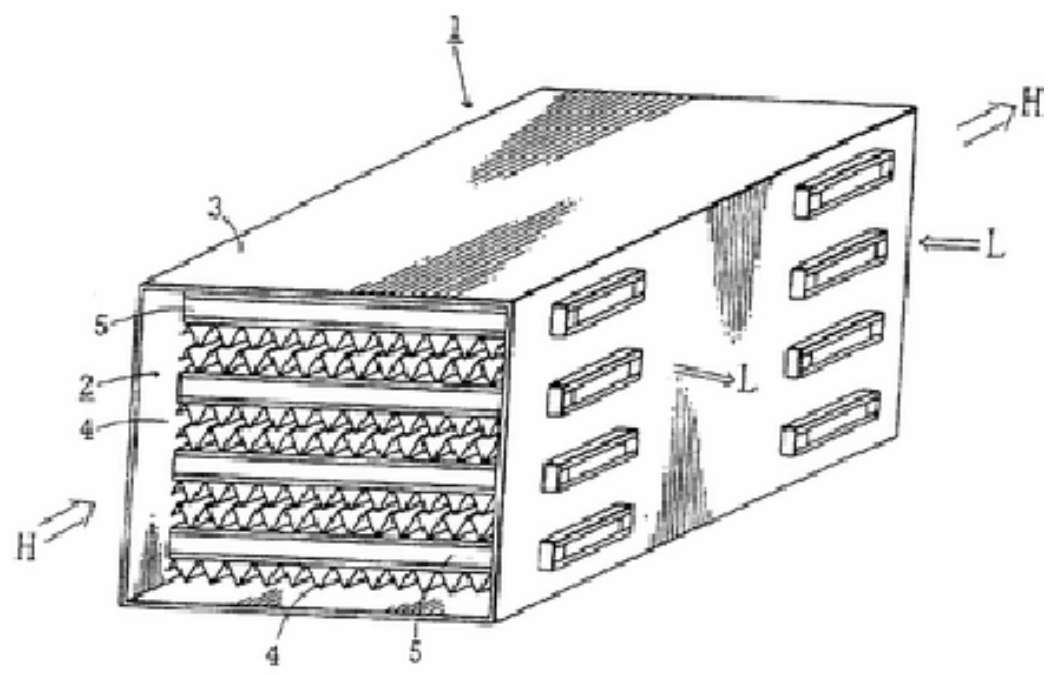

Figure 5-5. Plate-fin heat exchanger (Sherman and Chen 2008).

\subsubsection{Printed Circuit Heat Exchanger}

The printed circuit heat exchanger (PCHE) is a relatively new concept that has only been commercially manufactured by Heatric ${ }^{\mathrm{TM}}$ since 1985 . PCHEs are robust heat exchangers that combine compactness, low pressure drop, high effectiveness, and the ability to operate with a very large pressure differential between hot and cold sides (Heatric ${ }^{\mathrm{TM}}$ Homepage 2011). These heat exchangers are especially well suited to applications where compactness is important. The Heatric ${ }^{\mathrm{TM}}$ heat exchanger falls within the category of compact heat exchangers because of its high surface area density $\left(2,500 \mathrm{~m}^{2} / \mathrm{m}^{3}\right)$ (Hesselgreaves 2001).

As the name PCHE implies, they are manufactured by the same technique that is used for producing standard printed circuit boards for electronic equipment. In the first step of the manufacturing process, the fluid passages are photochemically etched into the metal plate as shown in Figure 5-6. Normally, only one side of each plate is etched to produce channels. The etched plates are thereafter joined by diffusion welding, resulting in

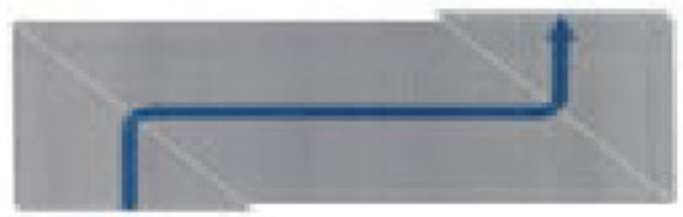
extremely strong all-metal heat exchanger cores shown in Figure 5-7. Plates for primary and secondary fluids are stacked alternately and formed into a module as shown in Figure 5-8. Modules may be used individually or joined with others to achieve the needed energy transfer capacity between fluids.

The diffusion welding process produces grain growth across the weld joint, thereby producing a uniform metallurgical structure which in turn gives strength near that of the unwelded parent metal. Because of the use of diffusion welding, the expected lifetime of the heat exchanger exceeds that of heat exchangers that are based on a brazed structure (Dewson and Thonon 2003). 


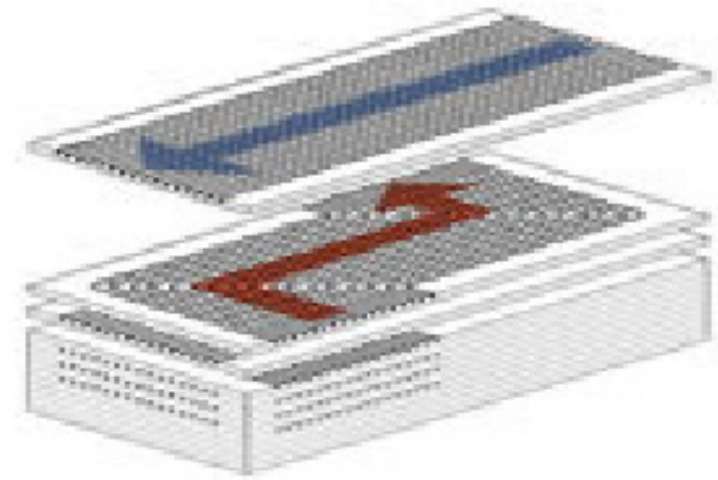

Figure 5-7. Second step-diffusion bonding of plates (Heatric ${ }^{\mathrm{TM}}$ Homepage 2011).

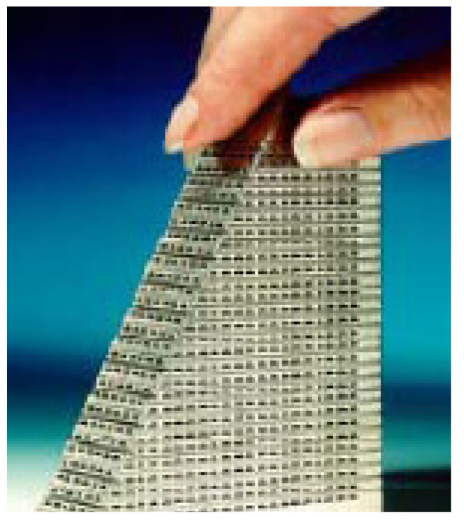

Figure 5-8. Diffusion-bonded PCHE section (Heatric $^{\mathrm{TM}}$ Homepage 2011).

A stack of the etched plates that have been bonded together comprise a block as a third step. The complete heat exchanger core is completed by fusion welding together as many of these blocks as the thermal duty (flow capacity) of the heat exchanger requires (see Figure 5-9).

The flow passages typically have a semicircular cross section as shown in Figure 5-10, and may also be radially corrugated as needed as shown in Figure 5-11. Their width and depth vary between 1.0 and $2.0 \mathrm{~mm}$ and 0.5 and $1.0 \mathrm{~mm}$, respectively (Hesselgreaves 2001).

Several unique characteristics contribute to the superior performance of PCHEs. The most distinctive characteristics are the high allowable pressure and temperature limits in combination with the compactness of the heat exchanger. Specifically, the manufacturing company claims that, as a result of its original design, Heatric ${ }^{\mathrm{TM}}$ heat exchangers are able to operate at pressures up

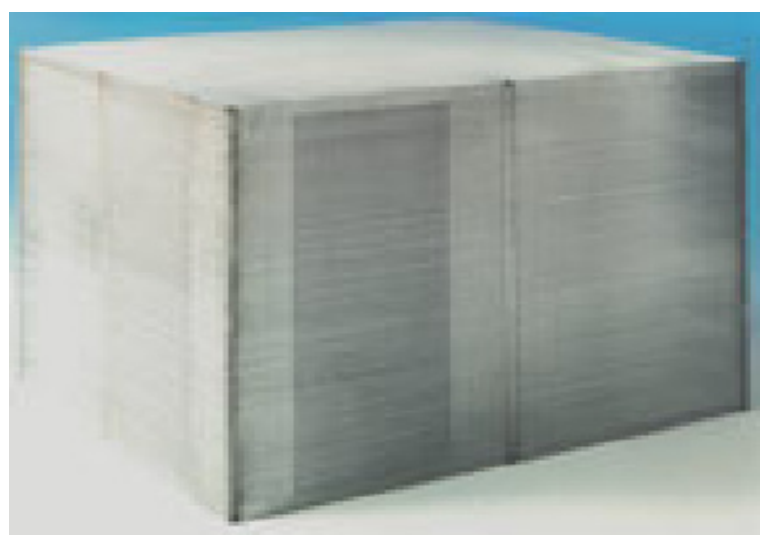

Figure 5-9. Third step-block composed of diffusion-bonded plates (Heatric ${ }^{\mathrm{TM}}$ Homepage 2011). to $60 \mathrm{MPa}$ and at temperatures not exceeding $900^{\circ} \mathrm{C}$ (Heatric ${ }^{\mathrm{TM}}$ Homepage 2011). To allow operation under such extreme conditions, the materials commonly employed in a PCHE include stainless steel, titanium, and nickel (pure/alloys) (Shah and Sekulic 2003). Heatric ${ }^{\mathrm{TM}}$ has supplied heat exchangers in the ranges indicated by the shaded area of Figure 5-12.

In addition to the wide operating range, the great potential of the PCHE is also illustrated by its enhancing safety features. As a result of its construction, it does not use or contain any gaskets or braze material. Consequently, the risk of leaks or fluid incompatibility is substantially reduced. In particular, the risk of leaks in a Heatric ${ }^{\mathrm{TM}}$ heat exchanger is approximately two orders of magnitude lower than for any other heat exchanger, thanks to its continuous passage (Dewson and Thonon 2003).

Flexibility of allowed fluid types is another distinguishing feature of Heatric ${ }^{\mathrm{TM}}$ heat exchangers. The versatility is particularly shown in the area of allowed fluid types and flow configurations. PCHEs can be designed for use in gas, liquid metal, and molten salt cooled reactors (Heatric ${ }^{\mathrm{TM}}$ Homepage 2011). The design also allows multifluid integration (multistream capacity). The most commonly employed flow configurations include counter flow, cross flow, and co-flow or any combination of these as shown in Figure 5-13. 


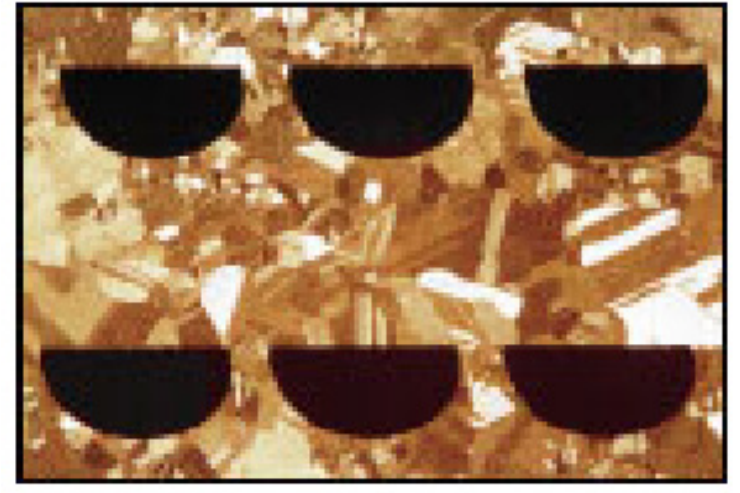

Figure 5-10. Cross sectional view of the semicircular passages (Heatric ${ }^{\mathrm{TM}}$ Homepage 2011).

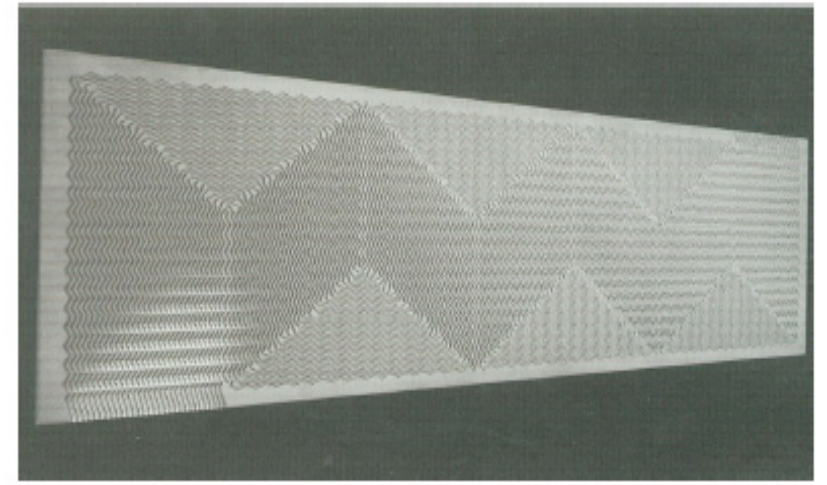

Figure 5-11. Side view of passage shapes (Hesselgreaves 2001).

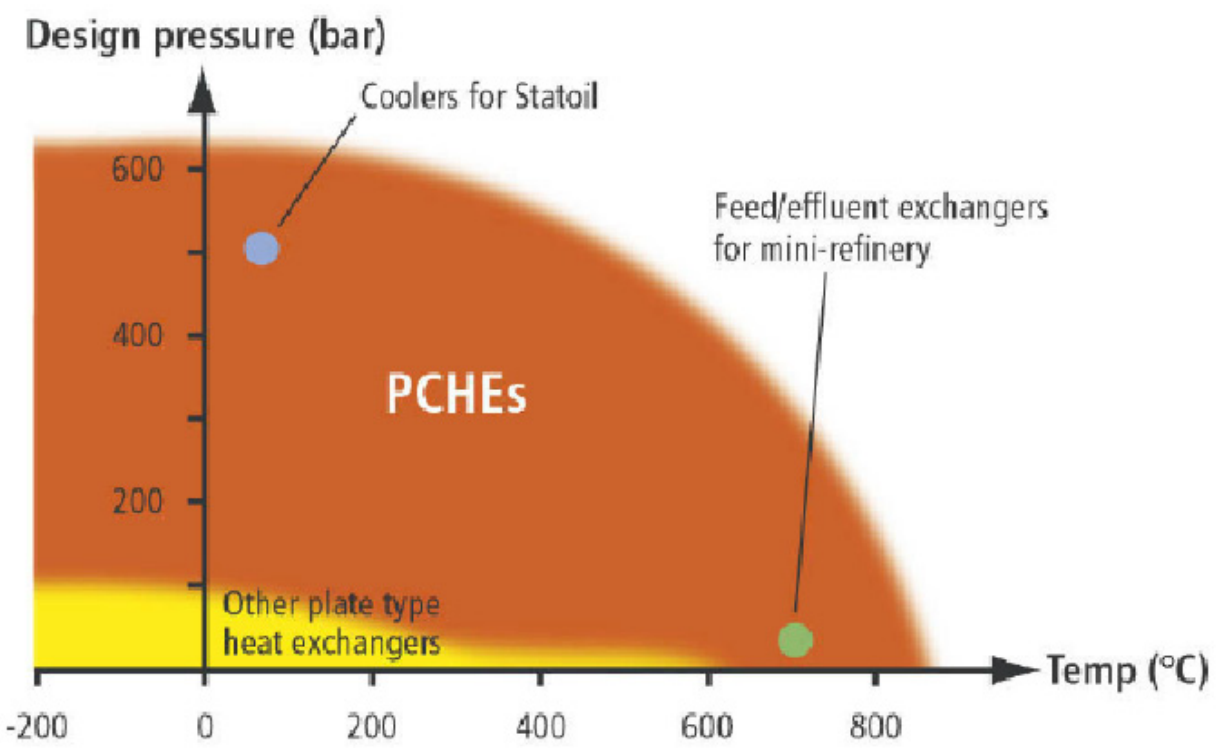

Figure 5-12. Current operating experience of Heatric ${ }^{T M}$ PCHEs (Gezelius 2004).
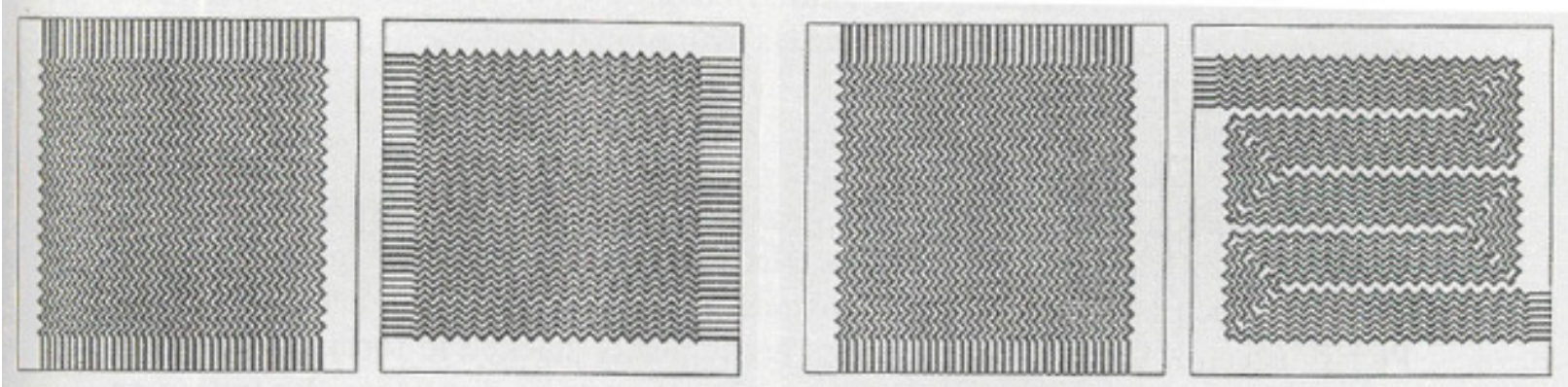

Figure 5-13. Simple cross flow (left) and cross-counterflow (right) configuration (Hesselgreaves 2001). 
Lastly, size and pressure drop considerations also favor the PCHE. Because of the compactness provided by its design, the volume of the Heatric ${ }^{\mathrm{TM}}$ type heat exchanger is normally between four and six times smaller than that of the standard heat exchanger type designed for the same thermal duty and pressure drop (Heatric ${ }^{\mathrm{TM}}$ Homepage 2011). With respect to mass, the Heatric ${ }^{\mathrm{TM}}$ heat exchanger has an average mass-to-duty ratio of 0.2 tons/MW, compared to 13.5 tonnes/MW for a shell-and-tube heat exchanger (Dewson and Thonon 2003). This reduction in size will cut the material and handling cost noticeably. The actual design does not put any constraints on the heat exchanger with regard to the pressure drop. The flow channels are usually short, which compensates for the narrow passages (Heatric ${ }^{\mathrm{TM}}$ Homepage 2011).

Heatric $^{\mathrm{TM}}$ has been developing a product to integrate the advantages of the PCHE and a plate and fin heat exchanger (Heatric ${ }^{\mathrm{TM}}$ Homepage 2011). This hybrid heat exchanger, shown in Figure 5-14, is called the $\mathrm{H}^{2} \mathrm{X}$. They are formed by alternating a fin layer with an etched plate, which are then diffusion bonded. This heat exchanger offers the high mechanical integrity and high efficiency of diffusion-welded heat exchangers combined with the large passages (lower pressure drop) and lower weight of the plate and fin heat exchanger (Heatric ${ }^{\mathrm{TM}}$ Homepage 2011).

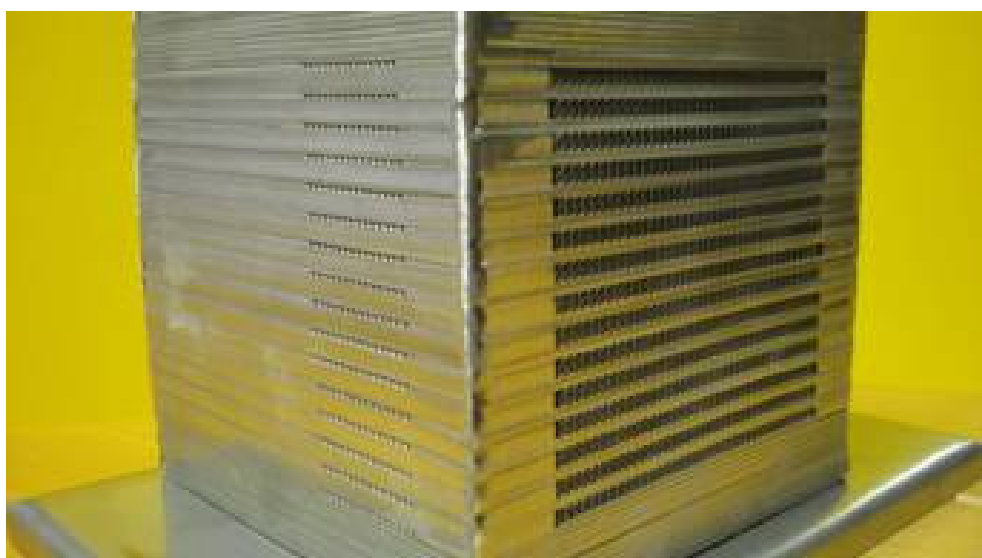

Figure 5-14. The Heatric ${ }^{\mathrm{TM}} \mathrm{H}^{2} \mathrm{X}$ heat exchanger-PCHE construction on the left side and plate and fin side on the right (Heatric ${ }^{\mathrm{TM}}$ Homepage 2011).

\subsubsection{Helical Coil Heat Exchanger}

Helical coil heat exchangers are shell and tube type heat exchangers that consist of tubes spirally wound into bundles and fitted in a shell as shown in Figure 5-15. The spiral geometry of the tubes results in a higher heat transfer rate than that for a straight tube (Shah and Sekulic 2003). Because of the tube bundle geometry, a considerable amount of surface can be accommodated inside the shell. These heat exchangers are used for gas-liquid heat transfer applications, primarily when the operating temperatures and/or pressures are very high. Cleaning a helical coil heat exchanger can be very difficult (Shah and Sekulic 2003).

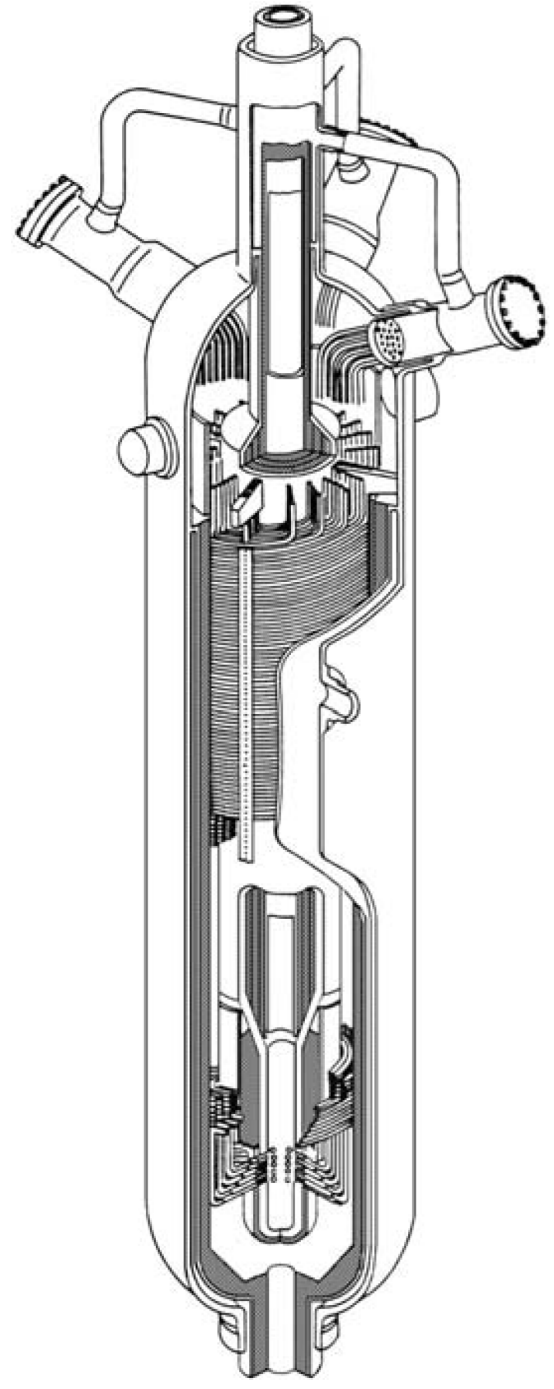

Figure 5-15. A helical-coil heat exchanger (Areva 2008). 


\subsubsection{Ceramic Heat Exchanger}

The main benefits of ceramic heat exchangers are their ceramic material properties. Silicon carbide (SiC) ceramics are the leading choice for heat exchangers because they are ideally suited for high temperature, corrosive environments. These ceramics are able to operate safely at higher temperatures $\left(\sim 1300^{\circ} \mathrm{C}\right)$ than metallic alloys (Heat Transfer International Homepage 2011$)$. A shell and tube type ceramic heat exchanger can operate at about 1.3 MPa (Heat Transfer International Homepage 2011). However, leakage between the primary and secondary fluids can be a significant issue if the pressure difference between the fluids is large. Stress analyses and material properties studies indicated that siliconized $\mathrm{SiC}$ is an attractive ceramic material for fabrication of pressurized heat exchangers (Taborek et al. 1983).

$\mathrm{SiC}$ ceramics are also highly inert chemically and have a low coefficient of thermal expansion. However, $\mathrm{SiC}$ can be susceptible to oxidation at high temperatures. Individual tubes can be easily replaced in the Heat Transfer International design (Heat Transfer International Homepage 2011). Particulate build-up can be removed and cleaning can be performed without process interruption (Heat Transfer International Homepage 2011).

The mechanical properties of $\mathrm{SiC}$ material are dependent on factors such as porosity and the impurity concentration (Snead et al. 2007). Under some conditions of high-temperature exposure, the helium permeability of $\mathrm{SiC}$ ceramics can increase by at least three orders of magnitude with a pressure difference of $520 \mathrm{kPa}$ across the tube walls (Taborek 1983). An area that requires further work is the fabrication of joint between ceramics and metallic piping systems.

Some of the potential applications of ceramic heat exchangers considered for advanced energy systems include gas turbines, in various configurations, and coal gasifiers (Taborek 1983).

\subsection{Summary}

The key to high efficiency is a highly effective heat exchanger. An efficient design of the secondary heat exchanger is critical for effective use of the energy generated in the FHR. The potential options for the secondary heat exchanger. The heat exchanger options will be examined to determine the best fit for the FHR applications. Analysis results will be presented in future deliverables. 


\section{COMPARISONS OF FHR COOLANT PROPERTIES AND SELECTION}

\subsection{Introduction}

The coolant comparison study is an essential part of the FHR heat exchanger study because major heat exchanger designs, performance, and issues are closely related to the coolant characteristics.

Figure 6-1 shows the basic outline of the FHR heat exchanger coolant study. This study basically consists of three steps. First, the coolant options for the primary and the secondary loops of the heat exchangers are identified. Since the heat exchangers in the FHR are used for various purposes, there are many options in the heat exchanger coolants. The key parameters associated with the coolants are reviewed and compared together. The key parameters include thermal/physical properties, corrosion characteristics, and material cost.

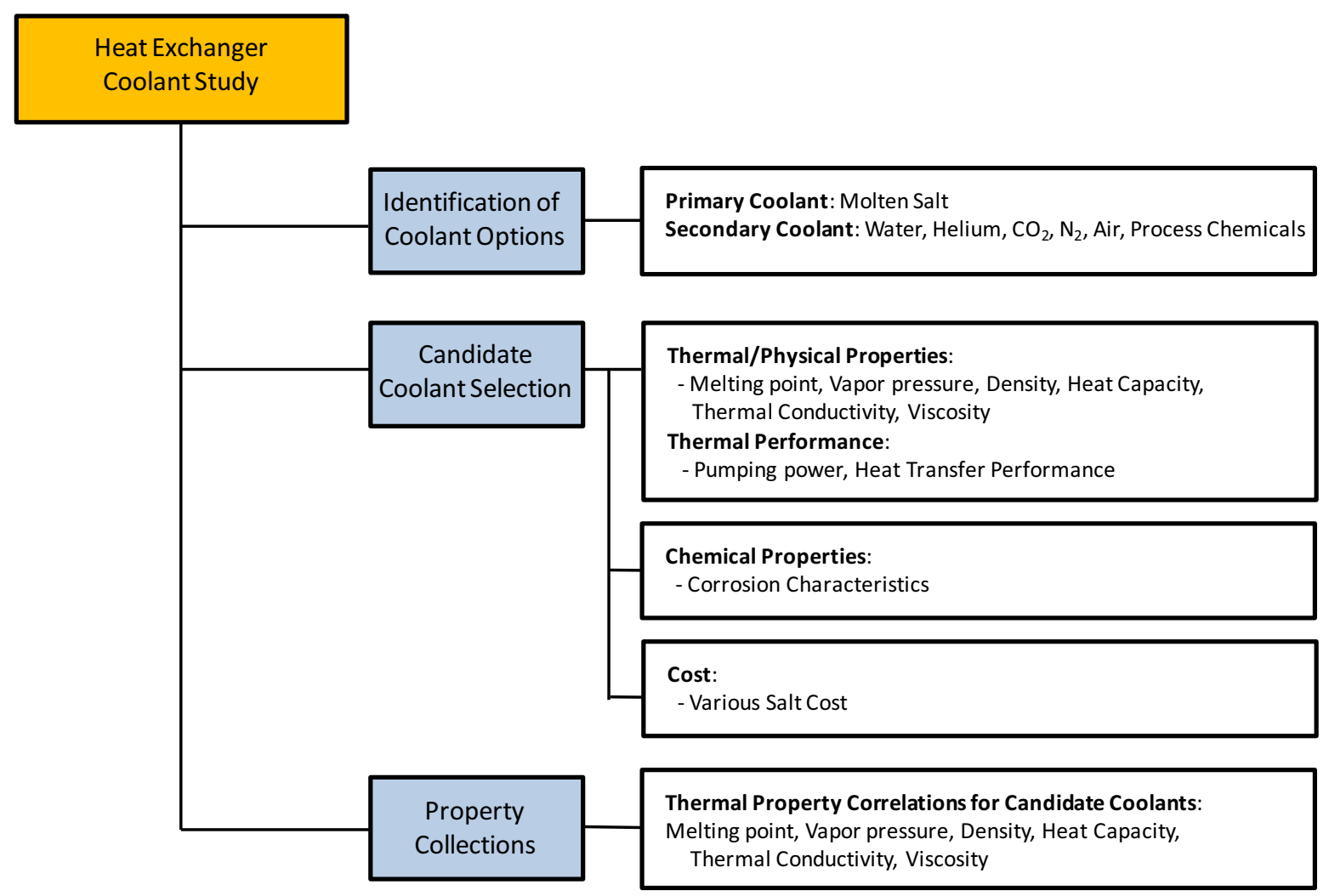

Figure 6-1. FHR Heat Exchanger Coolant Study.

\subsection{FHR Coolant Types}

In the FHR heat exchangers, the primary coolant is fluoride molten salt and the secondary coolants depending on the application could be: fluoride/chloride/nitride molten salts, helium, $\mathrm{CO}_{2}, \mathrm{~N}_{2}$, Air, Water, or Process chemicals. Many technical reports have recently been published; reviewing various molten salt coolant properties (Williams et al. 2006a, Williams et al. 2006b, and Sohal et al. 2010). According to Williams' (2006b), the following 11 molten salts are recommended as candidate coolants for heat transfer loop which are given with their mol\%, and their basic properties are listed in Table 6-1:

- $\quad$ LiF-NaF-KF (46-11.5-42.5) 
- $\mathrm{NaF}_{-\mathrm{ZrF}}$

$(59.5-40.5)$

- $\mathrm{KF}-\mathrm{ZrF}_{4}$

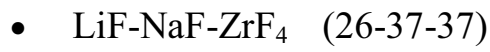

- $\quad \mathrm{LiCl}-\mathrm{KCl} \quad(59.5-40.5)$

- $\quad \mathrm{LiCl}-\mathrm{RbCl} \quad(58-42)$

- $\quad \mathrm{NaCl}-\mathrm{MgCl}_{2} \quad(63-37)$

- $\mathrm{KCl}_{-\mathrm{MgCl}_{2}} \quad(68-32)$

- $\mathrm{NaF}_{-} \mathrm{NaBF}_{4} \quad(8-92)$

- $\mathrm{KF}^{-\mathrm{KBF}_{4}}$ (25-75)

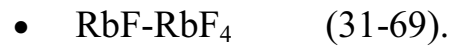

Table 6-1. Summary of the candidate molten salt properties for heat transfer loop (Williams et al. 2006b).

\begin{tabular}{|c|c|c|c|c|c|c|c|}
\hline \multirow[b]{2}{*}{ Salt $^{a}$} & \multirow[b]{2}{*}{$\begin{array}{c}\text { Formula } \\
\text { weight } \\
(\mathrm{g} / \mathrm{mol})\end{array}$} & \multirow[b]{2}{*}{$\begin{array}{l}\text { Melting } \\
\text { point } \\
\left({ }^{\circ} \mathrm{C}\right)\end{array}$} & \multirow[b]{2}{*}{$\begin{array}{c}900^{\circ} \mathrm{C} \text { vapor } \\
\text { pressure } \\
(\mathrm{mm} \mathrm{Hg})\end{array}$} & \multicolumn{4}{|c|}{ Heat-transfer properties at $700^{\circ} \mathrm{C}$} \\
\hline & & & & $\begin{array}{c}\rho, \\
\text { density } \\
\left(\mathrm{g} / \mathrm{cm}^{3}\right)\end{array}$ & $\begin{array}{c}\rho^{*} C p \\
\text { volumetric } \\
\text { heat capacity } \\
\left(\mathrm{cal} / \mathrm{cm}^{3}-{ }^{\circ} \mathrm{C}\right)\end{array}$ & $\begin{array}{c}\boldsymbol{\mu}, \\
\text { viscosity } \\
(\mathrm{cP})\end{array}$ & $\begin{array}{c}\boldsymbol{k}, \\
\text { thermal } \\
\text { conductivity } \\
(\mathrm{W} / \mathrm{m}-\mathrm{K})\end{array}$ \\
\hline LiF-NaF-KF & 41.3 & 454 & $\sim 0.7$ & 2.02 & 0.91 & 2.9 & 0.92 \\
\hline $\mathrm{NaF}-\mathrm{ZrF}_{4}$ & 92.7 & 500 & 5 & 3.14 & 0.88 & 5.1 & 0.49 \\
\hline $\mathrm{KF}-\mathrm{ZrF}_{4}$ & 103.9 & 390 & 1.2 & 2.80 & 0.70 & $<5.1$ & 0.45 \\
\hline $\mathrm{LiF}-\mathrm{NaF}-\mathrm{ZrF}_{4}$ & 84.2 & 436 & $\sim 5$ & 2.92 & 0.86 & 6.9 & 0.53 \\
\hline $\mathrm{LiCl}-\mathrm{KCl}$ & 55.5 & 355 & 5.8 & 1.52 & 0.435 & 1.15 & 0.42 \\
\hline $\mathrm{LiCl}-\mathrm{RbCl}$ & 75.4 & 313 & - & 1.88 & 0.40 & 1.30 & 0.36 \\
\hline $\mathrm{NaCl}-\mathrm{MgCl}_{2}$ & 73.7 & 445 & $<2.5$ & 1.68 & 0.44 & 1.36 & 0.50 \\
\hline $\mathrm{KCl}-\mathrm{MgCl}_{2}$ & 81.4 & 426 & $<2.0$ & 1.66 & 0.46 & 1.40 & 0.40 \\
\hline $\mathrm{NaF}-\mathrm{NaBF}_{4}$ & 104.4 & 385 & 9500 & 1.75 & 0.63 & 0.90 & 0.40 \\
\hline $\mathrm{KF}-\mathrm{KBF}_{4}$ & 109.0 & 460 & 100 & 1.70 & 0.53 & 0.90 & 0.38 \\
\hline $\mathrm{RbF}-\mathrm{RbF}_{4}$ & 151.3 & 442 & $<100$ & 2.21 & 0.48 & 0.90 & 0.28 \\
\hline
\end{tabular}

This study will use information provided by Williams et al. (2006b) and Sohal et Al. (2010), but the focus will be placed on the heat exchanger design and performance. 


\subsection{Key Parameters for the FHR Heat Exchanger Coolant Thermal Performance}

Some of the key parameters considered in choosing an FHR heat exchanger coolant (molten salt) can be summarized as follows:

- Melting Point: Melting point is a very important property of the molten salt for application in the heat transport loop because of coolant freezing issues. Typically, the coolant melting point is required as low as possible, preferably less than $525^{\circ} \mathrm{C}$ for the FHR (Williams et al. 2006a).

- Vapor Pressure: Vapor pressure is also an important coolant property. Lower vapor pressure is preferred for the heat transport loop or heat exchangers to avoid cavitations and coolant boiling issue.

- Density: Density is an important coolant property for thermal and fluid dynamic systems. Large density is generally preferred because of its high heat transport capability. However, density that is too large can cause undesirable hydrostatic heads and extra demands on pumping equipment. A large density gradient by temperature enhances natural circulation capability in accident conditions.

- Heat Capacity: Heat capacity is a measure of heat that can be stored in the material by unit temperature change. A large heat capacity is preferred, in the heat transport loop and heat exchangers for better heat transport performance. A large heat capacity needs less mass flow for the same heat transport, thus reducing pumping power. Fluoride salts have relatively large heat capacities compared to other coolants. The product of density and heat capacity (volumetric heat capacity) is $\sim 4.18 \mathrm{E} 6 \mathrm{~J} / \mathrm{m}^{3}$ $\left(1 \mathrm{cal} / \mathrm{cm}^{3}\right)$ for fluoride salts, which is similar to water.

- Thermal Conductivity: Thermal conductivity is the property that quantifies how fast heat can be transferred by conduction. Therefore, higher thermal conductivity is preferred for the coolants because it provides better heat transfer performance.

- Viscosity: Viscosity is related to the pressure drop and pumping power. A lower viscosity is preferred for the coolants because it results in less friction loss for the same traveling distance.

\subsection{Comparisons of Coolant Thermal-Hydraulic Performance}

If a certain coolant is superior to the other coolant for all properties, the selection of the coolant becomes straight forward. However, each coolant is generally good in some respect (properties) but poor in the others. Therefore, it is useful to compare some key parameters that determine coolant thermal performance in the system of interest. This section discusses coolant thermal-hydraulic characteristics; other characteristics will be discussed later.

Previously, some figures of merits (FOMs) were used for evaluating the thermal performance of the coolants on general purpose. Bonilla (1958) has provided the FOMs based on minimal pumping power for a given coolant temperature rise as follows:

$$
F O M=\mu^{0.2} /\left(\rho^{2} C_{P}^{2.8}\right)
$$

Where:

$$
\begin{aligned}
\mu & =\text { viscosity } \\
\rho & =\text { density } \\
C_{p} & =\text { heat capacity. }
\end{aligned}
$$


Sanders (1971) proposed the following FOM based on the heat exchanger surface area:

$F O M=\mu^{0.2} /\left(\rho^{0.3} C_{p}^{0.6} k^{0.6}\right)$

Williams (2006) used the above FOMs for comparing heat transfer performance of the molten salt coolants for a NGNP Nuclear Hydrogen Initiative heat transfer loop.

The above two parameters are very useful for comparing overall coolant heat transfer performance at the early stages of research. However, they are still not complete for evaluating all the important thermal performance parameters in the system of interest. Figure 6-2 shows the general thermal-hydraulic requirements for the intermediate coolant in the FHR systems.

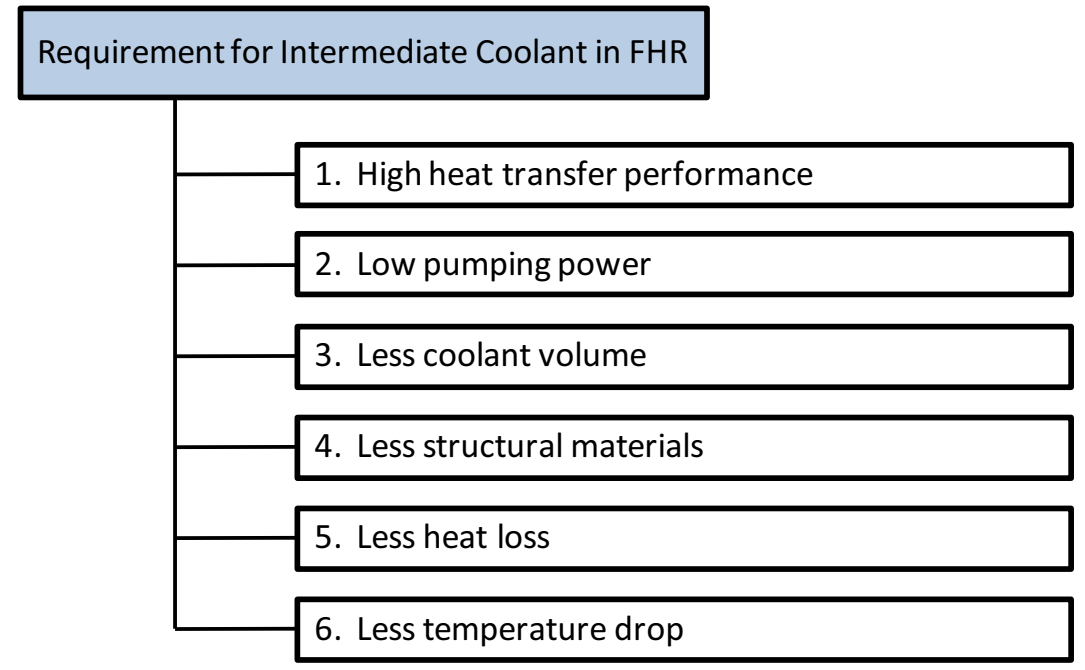

Figure 6-2. General thermal-hydraulic requirements for the intermediate coolant in the FHR systems.

The following are general thermal-hydraulic requirements for the coolant in the FHRs:

- High heat transfer performance: Coolant should transfer heat efficiently. Good heat transfer performance leads to efficient heat transfer between the primary and the secondary sides.

- Low pumping power: Coolant should require low pumping power to minimize efficiency loss and economic loss.

- Less coolant volume: Small volume of coolant is preferred for economic reasons.

- Less structural materials for containing coolant: Small amount of structural materials for the coolant containment is preferred for economic reasons.

- Less heat loss: Heat loss of the coolant should be minimized when transferring heat long distances for a more efficient system.

- Less temperature drop: The coolant temperature drop should be minimized when transferring heat long distances for a more efficient system.

With the six requirements mentioned above, six FOMs were developed in this study (See Appendix A for detail analysis). The following summarizes the FOMs and their physical meanings:

- Heat Transfer Performance Factor $\left(\mathbf{F O M}_{h t}\right)$ : This FOM represents the heat transfer performance of the coolant. It measures the heat transfer rate per unit pumping power for a given geometry. 
- Pumping Factor $\left(\mathbf{F O M}_{\mathbf{p}}\right)$ : This FOM represents the pumping power of the coolant. It measures the pumping power required to transport the same energy for a given coolant.

- Coolant Volume Factor $\left(\mathbf{F O M}_{\mathbf{c v}}\right)$ : This FOM represents the volume of the coolant. It measures the coolant volume required for transferring heat with the same heat and pumping power.

- Material Volume Factor $\left(\mathbf{F O M}_{\text {ccv }}\right)$ : This FOM represents the volume of the structural materials. It measures the volume of the coolant structural materials required for transferring heat with the same heat duty and pumping power under given operating conditions (temperature and pressure).

- Heat Loss Factor $\left(\mathbf{F O M}_{h l}\right)$ : This FOM represents the heat loss of the coolant. It measures the heat loss of the coolant when it is transported to same distance with the same heat duty and pumping power.

- Temperature Drop Factor $\left(\mathbf{F O M}_{\mathbf{d t}}\right)$ : This FOM represents the heat loss of the coolant. It measures the temperature drop of the coolant when it is transported to the same distance with the same heat duty and pumping power.

Table 6-2 summarizes all the FOMs derived and proposed for the IHTL coolants. Based on the FOMs summarized, heat transfer performance, pumping power, coolant volume, pipe material volume, coolant heat loss, and coolant temperature drop can be compared easily and quantitatively for the same heat duty and pumping power requirements. Plus $(+)$ sign of a sensitivity indicates that the FOM increases with the properties while minus (-) sign indicates that the FOM decreases with the properties. This table also shows the sensitivity of the FOMs in terms of various fluid properties. The sensitivities of the FOMs were estimated by the following formula:

$$
S_{\varphi}=\frac{\partial F O M / F O M}{\partial \varphi / \varphi}
$$

The numbers of the sensitivities shows that how much the FOMs are affected by each property. If the sensitivity is higher, the FOM is more significantly affected by that property. From this table, the effects of properties on the thermal-hydraulic performance of the coolants can be interpreted as follows:

- Increasing thermal conductivity can increase heat transfer performance by a power of 0.6 , but it also increases heat loss and temperature drop of the coolant at the same rate.

- Increasing coolant density can increase heat transfer performance and reduce coolant volume by powers of 0.58 and 0.84 respectively. It also decreases pumping power by a power of 2 .

- Increasing heat capacity can increase heat transfer performance and significantly reduce coolant/material volume by powers of 0.4 and 1.16, respectively, with decreases of pumping power. On the other hand, increases in heat loss and temperature drop are negligible $(=0.06)$.

- Increasing viscosity increases pumping power and coolant volume with significant reduction in heat transfer performance. 
Table 6-2. Summary of FOMs for heat transfer coolant (refer Appendix A for details).

\begin{tabular}{|c|c|c|c|c|c|}
\hline \multirow[b]{2}{*}{ Figure of Merits } & \multicolumn{5}{|c|}{ Sensitivity of Properties } \\
\hline & $S_{k}$ & $S_{\rho}$ & $S_{C p}$ & $S_{\mu}$ & $S_{P}$ \\
\hline $\begin{array}{l}\text { Heat transfer performance factor }\left(F O M_{h t}\right) \text { : } \\
F O M_{h t}=\frac{(k)^{0.6} \cdot(\rho)^{0.58} \cdot\left(C_{p}\right)^{0.4} \cdot(\mu)^{-0.47}}{R_{h t, 0}}\end{array}$ & 0.6 & 0.58 & 0.4 & -0.47 & 0.0 \\
\hline $\begin{array}{l}\text { Pumping factor }\left(F O M_{p}\right) \text { : } \\
F O M_{p}=\frac{\rho^{-2} \cdot C_{P}^{-2.8} \cdot \mu^{0.2}}{R_{p, 0}}\end{array}$ & 0.0 & -2 & -2.8 & 0.2 & 0.0 \\
\hline $\begin{array}{l}\text { Coolant volume factor }\left(F O M_{c v}\right) \text { : } \\
F O M_{c v}=\frac{(\rho)^{-0.84} \cdot\left(C_{p}\right)^{-1.16} \cdot(\mu)^{0.1}}{R_{c v, 0}}\end{array}$ & 0.0 & -0.84 & -1.16 & 0.1 & 0.0 \\
\hline $\begin{array}{l}\text { Material Volume factor }\left(F O M_{c c v}\right) \text { : } \\
F O M_{c c v}=\frac{(P) \cdot(\rho)^{-0.84} \cdot\left(C_{p}\right)^{-1.16} \cdot(\mu)^{0.1}}{R_{c c v, 0}}\end{array}$ & 0.0 & -0.84 & -1.16 & 0.1 & 1.0 \\
\hline $\begin{array}{l}\text { Heat loss factor }\left(F O M_{h l}\right): \\
F O M_{h l}=\frac{(k)^{0.6} \cdot(\rho)^{0.34} \cdot\left(C_{p}\right)^{0.06} \cdot(\mu)^{-0.44}}{R_{h l, 0}}\end{array}$ & 0.6 & 0.34 & 0.06 & -0.44 & 0.0 \\
\hline $\begin{array}{l}\text { Temperature drop factor }\left(F O M_{d t}\right) \text { : } \\
F O M_{d t}=\frac{(k)^{0.6} \cdot(\rho)^{0.34} \cdot\left(C_{p}\right)^{0.06} \cdot(\mu)^{-0.44}}{R_{d t, 0}}\end{array}$ & 0.6 & 0.34 & 0.06 & -0.44 & 0.0 \\
\hline
\end{tabular}

Table 6-3 shows the reference values for the FOMs that will be used in this study. These reference values are estimated based on water at $25^{\circ} \mathrm{C}$ and $0.1 \mathrm{MPa}$. Therefore, the estimated FOMs indicate coolant performance of a certain coolant relative to water at $25^{\circ} \mathrm{C}$ and $1 \mathrm{~atm}(0.1 \mathrm{MPa})$. Water is one of the most common coolant with wide applications, thus was used for comparison purposes.

Table 6-3. Summary of Reference Values in FOMs (Water at $\left.25^{\circ} \mathrm{C}, 1 \mathrm{~atm}\right)$ (SI unit).

\begin{tabular}{|l|c|c|c|c|c|c|}
\hline & $\mathbf{k}$ & $\begin{array}{c}\boldsymbol{\rho} \\
{[\mathbf{W} / \mathbf{m} \mathbf{~ K}]}\end{array}$ & $\begin{array}{c}\mathbf{C}_{\mathbf{p}} \\
{\left[\mathbf{k g} / \mathbf{m}^{3}\right]}\end{array}$ & $\begin{array}{c}\boldsymbol{\mu} \\
{[\mathbf{J} / \mathbf{k g ~ K}]}\end{array}$ & $\begin{array}{c}\mathbf{P} \\
{[\mathbf{P a}]}\end{array}$ & Reference Values \\
\hline$R_{h t, 0}$ & 0.61 & 997.05 & 4181 & 0.00089 & $1.0 \mathrm{E}+05$ & $3.11 \mathrm{E}+04$ \\
\hline$R_{p, 0}$ & 0.61 & 997.05 & 4181 & 0.00089 & $1.0 \mathrm{E}+05$ & $1.79 \mathrm{E}-17$ \\
\hline$R_{c v, 0}$ & 0.61 & 997.05 & 4181 & 0.00089 & $1.0 \mathrm{E}+05$ & $1.08 \mathrm{E}-07$ \\
\hline$R_{c c v, 0}$ & 0.61 & 997.05 & 4181 & 0.00089 & $1.0 \mathrm{E}+05$ & $1.08 \mathrm{E}-07$ \\
\hline$R_{h l, 0}$ & 0.61 & 997.05 & 4181 & 0.00089 & $1.0 \mathrm{E}+05$ & $2.82 \mathrm{E}+02$ \\
\hline$R_{d t, 0}$ & 0.61 & 997.05 & 4181 & 0.00089 & $1.0 \mathrm{E}+05$ & $2.82 \mathrm{E}+02$ \\
\hline
\end{tabular}




\subsubsection{Comparisons of Coolant Thermal-Hydraulic Performance}

Table 6-4 shows the comparisons of the thermal-hydraulic characteristics of the molten-salt coolants based on the estimated FOMs. All of the FOMs were estimated based on a temperature of $700^{\circ} \mathrm{C}$. The following summarizes the results:

- $\quad \boldsymbol{F O M}_{\text {th }}: F O M_{\text {th }}$ physically represents the heat transfer rate per unit pumping power for a given geometry. Therefore, a higher $F O M_{t h}$ is preferred for better heat transfer performance. According to the comparisons, LiF-NaF-KF shows the highest value $(=0.8)$, then $\mathrm{NaF}_{-} \mathrm{NaBF}_{4}(=0.71)$, followed by $\mathrm{KF}_{-\mathrm{KBF}_{4}}(=0.64)($ See Figure 6-3).

- $\quad \boldsymbol{F O M}$ : Lower $\mathrm{FOM}_{p}$ is preferred because it requires less pumping power for transferring the same amount of heat. According to the comparisons, LiF-NaF-KF shows the lowest values $(=2.82)$, then $\mathrm{NaF}-\mathrm{ZrF}_{4}(=5.02)$, followed by LiF-NaF-ZrF 4 (=5.36) (See Figure 6-4).

- $\boldsymbol{F O M}_{c v}$ : Lower $F O M_{c v}$ is preferred because it requires less coolant volume to provide the same amount of heat transfer performance under the same pumping power. According to the comparisons, LiF-NaF-KF shows the lowest value (=1.57), then $\mathrm{NaF}_{-2 r F}(=1.98)$, followed by NaF-NaBF 4 $(=2.04)$ (See Figure 6-5).

- $\quad \boldsymbol{F O M}_{c c v}$ : Lower $F O M_{c c v}$ is preferred because it requires less structural material volume for both heat transfer pipes and components. According to the comparisons, LiF-NaF-KF shows the lowest values $(=1.57)$, then $\mathrm{NaF}_{-2} \mathrm{ZF}_{4}$ (=1.98), followed by $\mathrm{NaF}_{-} \mathrm{NaBF}_{4}$ (=2.04) (See Figure 6-6).

- $\quad \boldsymbol{F O} \boldsymbol{M}_{h l}$. Lower $\mathrm{FOM}_{h l}$ is preferred because it requires less insulation for preventing heat loss.

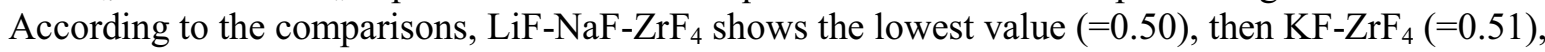
followed by $\mathrm{NaF}-\mathrm{ZrF}_{4}(=0.56)$ (See Figure 6-7).

- $\quad \boldsymbol{F O M}_{d t}$ : Lower $F O M_{d t}$ is preferred because more thermal energy can be transferred longer distances with less of a temperature drop. According to the comparisons, LiF-NaF-ZrF4 shows the lowest value $(=0.50)$, then $\mathrm{KF}-\mathrm{ZrF}_{4}(=0.51)$, followed by $\mathrm{NaF}_{-} \mathrm{ZrF}_{4}(=0.56)$ (See Figure 6-8).

Overall, LiF-NaF-KF is considered the best heat transfer coolant compared to the other molten salt coolants that were used in this analysis. It shows the best performance in heat transfer, pumping power, coolant volume, and structural material volume. However, it shows the worst performance for heat loss and temperature drop. These two factors generally are lower priorities because the problem can be easily addressed by thickening or adding multiple insulation layers. Figures 6-3 to 6-8 show the results. See Appendix A for a detailed study. 
Table 6-4. Comparisons of FOMs for the Various Molten Salt Coolants.

\begin{tabular}{|c|c|c|c|c|c|c|c|c|c|c|c|c|}
\hline Coolant & $\begin{array}{c}\text { Melting } \\
\text { Point }\left({ }^{\circ} \mathbf{C}\right) \\
\end{array}$ & $\begin{array}{c}\mathbf{K} \\
(\mathbf{W} / \mathbf{m} \mathbf{K}) \\
\end{array}$ & $\begin{array}{c}\rho \\
(\mathrm{kg} / \mathrm{m} 3)\end{array}$ & $\begin{array}{c}\mathrm{Cp} \\
(\mathrm{J} / \mathrm{kg} \mathrm{K}) \\
\end{array}$ & $\begin{array}{c}\mu \\
(\mathbf{P a} \mathbf{s})\end{array}$ & $\begin{array}{c}\mathbf{P} \\
(\mathbf{a t m})\end{array}$ & FOM $_{\text {th }}$ & FOM $_{p}$ & FOM $_{\mathrm{cv}}$ & $\mathbf{F O M}_{\mathrm{ccv}}$ & FOM $_{\text {hl }}$ & FOM $_{d t}$ \\
\hline Water $\left(25^{\circ} \mathrm{C}\right)$ & 0 & 0.61 & 997.05 & 4181 & 0.00089 & 1 & 1.00 & 1.00 & 1.00 & 1.00 & 1.00 & 1.00 \\
\hline LiF-NaF-KF & 454 & 0.92 & 2020 & 1886 & 0.0029 & 1 & 0.80 & 2.87 & 1.57 & 1.57 & 0.92 & 0.92 \\
\hline $\mathrm{NaF}-\mathrm{ZrF}{ }_{4}$ & 500 & 0.49 & 3140 & 1173 & 0.0051 & 1 & 0.45 & 5.02 & 1.98 & 1.98 & 0.56 & 0.56 \\
\hline $\mathrm{KF}-\mathrm{ZrF} \mathrm{F}_{4}$ & 390 & 0.45 & 2800 & 1046 & 0.0051 & 1 & 0.38 & 8.69 & 2.49 & 2.49 & 0.51 & 0.51 \\
\hline LiF-NaF-ZrF 4 & 436 & 0.53 & 2920 & 1233 & 0.0069 & 1 & 0.40 & 5.36 & 2.05 & 2.05 & 0.50 & 0.50 \\
\hline $\mathrm{LiCl}-\mathrm{KCl}$ & 355 & 0.42 & 1520 & 1198 & 0.00115 & 1 & 0.55 & 14.99 & 3.07 & 3.07 & 0.76 & 0.76 \\
\hline $\mathrm{LiCl}-\mathrm{RbCl}$ & 313 & 0.36 & 1880 & 890 & 0.0013 & 1 & 0.47 & 23.03 & 3.66 & 3.66 & 0.70 & 0.70 \\
\hline $\mathrm{NaCl}-\mathrm{MgCl}_{2}$ & 445 & 0.5 & 1680 & 1096 & 0.00136 & 1 & 0.58 & 16.26 & 3.18 & 3.18 & 0.81 & 0.81 \\
\hline $\mathrm{KCl}-\mathrm{MgCl}_{2}$ & 426 & 0.4 & 1660 & 1160 & 0.0014 & 1 & 0.50 & 14.30 & 3.02 & 3.02 & 0.70 & 0.70 \\
\hline $\mathrm{NaF} \mathrm{NaBF}_{4}$ & 385 & 0.4 & 1750 & 1507 & 0.0009 & 1 & 0.71 & 5.66 & 2.04 & 2.04 & 0.88 & 0.88 \\
\hline $\mathrm{KF}-\mathrm{KBF}_{4}$ & 460 & 0.38 & 1700 & 1305 & 0.0009 & 1 & 0.64 & 8.98 & 2.47 & 2.47 & 0.84 & 0.84 \\
\hline $\mathrm{RbF}-\mathrm{RbF}_{4}$ & 442 & 0.28 & 2210 & 909 & 0.0009 & 1 & 0.54 & 14.61 & 3.01 & 3.01 & 0.75 & 0.75 \\
\hline
\end{tabular}




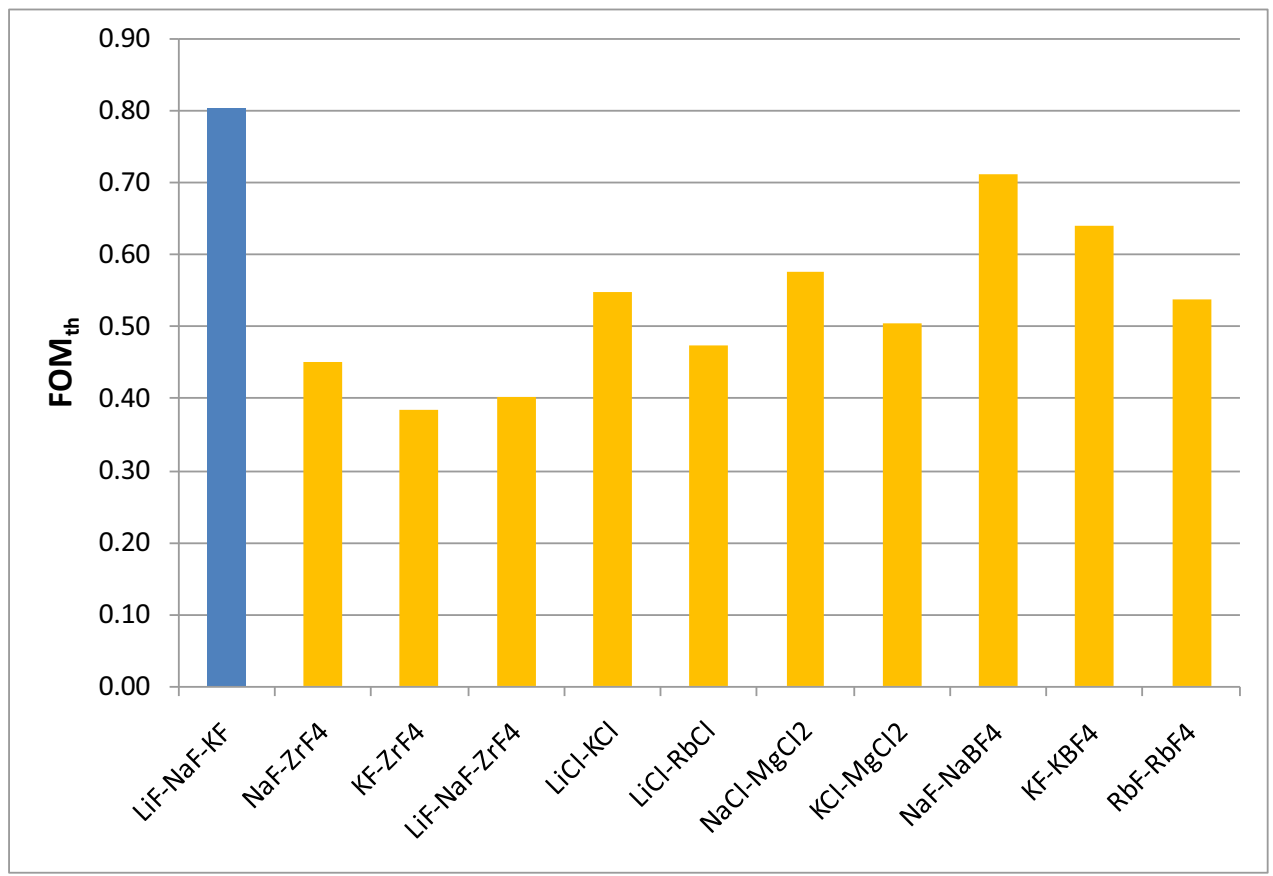

Figure 6-3. Comparisons of $\mathrm{FOM}_{\mathrm{th}}$ for molten salt coolants.

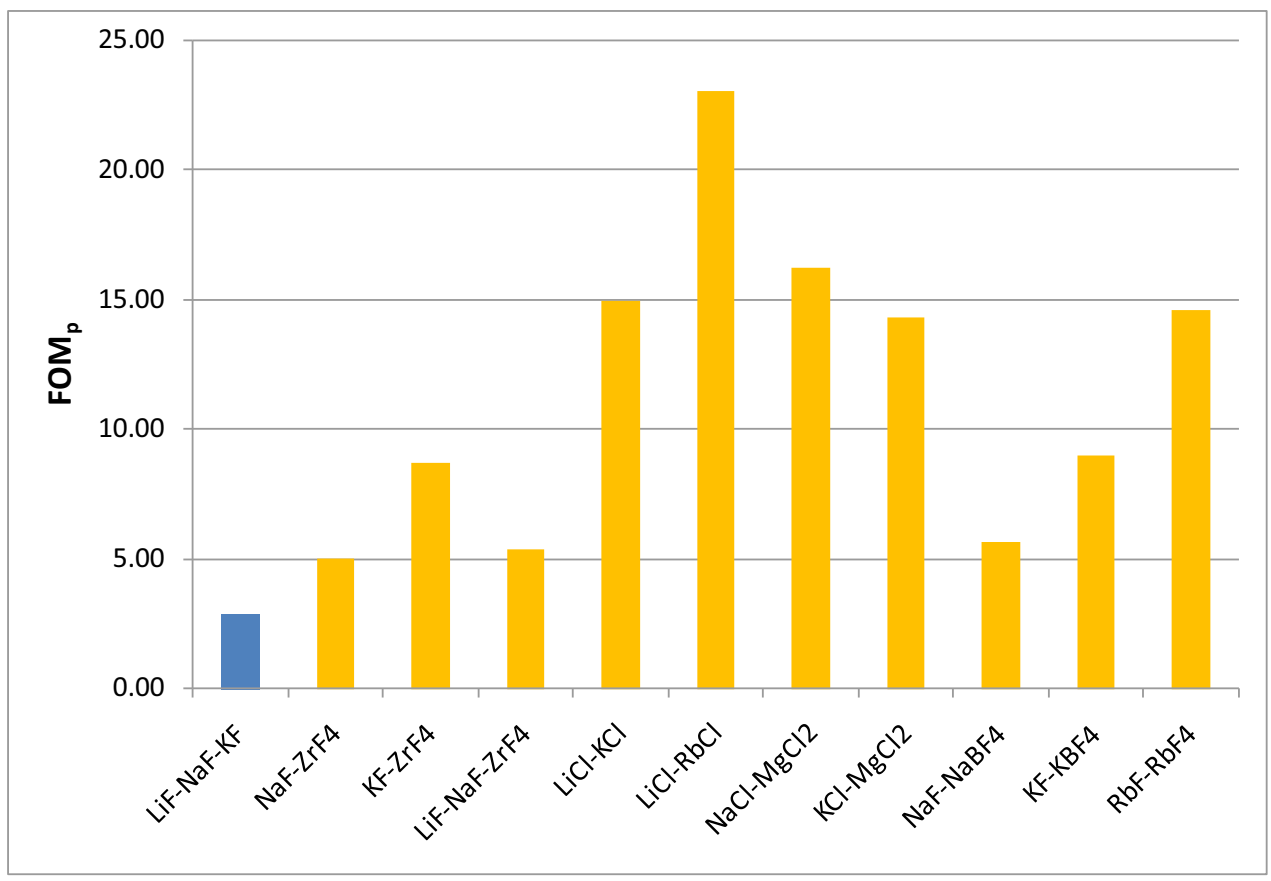

Figure 6-4. Comparisons of $\mathrm{FOM}_{\mathrm{p}}$ for molten salt coolants. 


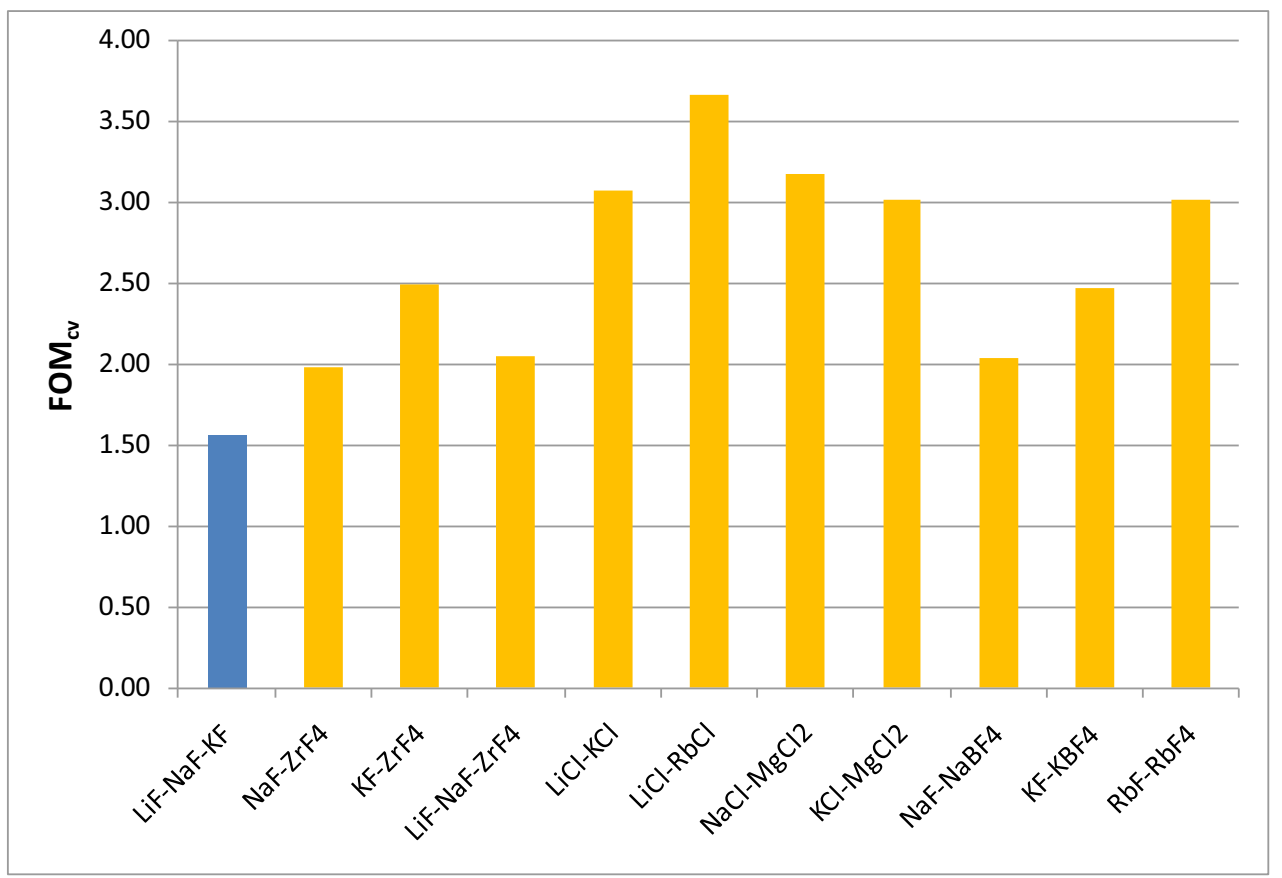

Figure 6-5. Comparisons of $\mathrm{FOM}_{\mathrm{cv}}$ for molten salt coolants.

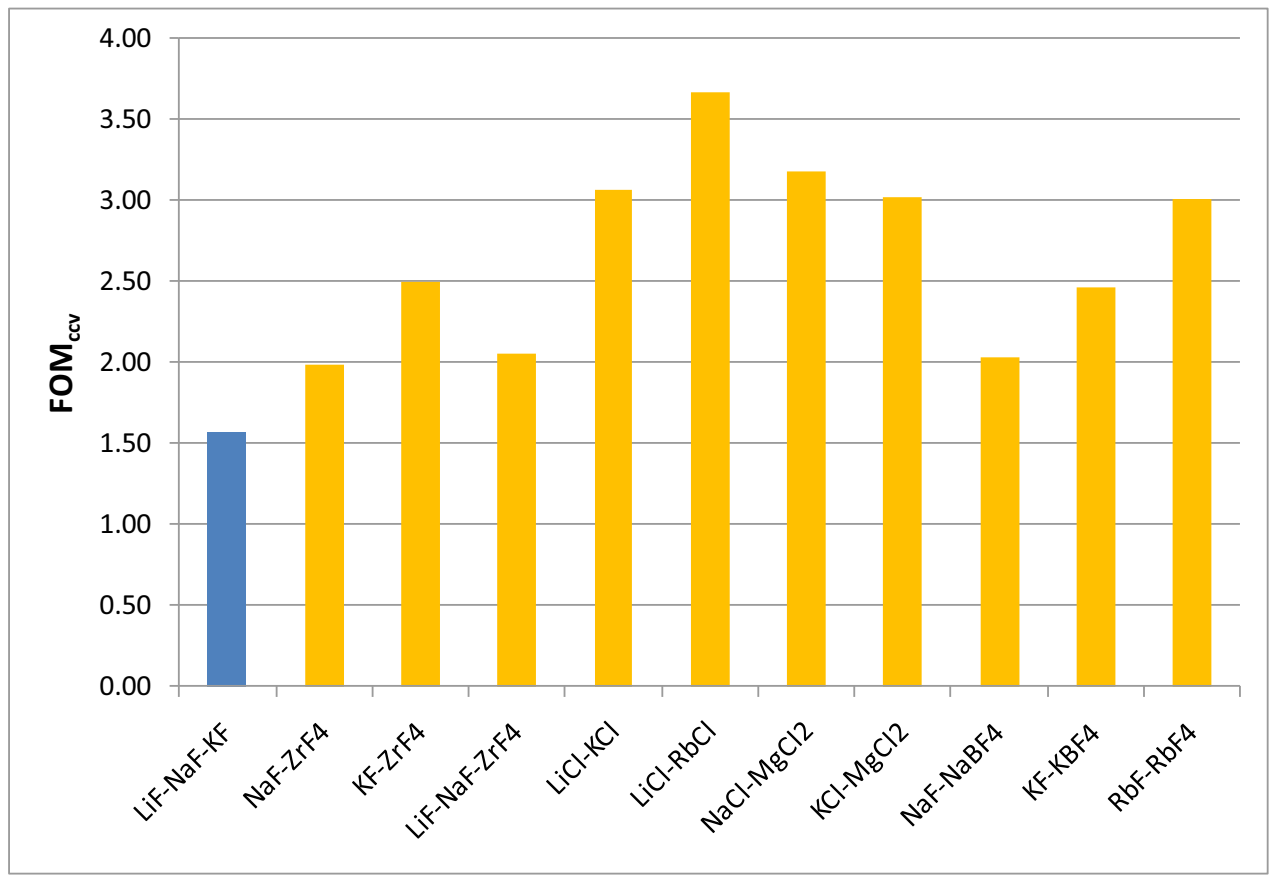

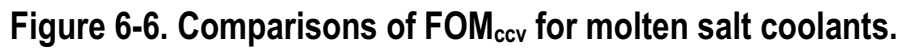




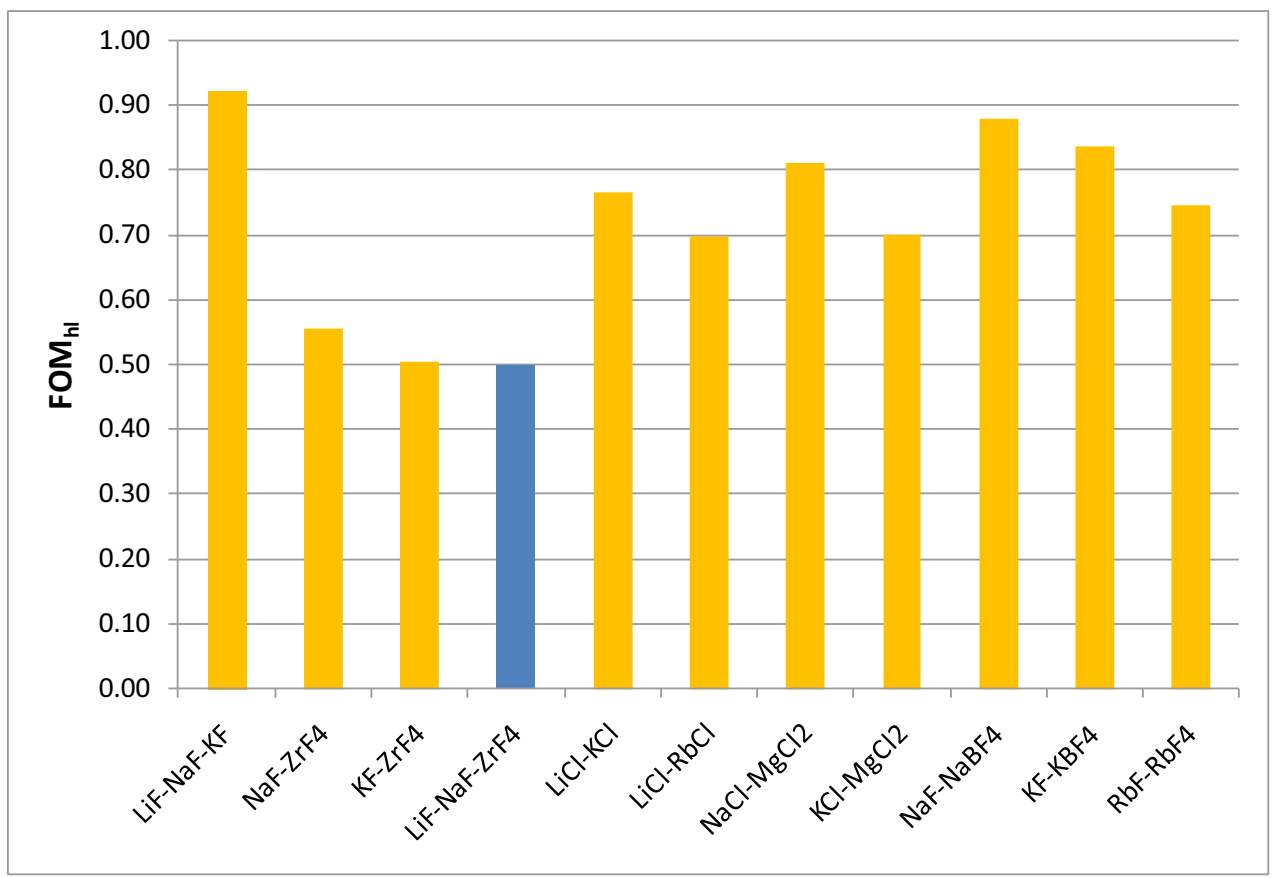

Figure 6-7. Comparisons of $\mathrm{FOM}_{\mathrm{hl}}$ for molten salt coolants.

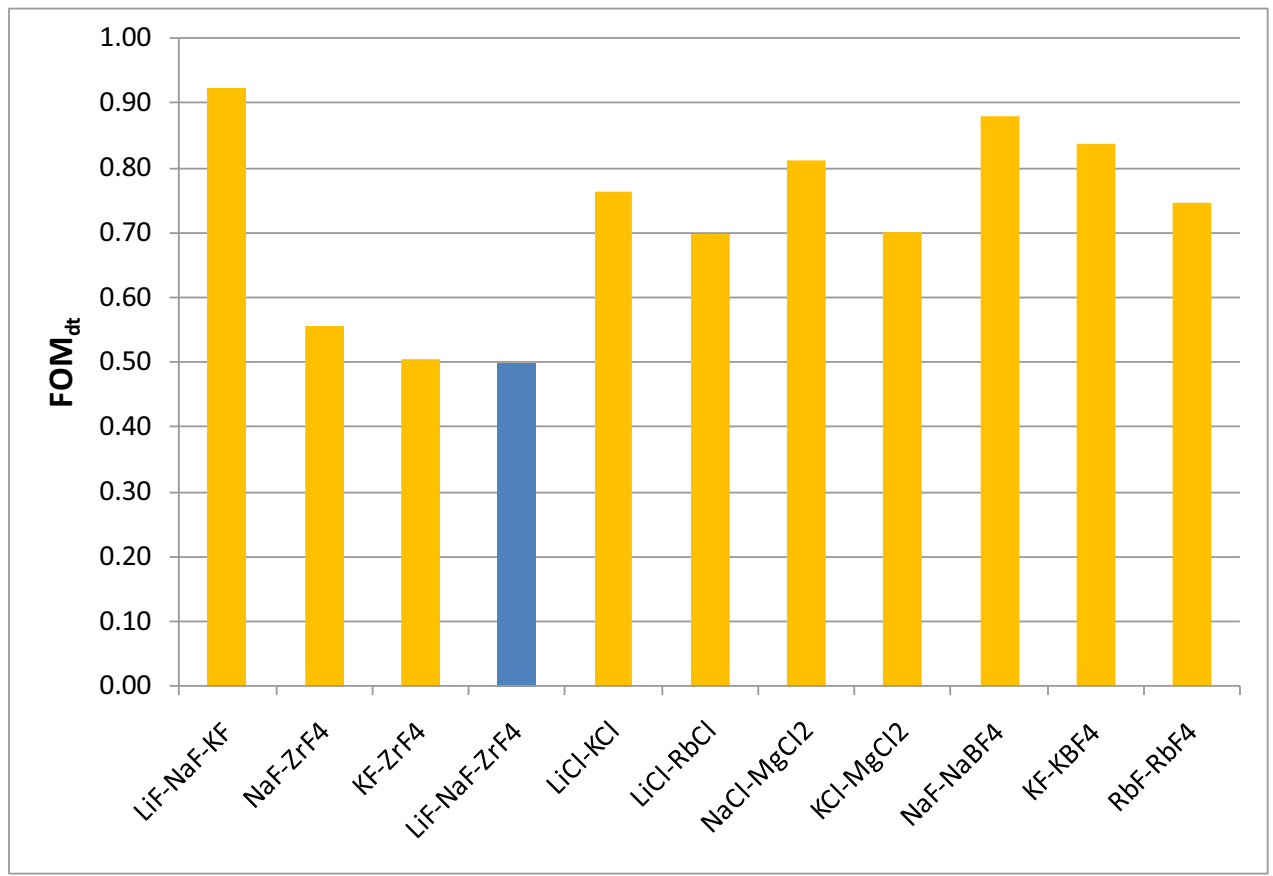

Figure 6-8. Comparisons of FOM dt for molten salt coolants. 


\subsection{Coolant Cost (Cost of Salts)}

Cost of the coolant is an important factor for selecting the intermediate coolant. The cost of the coolant was relatively estimated based on the data summarized by Williams (2006). Total cost of the coolants required in the intermediate heat transfer loop can be simply expressed by

$C_{t}=V_{c} \cdot c_{c}$

where:

$$
\begin{aligned}
& C_{t}=\text { total coolant cost }(\$) \\
& V_{c}=\text { total coolant volume }\left(\mathrm{m}^{3}\right) \\
& c_{c}=\text { raw material cost } / \text { volume }\left(\$ / \mathrm{m}^{3}\right) .
\end{aligned}
$$

However, in Eq. (6-4), the total volume cannot be determined before the final design of the system. Therefore, in this study, the relative volumes of the coolants were taken into considerations based on the coolant volume factor $\left(F O M_{c v}\right)$. The following expressions were used for coolant cost comparisons:

$R_{C_{t}}=F O M_{c v} \cdot c_{c}$

where:

$R_{C t}=$ relative total coolant cost $\left(\$ / \mathrm{m}^{3}\right)$

$F O M_{c v}=$ coolant volume factor

$c_{c}=$ raw material cost $/$ volume $\left(\$ / \mathrm{m}^{3}\right)$.

The cost data for the raw material cost/volume was obtained from the report by Williams (2006). In this estimation, not all the candidate coolants were taken into considerations because of a lack of available information. Table 6-5 summarizes the raw material cost data and relative total cost estimations. According to the comparisons, $\mathrm{KCl}-\mathrm{MgCl}_{2}$ shows the lowest cost followed by $\mathrm{NaCl}-\mathrm{MgCl}_{2}$; all other molten salt costs are about two orders of magnitude higher than these two coolants. The most expensive

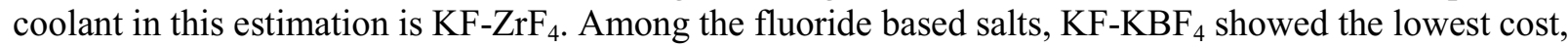

\begin{tabular}{|c|c|c|c|c|}
\hline Coolant & $\begin{array}{c}\text { Cost/volume } \\
(\$ / L)\end{array}$ & $\begin{array}{c}\text { Cost/Volume } \\
\left(\$ / \mathbf{m}^{3}\right)\end{array}$ & FOM $_{\mathrm{cv}}$ & $\begin{array}{c}\mathbf{R}_{\mathrm{ct}} \\
\left(\$ / \mathbf{m}^{3}\right)\end{array}$ \\
\hline LiF-NaF-KF & 15.79 & 15790 & 1.57 & 24724 \\
\hline $\mathrm{NaF}_{-2 \mathrm{ZF}}$ & 12.63 & 12630 & 1.98 & 25053 \\
\hline $\mathrm{KF}-\mathrm{ZrF}_{4}$ & 13.58 & 13580 & 2.49 & 33862 \\
\hline LiF-NaF-ZrF ${ }_{4}$ & - & - & - & - \\
\hline $\mathrm{LiCl}-\mathrm{KCl}$ & 7.71 & 7710 & 3.07 & 23656 \\
\hline LiCl-RbCl & - & - & - & - \\
\hline $\mathrm{NaCl}-\mathrm{MgCl}_{2}$ & 0.42 & 420 & 3.18 & 1335 \\
\hline $\mathrm{KCl}-\mathrm{MgCl}_{2}$ & 0.35 & 350 & 3.02 & 1055 \\
\hline NaF-NaBF 4 & 8.55 & 8550 & 2.04 & 17426 \\
\hline $\mathrm{KF}-\mathrm{KBF}_{4}$ & 6.26 & 6260 & 2.47 & 15447 \\
\hline
\end{tabular}
followed by $\mathrm{NaF}_{-} \mathrm{NaBF}_{4}$ and $\mathrm{LiF}-\mathrm{NaF}-\mathrm{KF}$, respectively.

Table 6-5. Raw material costs for various salt mixtures and relative total cost estimations. 


\subsection{Coolant Chemical (Corrosion) Considerations}

Coolant chemistry is an essential factor for the molten salt coolant selection. However, it is a very complex mechanism affected by various factors, and therefore it is practical to be quantified for precise comparisons at this stage. According to previous reports that present a review and discussions on the molten salt coolant corrosion (Williams 2006, Williams et al. 2006, and Sohal et al. 2010), the most important chemical factor in the coolant selection is to maintain the corrosion level at an acceptably low level that will allow fabrication of components that meet design life requirements.

Currently, the corrosion data for various molten salt coolants are much limited for reliable comparisons of corrosion resistance to the various alloys. The evidence for selecting a coolant based on corrosion is not adequate at present (Williams et al. 2006). So coolant salt selection factors for corrosion discussed in this section are briefly summarized based on the previous study. The four factors discussed by Williams et al. (2006) for the coolant selection are:

- Oxidation state of corrosion product

- Temperature dependence of dissolved chromium concentration

- Polythermal corrosion test loops with coolant salts

- Redox control factors.

According to the literature survey, corrosion of FLiNaK (LiF-NaF-KF) is among the worst in various perspectives. In addition, none of the redox-control strategies have been developed to the extent that can be relied on for coolant salt selection. However, for a lower-temperature system $\left(<750^{\circ} \mathrm{C}\right)$, Hastelloy $\mathrm{N}$ appears to be fully capable of being used as a containment alloy, even without the need for a redox strategy.

Williams et al. (2006) also suggested the following approaches for resolving molten salt corrosion issues:

- Using low-chromium/chromium-free alloys or suitable clad systems as a container (structural materials)

- Selecting a salt that should support the minimum level of corrosion in the absence of a highly reducing environment $\left(\mathrm{ZrF}_{4}\right.$ salts, $\mathrm{BeF}_{2}$ salts $)$

- Selecting a salt with a large redox window that can be maintained in a highly reducing state (FLiNaK, $\mathrm{BeF}_{2}$ salts).

Finally, $\mathrm{ZrF}_{4}$ salts without strong reductants or FLiNaK with strong reductants and redox buffer were recommended to be a promising approach because of high expense and difficulty in development of beryllium-containing salt.

\subsection{Summary and Recommendations}

The characteristics of candidate coolants in this study were extensively investigated in three different aspects (see Appendix A for details): coolant thermal performance, coolant cost, and coolant chemistry (corrosion). The following summarizes the conclusions:

- Thermal Performance: Six FOMs were developed in this study by analytical approach for comparisons on the thermal characteristics of various coolants. The FOMs include heat transfer performance, pumping power, coolant volume, heat loss, and temperature drop. All of the FOMs were mathematically derived and the sensitivity of each property on the FOMs was also estimated in this 
study. Overall, FLiNaK (LiF-NaF-KF) showed superior thermal performance to the other candidate coolants, although it will require some additional considerations for the heat loss and insulation.

- Coolant Cost: Total coolant costs required in the intermediate loop were relatively estimated using raw materials cost data summarized by Williams (2006) and the fluid volume factor $\left(\mathrm{FOM}_{\mathrm{cv}}\right)$ developed for thermal performance estimation. According to the comparisons, $\mathrm{KCl}-\mathrm{MgCl}_{2}$ shows the lowest cost followed by $\mathrm{NaCl}-\mathrm{MgCl}_{2}$. All other molten salt costs are about two-orders of magnitude higher than these two coolants. Among the Fluoride based salts, $\mathrm{KF}_{-} \mathrm{KBF}_{4}$ showed the lowest cost, followed by $\mathrm{NaF}_{-} \mathrm{NaBF}_{4}$ and LiF-NaF-KF. However, detailed system economics need to be considered associated with total component sizes and costs, which are affected by coolant thermal performance and chemistry.

- Coolant Chemistry (Corrosion): Corrosion is an essential issue with the molten salt coolant. According to the literature, careful alloy design and intelligent salt-chemistry control will permit the intermediate loop to be operated with fluoride salts with a tolerable level of corrosion. Because of a lack of experience, a large degree of uncertainty is expected for using the chlorides and fluoroborate salts in the high temperature system at this time. Overall, more experimental investigations will be required for the coolant corrosion of the FHR heat exchangers not only for the bare materials but also for the diffusion bonding and welding.

In conclusion, FLiNaK (LiF-NaF-KF) is considered as the best candidate salt for the FHR intermediate loop at this stage. It exhibits the best thermal performance, reasonable coolant cost among the Fluoride salts, and controllable corrosion effect with careful alloy selection (Hastelloy N) and chemistry control (reductants and redox buffer). 


\section{HEAT EXCHANGER EVALUATION AND SELECTION METHOD 7.1 Introduction}

A variety of heat exchangers are available in industry, including shell-and-tube, plate-and-frame, brazed-plate, plate-and-fin, PCHE, bayonet, etc. Heat exchanger design and selection involves many trade-offs associated with geometrical and operational variables.

In this study, the heat exchanger selection was conducted by the following two steps:

1. Screening of candidate heat exchanger types based on the operating parameters

2. Evaluation matrix for selection of FHR heat exchanger.

First, some candidate heat exchangers were selected based on the operating parameters (mainly temperature and pressure). Then, more detailed comparisons were carried out among the candidate designs using evaluation matrix and further multi-criteria decision analysis (MCDA) will be used to select the optimum heat exchanger for a given application.

\subsection{Initial Screening of Heat Exchanger Type Based on Operating Parameters}

To evaluate and select the SHX for the FHR, the following base assumptions and requirements were followed:

- Base Assumptions and Requirements:

- Reactor Outlet Temperature (ROT): $700^{\circ} \mathrm{C}$

- Application Type: Power Conversion System (20 MW(t))*

- Helium Brayton $(\eta=40.3 \%)$

- Steam Rankine $(\eta=41.9 \%)$

- Supercritical $\mathrm{CO}_{2}$ Modified Brayton $(\eta=43.7 \%)$

- Supercritical Rankine $(\eta=44.0 \%)$

- Pressure:

- SHX primary: $0.1 \mathrm{MPa}$

- SHX secondary:

— Helium Brayton: 7.11 MPa

- Steam Rankine: 17.7 MPa

- Supercritical $\mathrm{CO}_{2}$ Modified Brayton: 24.99 MPa

- Supercritical Rankine: 21.66 MPa

- Coolant:

- SHX primary: FLiNaK

- SHX secondary:

- Helium Brayton: Helium

- Steam Rankine: Water (Steam)

- Supercritical $\mathrm{CO}_{2}$ Modified Brayton: Supercritical $\mathrm{CO}_{2}$

- Supercritical Rankine: Water (Steam) 
The type of power conversion system (PCS) has not been determined yet in this study. It will be finally decided in the next phase of the feasibility study. Once the type of PCS is decided, the assumptions and requirements will be narrowed down.

Table 7-1 summarizes general operating conditions and principal features for various heat exchanger types (Shah, 2003) in the current industry. This table summarizes the following:

- HX type: Sixteen heat exchanger types are listed in this table.

- Compactness: Compactness indicates (surface area)/ (heat exchanger core volume). If compactness is high, the heat exchanger can be smaller.

- System Type: System type indicates what fluid phases are generally used for a certain heat exchanger type in the industry.

- Material: Material indicates what material has been used and experienced for a certain type of heat exchanger in the current industry.

- Temperature Range: Temperature range indicates the applicable temperature ranges of a certain type of heat exchanger.

- Maximum Pressure: Pressure indicates the applicable pressure ranges of a certain type of heat exchanger.

- Cleaning Method: Cleaning method indicates if the heat exchanger can be cleaned physically or chemically.

- Multistream Capability: Multistream capability indicates if it can connect several independent flow loops in a single heat exchanger.

- Multipass Capability: Multipass capability indicates if it can split flow into several paths in the heat exchanger.

According to this table, only a few heat exchanger types can meet the minimum requirements with sufficient margin because of the severe requirements of an FHR. Currently, the available heat exchanger types are as follows:

- Shell-and-tube

- PCHE.

The shell-and-tube heat exchanger is the most typical type of heat exchanger. These heat exchangers are generally built of circular tubes and have considerable flexibility in design. They can be designed for high pressures relative to the environment and high-pressure differences between the fluids. PCHE is a plate type heat exchanger. The plates are chemically etched and then diffusion-welded. Fluid inlet/outlet headers are then welded on. Details on the heat exchanger types are presented in Section 5. 
Table 7-1. Principal features of several types of heat exchangers (Shah 2003).

\begin{tabular}{|c|c|c|c|c|c|c|c|c|}
\hline HX Type & $\begin{array}{c}\text { Compactness } \\
\left(\mathrm{m}^{2} / \mathrm{m}^{3}\right)\end{array}$ & System Types & Material & $\begin{array}{c}\text { Temperature } \\
\text { Range } \\
(\text { C })^{\mathrm{a}}\end{array}$ & $\begin{array}{c}\text { Maximum } \\
\text { Pressure } \\
\text { (bar) }^{\mathrm{b}}\end{array}$ & $\begin{array}{l}\text { Cleaning } \\
\text { Method }\end{array}$ & $\begin{array}{c}\text { Multistream } \\
\text { Capability }^{\mathrm{c}}\end{array}$ & $\begin{array}{c}\text { Multipass } \\
\text { Capability }^{\mathrm{d}} \\
\end{array}$ \\
\hline Shell and Tube & $\sim 100$ & $\begin{array}{l}\text { Liquid/Liquid, Gas/Liquid, } \\
\text { 2Phase }\end{array}$ & $\begin{array}{l}\text { s/s, Ti, Incoloy, Hastelloy, } \\
\text { graphite, polymer }\end{array}$ & $\sim+900$ & $\sim 300$ & $\begin{array}{l}\text { Mechanical, } \\
\text { Chemical }\end{array}$ & No & Yes \\
\hline $\begin{array}{l}\text { Plate-and-frame } \\
\text { (gaskets) }\end{array}$ & $\sim 200$ & $\begin{array}{l}\text { Liquid/Liquid, Gas/Liquid, } \\
\text { 2Phase }\end{array}$ & $\begin{array}{l}\text { s/s, Ti, Incoloy, Hastelloy, } \\
\text { graphite, polymer }\end{array}$ & $-35 \sim+200$ & 25 & Mechanical & Yes & Yes \\
\hline Partially welded plate & $\sim 200$ & $\begin{array}{l}\text { Liquid/Liquid, Gas/Liquid, } \\
\text { 2Phase }\end{array}$ & s/s, Ti, Incoloy, Hastelloy & $-35 \sim+200$ & 25 & $\begin{array}{l}\text { Mechanical, } \\
\text { Chemical }\end{array}$ & No & Yes \\
\hline $\begin{array}{l}\text { Fully welded plate } \\
\text { (Alfa Rex) }\end{array}$ & $\sim 200$ & $\begin{array}{l}\text { Liquid/Liquid, Gas/Liquid, } \\
\text { 2Phase }\end{array}$ & $\mathrm{s} / \mathrm{s}, \mathrm{Ti}, \mathrm{Ni}$ alloys & $-50 \sim+350$ & 40 & Chemical & No & Yes \\
\hline Brazed plate & $\sim 200$ & Liquid/Liquid, 2Phase & $\mathrm{s} / \mathrm{s}$ & $-195 \sim+220$ & 30 & Chemical & No & No \\
\hline Bavex plate & 200 to 300 & $\begin{array}{l}\text { Gas/Gas, Liquid/Liquid, } \\
\text { 2Phase }\end{array}$ & $\mathrm{s} / \mathrm{s}, \mathrm{Ni}, \mathrm{Cu}, \mathrm{Ti}$, special steels & $-200 \sim+900$ & 60 & $\begin{array}{l}\text { Mechanical, } \\
\text { Chemical }\end{array}$ & Yes & Yes \\
\hline Platular plate & 200 & $\begin{array}{l}\text { Gas/Gas, Liquid/Liquid, } \\
\text { 2Phase }\end{array}$ & s/s, Hastelloy, Ni alloys & $\sim 700$ & 40 & Mechanical & Yes & Yes \\
\hline Compabloc plate & $\sim 300$ & Liquid/Liquid & s/s, Ti, Incoloy & $\sim 300$ & 32 & Mechanical & Not usually & Yes \\
\hline Packinox plate & $\sim 300$ & $\begin{array}{l}\text { Gas/Gas, Liquid/Liquid, } \\
\text { 2Phase }\end{array}$ & s/s, Ti, Hastelloy, Inconel & $-200 \sim+700$ & 300 & Mechanical & Yes & Yes \\
\hline Spiral & $\sim 200$ & Liquid/Liquid, 2Phase & s/s, Ti, Incoloy, Hastelloy & $\sim 400$ & 25 & Mechanical & No & No \\
\hline Brazed plate fin & 800 to 1500 & $\begin{array}{l}\text { Gas/Gas, Liquid/Liquid, } \\
\text { 2Phase }\end{array}$ & $\mathrm{Al}, \mathrm{s} / \mathrm{s}, \mathrm{Ni}$ alloy & $\sim 650$ & 90 & Chemical & Yes & Yes \\
\hline $\begin{array}{l}\text { Diffusion bonded plate } \\
\text { fin }\end{array}$ & 700 to 800 & $\begin{array}{l}\text { Gas/Gas, Liquid/Liquid, } \\
\text { 2Phase }\end{array}$ & $\mathrm{Ti}, \mathrm{s} / \mathrm{s}$ & $\sim 500$ & $>200$ & Chemical & Yes & Yes \\
\hline Printed circuit & 200 to 5000 & $\begin{array}{l}\text { Gas/Gas, Liquid/Liquid, } \\
\text { 2Phase }\end{array}$ & $\mathrm{Ti}, \mathrm{s} / \mathrm{s}$ & $-200 \sim+900$ & $>400$ & Chemical & Yes & Yes \\
\hline $\begin{array}{l}\text { Polymer (e.g. channel } \\
\text { plate) }\end{array}$ & 450 & Gas/Liquid & PVDF, PP & $\sim 150$ & 6 & Water Wash & No & No \\
\hline Plate and shell & - & Liquid/Liquid & $\mathrm{s} / \mathrm{s}, \mathrm{Ti}$ & $\sim 350$ & 70 & $\begin{array}{l}\text { Mechanical, } \\
\text { Chemical }\end{array}$ & Yes & Yes \\
\hline \multicolumn{9}{|c|}{$\begin{array}{ll}\text { s/s } & \text { Stainless steel. } \\
\text { a. } & \text { Heat exchanger operational temperature ranges. } \\
\text { b. } & \text { Heat exchanger maximum applicable pressure. } \\
\text { c. } & \text { Capability to connect several independent flow loops in a single heat exchanger. } \\
\text { d. } & \text { Capability to split flow into several paths in the heat exchanger. } \\
\end{array}$} \\
\hline
\end{tabular}




\subsection{Evaluation Method and Plan for Selection of FHR Heat Exchanger}

This section describes the method for FHR heat exchanger evaluation and selection based on MCDA.

\subsubsection{Evaluation Method: Analytical Hierarchy Process}

In the previous sections, major alternatives for the FHR heat exchangers are described. This section describes how these criteria and the alternatives are evaluated. This study uses analytical hierarchy process (AHP) to evaluate the candidate heat exchangers, which is a structured technique developed for multi-criteria decision-making problems and currently among the most widely used MCDA techniques. The AHP helps decision makers find the best option that suits their goal and their understanding of the problem. It provides a comprehensive and rational framework for structuring a decision problem, for representing and quantifying its elements, for relating those elements to overall goals, and for evaluating alternative solutions.

AHP allows for the application of data, experience, insight, and intuition in a logical way. AHP enables decision-makers to derive ratio scale priorities or weights as opposed to arbitrary assigning of values. Therefore, AHP not only supports decision-makers by enabling them to structure complexity and exercise judgment, but allows them to incorporate both objective and subjective considerations in the decision process.

In the AHP method, weights and scores are done by structuring complexity as a hierarchy and by deriving ratio scale measures through pair-wise relative comparisons. The pair-wise comparison process can be performed using words, numbers, or graphical bars, and typically incorporates redundancy, which results in a reduction of measurement error as well as producing a measure of consistency of the comparison judgments. This method is based on the fact that humans are much more capable of making relative rather than absolute judgments. The use of redundancy permits accurate priorities to be derived from verbal judgments even though the words are not very accurate. Therefore, the weights or priorities are not arbitrary assigned in the AHP method.

The AHP involves the mathematical synthesis of numerous judgments about the decision problem at hand. It is not uncommon for these judgments to number in the dozens or even the hundreds. While the math is pretty straight forward, it is far more common to use one of several computerized methods for entering and synthesizing the judgments.

The procedure for using the AHP can be summarized as (Satty 1996, Forman 2001, Howell 2007, Bhushnan 2004):

1. Problem identification and description.

2. Setting up final goal and objective.

3. Selecting alternatives.

4. Identifying and listing criteria.

5. Modeling the problem as a hierarchy containing the decision goal, the alternatives for reaching it, and the criteria for evaluating the alternatives.

6. Establish priorities among the elements of the hierarchy by making a series of judgment based on pair-wise comparisons of the elements. For example, when comparing potential real estate purchases, the investors might say they prefer location over price and price over timing. 
7. Synthesize these judgments to yield a set of overall priorities for the hierarchy. This would combine the investors' judgments about location, price and timing for properties A, B, C, and D into overall priorities for each property.

8. Check the consistency of the judgments.

9. Come to a final decision based on the results of this process.

\subsubsection{Goal, Alternatives, and Criteria for FHR Heat Exchanger Selection}

This section describes a goal, alternatives and criteria for the FHR heat exchanger selection.

\subsubsection{Goal}

The final goal of this study is to evaluate and select the best heat exchanger type for the FHR SHX.

\subsubsection{Alternatives}

From the screening process described in the previous section, the two heat exchanger types identified to be the possible SHX options that meet the base requirements are shell-and-tube and PCHE.

\subsubsection{Criteria}

Table 7-2 summarizes the criteria for the FHR SHX evaluation and selection. The details are explained below.

\section{Thermal Performance}

Thermal performance is the primary criterion for most of the heat exchanger selection process since the effective heat transfer is the main purpose of the heat exchanger. Thermal performance consists of the following three subcriteria:

- High Heat Transfer Performance: In the heat exchanger, heat transfer performance is highly affected by the heat exchanger types because of their different channel geometries and configurations. Generally, smaller channel size can provide a better heat transfer coefficient for the same flow-rates. However, it causes higher frictional losses.

- Effectiveness: When heat is transferred, the system requires minimizing loss of useful thermal energy. Therefore, the heat exchanger effectiveness is generally considered as a very important parameter in design. Higher effectiveness means that the heat exchanger design is closer to the ideal heat exchanger design. Typical values for the effectiveness are 0.7 to 0.9 for conventional shell-andtube design, and 0.9 to 0.98 for the compact heat exchanger design.

- Fouling: Fouling is also an important factor because it significantly degrades thermal performance of the heat exchanger especially for liquid coolants. Because of the fouling, oversized heat exchanger design is required and cleaning strategies are needed for specific applications.

\section{Structural Performance}

Structural performance is one of the most important criteria for the SHX heat exchangers since they should be safely operated at high temperature and large pressure differences for long plant life-time. Heat exchanger integrity can be categorized primarily by how it operates under steady-state and transient conditions. The FHR is exposed mainly to mechanical stress and thermal stress. Vibration is also an important SHX criterion because it could degrade the integrity of the heat exchanger. Thus, an SHX less prone to vibration instabilities is preferred. Since the SHX is operated over a long period of time at high temperature, creep, fatigue, and creep-fatigue are also important issues that should be considered. 
Validating the effects of system pressure and temperature on the integrity of the joints (diffusion welding, brazing, and fusion welding) in a molten salt environment under steady-state and transient conditions is necessary and would enable a better selection of the SHX. Joints are subjected to static and dynamic loading while the heat exchanger is operating; the one with better performance will be ranked higher. Brazed heat exchangers are appropriate at lower temperatures, but there are potential mechanical integrity problems at higher temperatures with temperature cycling (Tatara 1997). The heat exchanger with a proven joining technique will be preferred when compared with an unproven technique.

The materials being considered for the SHX (alloys 617, 230, 800H and Hastelloy N) all spontaneously form chromium rich oxide scales that will present problems in making diffusion welds. The diffusion welding process needs to be further developed and bonding process parameters and controls identified. The technical literature addresses microstructure and mechanical properties, but not the parameters used to perform the bonding. Techniques such as mating surface pickling, nickel plating, or a nickel foil interlayer will have to be investigated. Mechanical testing of the diffusion welded joints will be needed to identify promising joining parameters, such as temperature, applied pressure, and hold time for optimization. In addition to optimizing process parameters and inspection of diffusion bonds, other specific concerns must be addressed:

- Microstructural stability during the high temperature exposure associated with diffusion welding.

- Production of large components is limited by the size of the fabrication equipment used.

Creep and creep-fatigue will be influenced by peak stresses because of the stress concentration effects of the coolant channels. Creep fatigue combined with the high temperature environmental degradation due to the influence of the FHR environment makes the creep-fatigue characterization very complicated. Creep and creep-fatigue data at these high temperatures will be needed for the selected material in order to develop a creep-fatigue interaction diagram.

In this study, the structural performance consists of the following three subcriteria:

- Mechanical stress: In the FHR, the SHX is exposed to large pressure difference at high temperature between the primary and the secondary sides depending on the integrated systems. Therefore, mechanical stress should be considered in evaluating and selecting the SHX. Mechanical stress in the heat exchanger is significantly affected by channel/tube configuration, size, and geometry. Joining methods are also very important in the mechanical integrity of the heat exchanger. The heat exchanger type should be able to withstand the mechanical stress in the given environment.

- Thermal stress: Thermal stress is also important parameter and should be considered because large temperature gradients exist in the heat exchanger. Thermal stress is affected by heat exchanger configurations and geometries. Therefore, the thermal stress should be minimized in the heat exchanger design.

- Vibration: Vibration is one of the major failure mechanisms of the heat exchanger tube or channel. It is highly affected by heat exchanger geometry and configuration. Therefore, the vibration should be minimized in the heat exchanger design.

\section{Material Performance}

Corrosion is an important criterion for the FHR heat exchanger because of the environmental degradation caused by the fluoride salt at high temperature. A factor in the lifetime of a heat exchanger will be its resistance to corrosion in the FHR environment. Corrosion resistance will be a function of the materials of construction as well as the thickness of various sections. Design features of the heat exchanger and the material of construction will also impact corrosion. Corrosion is resisted by using special alloys in construction. If the selected material cannot effectively prevent corrosion, a better or a 
preferred option will be for the heat exchanger to have thicker walls (more forgiving) and more corrosion allowance incorporated into its design when compared with other heat exchangers.

The subcriteria are:

- Geometry

- Corrosion allowance in design (uniform corrosion)

- Localized corrosion/environmental cracking

- Fluid compatibility.

\section{Technology Readiness}

Technology Readiness should also be considered for the FHR heat exchanger selection. A technology may look promising in the industrial applications but still need to be demonstrated under the FHR operating conditions and environment. The subcriteria selected are:

- Material: In manufacturing a FHR SHX, material is a major issue because of its severe environment (high temperatures and high corrosives). Therefore, technology readiness of the materials should be importantly considered in the heat exchanger evaluation.

- Fabrication method: Some heat exchanger types such as PCHE have unique fabrication methods such as diffusion welding. Therefore, the readiness for the fabrication method should be evaluated for the selected candidate material.

- ASME B\&PV Code status: To manufacture a heat exchanger using a certain material, the material should be supported by the American Society of Mechanical Engineers (ASME) Boiler and Pressure Vessel (BPV) Code (Section 3 deals with primary pressure boundaries applicable to nuclear service, Section 8 deals with secondary processes applicable to SHXs).Therefore, readiness of the ASME BPV Code should be considered in the heat exchanger evaluation process.

- Industrial experience: In a nuclear energy system, a proven technology is always recommended because of its experience and low uncertainty.

\section{System Integration}

The main role of the SHX in the FHR is to integrate the nuclear reactor with the power conversion system or with a process heat application plant. Integration should therefore be considered. The applicable subcriteria are:

- Size: Size of the heat exchanger is important in the integration of the heat exchanger with the systems. Smaller size is generally preferred.

- Adaptability: Adaptability is the ease of integrating the SHX with various applications. This adaptability will depend on what system will be integrated with the heat exchanger.

\section{Tritium Permeation}

Tritium is mainly generated in the FHR core by ternary fissions and various neutron reactions. Tritium is a major concern because it easily permeates high temperature metallic surfaces. Since this tritium is a radioactive isotope, it eventually radioactively contaminates the industrial system and products. For mitigating tritium permeation, less heat transfer surface area and larger heat exchanger thickness are preferred in the design. The subcriteria for tritium permeation are:

- Material: In the heat exchanger, tritium permeation is significantly affected by the types of tube or channel materials. It is also highly affected by existing oxide-layers and applied coatings 
- Geometry: Total tritium permeation through the heat transfer surface is also affected by heat exchanger geometrical parameters such as heat transfer area and wall thickness. Tritium permeation is proportional to the heat transfer area and inversely proportional to the wall thickness.

\section{Inspection}

Inspection should be easily accomplished to determine the state of the equipment. Compact heat exchangers, being small units, will not be easy to inspect. A heat exchanger designed so that joints can be examined and cracks and crack growth identified more easily over its operational lifetime is preferred. Nondestructive evaluation (such as eddy current testing, ultrasonic testing, radiography, and pressure leak testing) may be used to evaluate the structural integrity of heat exchanger components. It is not possible to offer more insight because of the lack of historical inspection and operation data for the compact heat exchangers being considered.

\section{Maintenance}

The ease of maintenance, such as cleaning, repair, and serviceability, is an important characteristic for a successful FHR heat exchanger. All heat exchangers should be chemically cleanable, which is more effective and efficient than dismantling and physically cleaning them. The heat exchanger should also have provision for replacing any components subject to corrosion, unless it is more economical to replace the whole unit (Shah 2003). Thus, a heat exchanger with these capabilities is preferred. The subcriteria for maintenance are:

- Cleaning: The heat exchanger should be cleaned regularly to remove fouling on the channel/tube inside. Generally, it can be cleaned physically, chemically, or by both methods, depending on the heat exchange type.

- Waste: When cleaning and repairing heat exchangers, some waste is discharged. Waste also should be considered in the evaluation of heat exchangers.

- Repairing: The heat exchanger should be easily repaired when tube rupture or some other problems occur.

\section{Initial Cost}

In one respect, the life-cycle cost for a given heat exchanger can serve as a single criterion for comparison. Such aspects as development, design, fabrication, installation, and maintenance costs can be included in the life-cycle cost. However, at this point in the project, the heat exchanger concepts are not sufficiently developed to provide accurate cost information on which to base these comparisons. Therefore, the cost comparisons will be qualitatively addressed. The cost could be characterized as:

- Fabrication Cost: Costs associated with fabrication are the fabrication costs. Complicated designs might cost more to fabricate than simpler designs. In order to increase the surface area density of the heat exchanger, the fluid channel diameter (or effective diameter) is reduced, which generally increases the net fabrication cost. The fabrication method has to be acceptable and meet all the requirements imposed by ASME. The heat exchanger designs are still in the development phase, so fabrication cost values are rough estimates. The equivalent (same thermal duty) heat exchanger will be compared based on the net fabrication cost; the one with the highest value for a specific thermal load in $\mathrm{kW}$ (quantitatively measured as Heat Load (Q) in kW per dollar (\$) spent) per money spent will be ranked higher than the others.

- Materials Cost: Cost associated with construction of the heat exchanger. More material will be required for bigger/larger heat exchanger, thus increasing the cost.

- Installation Cost: Cost associated with installing the heat exchanger could potentially be higher for conventional designs when compared with compact designs. 


\section{Operability}

It is not possible as of now to give details on operability of the compact heat exchangers because of lack of operation data in the molten salt environment and high operating conditions. The subcriteria for the operability are reliability and operating and maintenance.

Table 7-2. Criteria for FHR heat exchanger selection.

\begin{tabular}{|c|c|}
\hline Criteria & Subcriteria \\
\hline \multirow[t]{3}{*}{ Thermal Performance } & High Heat Transfer Performance (heat transfer / pumping power) \\
\hline & High Effectiveness \\
\hline & Fouling \\
\hline \multirow{3}{*}{$\begin{array}{l}\text { Structural Performance (Evaluated } \\
\text { by ASME B\&PV Design rules) }\end{array}$} & Mechanical Stress \\
\hline & Thermal Stress \\
\hline & Vibration \\
\hline \multirow[t]{4}{*}{ Material Performance } & Geometry (heat exchanger wall thickness) \\
\hline & Corrosion Allowance in Design (uniform corrosion) \\
\hline & Localized Corrosion/Environmental Cracking \\
\hline & Fluid Compatibility \\
\hline \multirow[t]{4}{*}{ Technology Readiness } & Material \\
\hline & Fabrication Method \\
\hline & ASME B\&PV Code Status \\
\hline & Industrial Experience \\
\hline \multirow[t]{2}{*}{ System Integration } & Size \\
\hline & Adaptability \\
\hline \multirow[t]{2}{*}{ Tritium Permeation } & Material \\
\hline & Geometry (total heat transfer area + wall thickness) \\
\hline Inspection & Ease of Inspection (geometry) and field access \\
\hline \multirow[t]{3}{*}{ Maintenance } & Cleaning \\
\hline & Waste \\
\hline & Repairing \\
\hline \multirow[t]{3}{*}{ Initial Cost ${ }^{\mathrm{a}}$} & Material \\
\hline & Fabrication \\
\hline & Installation \\
\hline \multirow[t]{2}{*}{ Operability } & Reliability \\
\hline & Operating \& Maintenance \\
\hline
\end{tabular}

\subsubsection{Modeling of the FHR Heat Exchanger Selection}

The AHP hierarchy for the FHR heat exchanger selection is shown in Figure 7-1, which is developed based on criteria in Table 7-2 and alternatives in Section 7.3.2. 


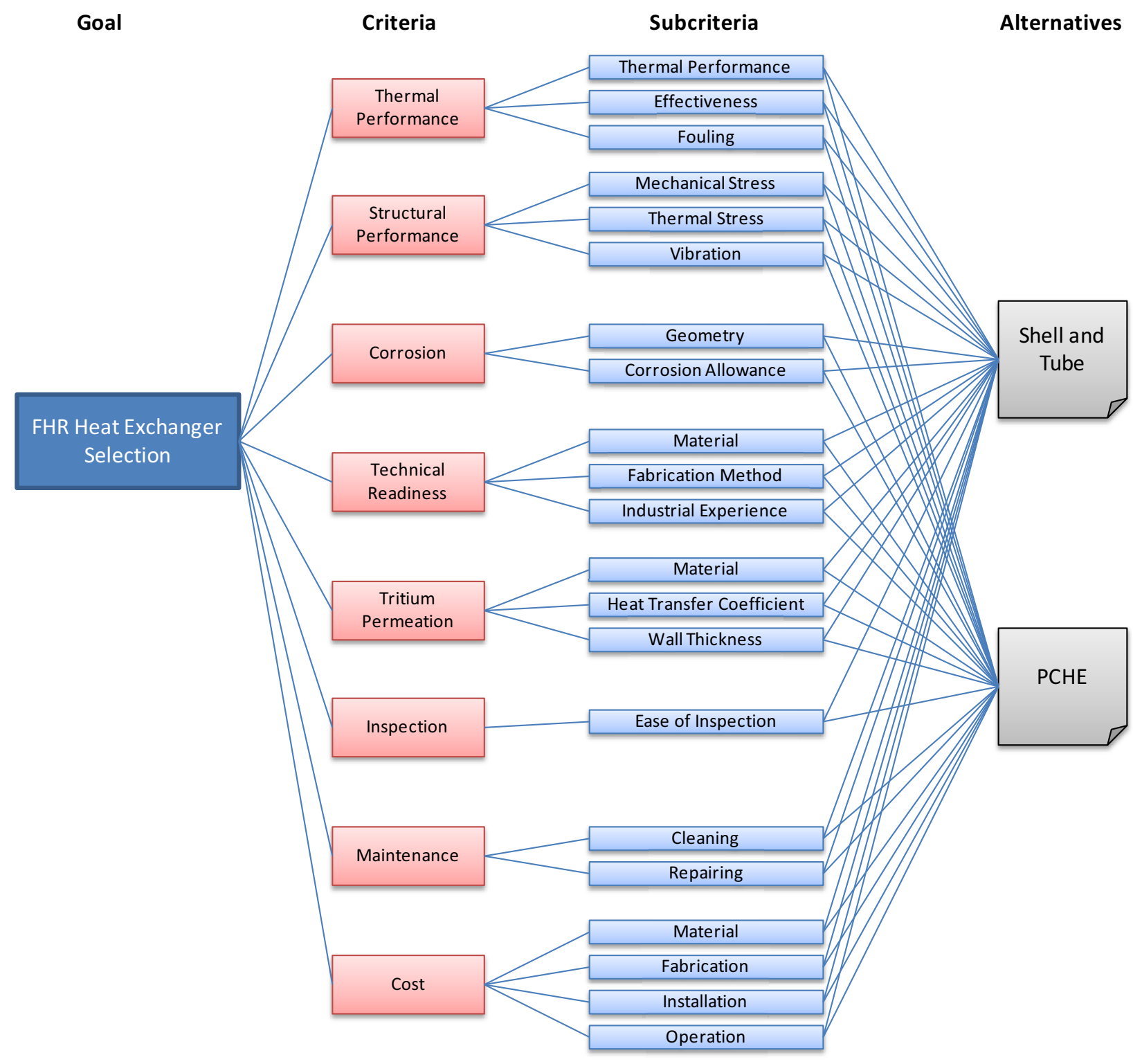

Figure 7-1. Decision Hierarchy for FHR Heat Exchanger Selection.

\subsubsection{Pair-wise Comparisons}

In the AHP, once the hierarchy has been constructed, the participants analyze it through a series of pair-wise comparisons that derive numerical scales of measurement for the nodes. The criteria are pairwise compared with the goal for importance. The alternatives are pair-wise compared against each of the criteria for preference. The comparisons are processed mathematically, and priorities are derived for each node. Table 7-3 shows the fundamental scale for pair-wise comparison recommended in the AHP (Forman 2001). 
Table 7-3. Fundamental scale for pair-wise comparison in AHP (Forman 2001).

\begin{tabular}{|c|l|l|}
\hline \multicolumn{3}{|c|}{ The Fundamental Scale for Pairwise Comparisons } \\
\hline $\begin{array}{c}\text { Intensity of } \\
\text { Importance }\end{array}$ & \multicolumn{1}{|c|}{ Definition } & \multicolumn{1}{c|}{ Explanation } \\
\hline 1 & Equal importance & $\begin{array}{l}\text { Two elements contribute equally to the } \\
\text { objective }\end{array}$ \\
\hline 3 & Moderate importance & $\begin{array}{l}\text { Experience and judgment slightly favor } \\
\text { one element over another }\end{array}$ \\
\hline 5 & Strong importance & $\begin{array}{l}\text { Experience and judgment strongly favor } \\
\text { one element over another }\end{array}$ \\
\hline 7 & Very strong importance & $\begin{array}{l}\text { One element is favored very strongly } \\
\text { over another, its dominance is } \\
\text { demonstrated in practice }\end{array}$ \\
\hline 9 & Extreme importance & $\begin{array}{l}\text { The evidence favoring one element } \\
\text { over another is of the highest possible } \\
\text { order of affirmation }\end{array}$ \\
\hline $\begin{array}{l}\text { Intensities of } 2,4,6 \text {, and } 8 \text { can be used to express intermediate values. Intensities } \\
1.1,1.2,1.3, \text { etc. can be used for elements that are very close in importance. }\end{array}$ \\
\hline
\end{tabular}

\subsubsection{AHP Software (for Evaluation of Model): MakeltRational}

This study uses MakeItRational software for evaluation and selection of the FHR heat exchanger. MakeItRational is well-known multi-criteria decision making software. This Web-based software is based on the AHP method and uses pair-wise comparisons for weighting and rating preferences. This software provides group decision evaluations and also sensitivity analysis results. Figure 7-2 is a screen shot of this software. Currently, all the goals, alternatives, criteria, and subcriteria are implemented into the software with the hierarchy structure shown in Figure 7-1. This set-up will be finally used to evaluate and select the FHR heat exchanger in the next stage with feasibility studies.

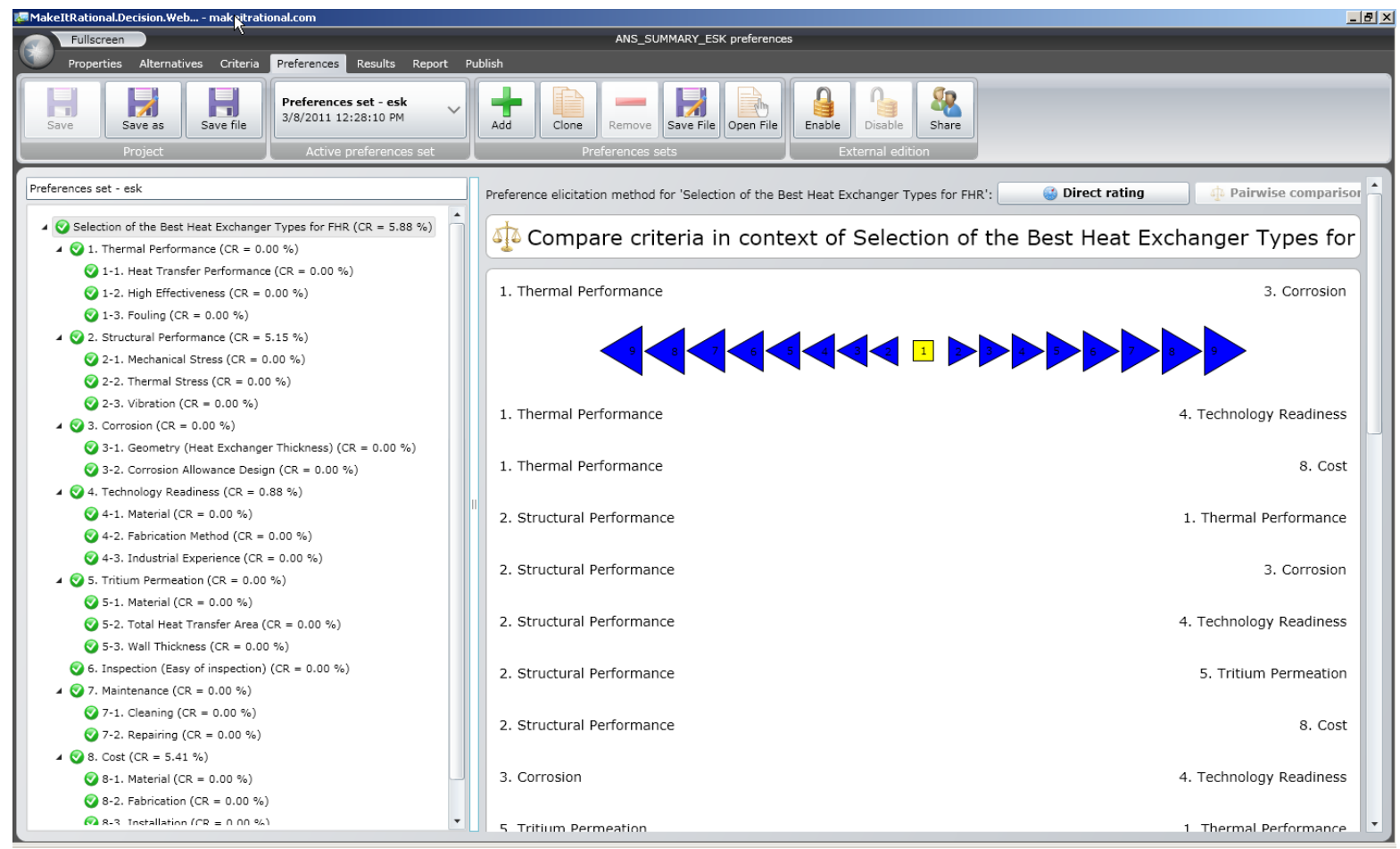

Figure 7-2. Screenshot of MakeltRational. 


\subsubsection{Plan for FHR Heat Exchanger Evaluation and Selection}

Currently, the basic setup for the FHR heat exchanger selection has been established with evaluation goals, alternatives, and criteria as shown in the previous sections. However, without sufficient information and knowledge, it is difficult to make a right decision. The current priority is therefore to collect information to help decision making.

In the next term of this study, feasibility studies will be conducted to provide sufficient information for the evaluation and decision making process. Once sufficient information is collected, it will be distributed and shared throughout the members who will participate in the final decision making. Currently, eight members with different background and expertise have been identified to participate in this process.

Development of the integration methodology is an ongoing task and will be covered in the later reports as the work progresses. 


\section{SUMMARY AND CONCLUSION}

The primary purpose of this study is to aid in the development and selection of the required heat exchanger for power production and process heat application for an FHR. The FHR currently has a ROT of $704^{\circ} \mathrm{C}$, which may increase with later designs. In order to have a high temperature available for power production or process heat applications, the most vital component is the heat exchanger. To design a secondary heat exchanger for the FHR, various aspects need to be considered. Of primary importance is how the heat from the reactor will be used. The heat from the reactor is anticipated to be used for power generation and process heat applications.

The molten salt coolants considered for use in the secondary coolant loop are LiF-NaF-KF (FLiNaK), $\mathrm{KF}-\mathrm{ZrF}_{4}$, and $\mathrm{KCl}-\mathrm{MgCl}_{2}$. The potential power conversion cycles identified are super-critical Rankine steam cycle, super-critical $\mathrm{CO}_{2}$ cycle, subcritical Rankine steam cycle, and a helium Brayton cycle. The results of the analysis of the different cycles showed the following:

- The super-critical Rankine steam cycle has the highest power cycle efficiency (44.0\%) and also is a current commercial technology. The cycle has the disadvantage of having the highest turbine inlet pressure $(24.99 \mathrm{MPa})$.

- The super-critical $\mathrm{CO}_{2}$ cycle has a power cycle efficiency (43.7 to $43.9 \%$ ) that is nearly the same as the super-critical Rankine steam cycle. It also has a maximum pipe diameter that is less than the other power cycles. The cycle also has the advantage of very few components. The disadvantage of the cycle is the high turbine inlet pressure $(21.66 \mathrm{MPa})$. This cycle is in small-scale testing and not available commercially.

- The subcritical Rankine steam cycle is currently used in commercial power plants. The power cycle efficiency of 41.9 to $42.0 \%$ is reasonable.

- The helium Brayton cycle has the advantage of adjustable pressures to reduce the pressure difference across the IHX. Brayton cycles have been developed for future gas reactors, however commercial cycles are not available.

- Using FLiNaK as the secondary coolant results in the smallest heat exchanger size; however, the difference is not large enough to make a conclusive decision.

- The binary salts $\left(\mathrm{KF}_{-} \mathrm{ZrF}_{4}\right.$ and $\left.\mathrm{KCl}-\mathrm{MgCl}_{2}\right)$ have identical results with respect to the IHX design.

The key to high efficiency heat transfer is a highly effective heat exchanger. An efficient design of the secondary heat exchanger is critical for effective use of the thermal energy generated in the FHR. The potential options explored for use as a secondary heat exchanger are shell and tube, plate, plate and fin, printed circuit, helical coil, and ceramic. The heat exchanger type will continue to be evaluated as the decision is finalized.

The evaluation of potential process heat applications was made considering a maximum available temperature of $650^{\circ} \mathrm{C}$. The current FHR design could provide process heat for the following applications (the long term processes will require higher ROT from FHR):

- $\quad$ Near Term Integration $\left(<650^{\circ} \mathrm{C}\right)$ :

- Power production cycles (steam Rankine cycles, helium Brayton cycle, $\mathrm{SCO}_{2}$ cycle)

- Oil shale (in situ)

- Oil shale (ex situ)

- Oil sands. 
- $\quad$ Long Term Integration $\left(>650^{\circ} \mathrm{C}\right)$ :

- Hydrogen production via steam methane reforming

- Substitute natural gas production

- Coal to liquid production

- Natural gas to liquid production

- Methanol to gasoline production

- Ammonia production.

A summary of long-term $\left(>650^{\circ} \mathrm{C}\right)$ and near-term goals $\left(<650^{\circ} \mathrm{C}\right)$ for FHR process applications are illustrated below.

\section{Oil Shale (Ex Situ) \\ Oil Shale (In Situ) \\ Oil Sand Recovery \\ $\mathrm{H}_{2}$ Production Hybrid Sulfur \\ Hydrogen Production (SI) \\ Hydrogen Production (HTSE) \\ Steam Methane Reforming \\ Methanol to Gasoline (MTG) \\ Ammonia Production \\ Steam Rankine Cycle \\ Helium Brayton Cycle \\ $\mathrm{SCO}_{2}$ Cycle}

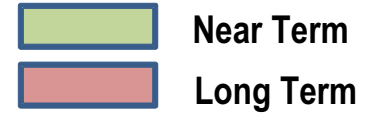

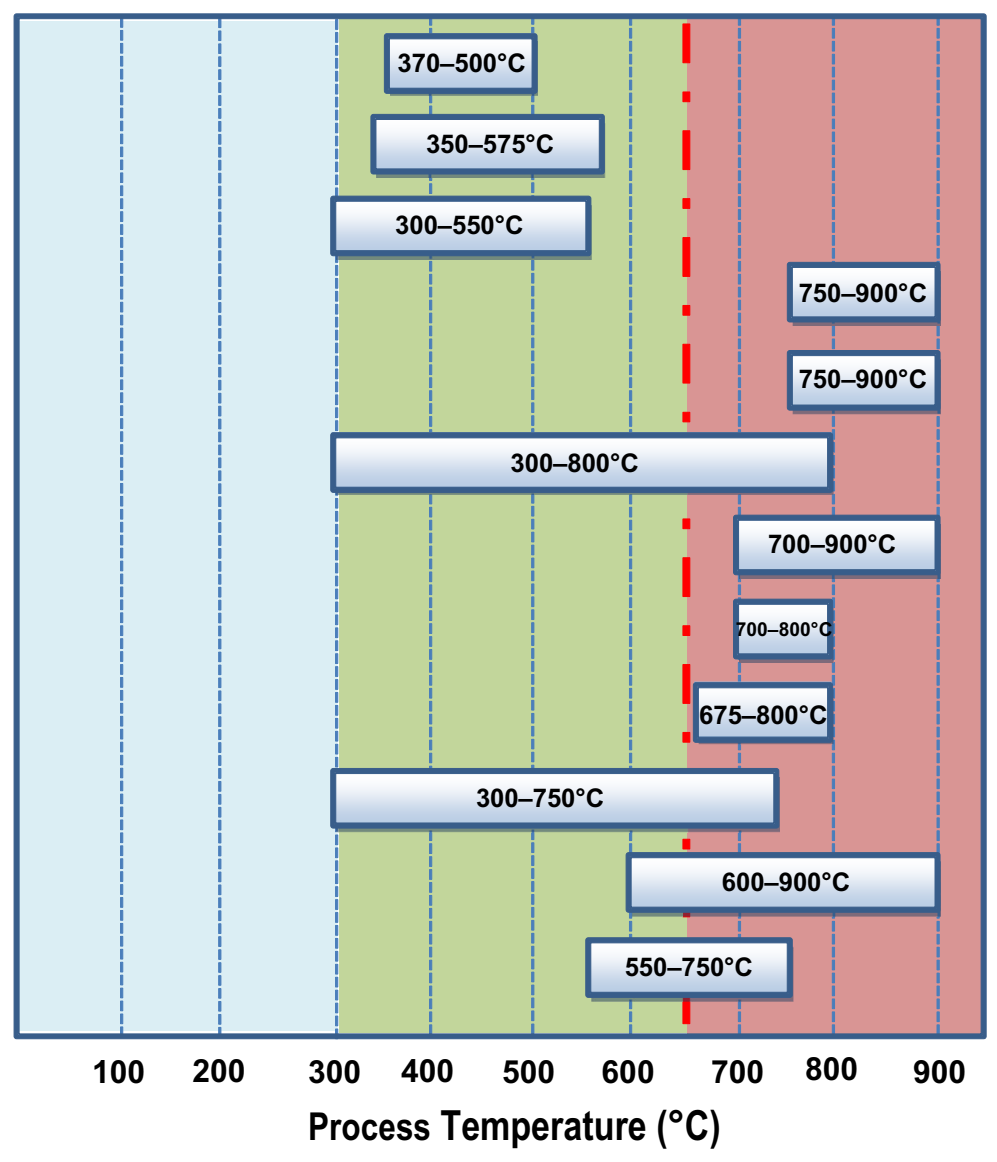

The characteristics of candidate molten salt coolants were extensively investigated in three different aspects; coolant thermal performance, coolant cost, and coolant chemistry (corrosion). The conclusions are summarized as follows (see Appendix A for details):

- Thermal Performance: The six FOMs developed in this study by an analytical approach to compare the thermal characteristics of various coolants are:

- Heat transfer performance

- Pumping power

- Coolant volume 
- $\quad$ Pipe material volume

- Heat loss

- Temperature drop.

The FOMs were mathematically derived and the sensitivity of each property on the FOMs was estimated in this study. Overall, FLiNaK (LiF-NaF-KF) showed much superior thermal performance to the other candidate coolants although it requires additional considerations for the heat loss and insulation.

- Coolant Cost: The cost of the coolant in the intermediate loop was estimated. According to the comparisons, $\mathrm{KCl}-\mathrm{MgCl}_{2}$ had the lowest cost followed by $\mathrm{NaCl}-\mathrm{MgCl}_{2}$. All other molten salt costs are about two-orders of magnitude more. Among the Fluoride based salts, $\mathrm{KF}^{-\mathrm{KBF}_{4}}$ had the lowest cost, then $\mathrm{NaF}_{-\mathrm{NaBF}}$, followed by LiF-NaF-KF. However, entire system economics need to be considered because component sizes will be different for each coolant.

- Coolant Chemistry (Corrosion): Corrosion is an essential issue for molten salt coolants. Careful alloy design and salt-chemistry control will be necessary to operate fluoride salt coolants with a tolerable level of corrosion. A large degree of uncertainty is expected when using chloride and fluoroborate salts in a high temperature system because of a lack of experimental data. Investigations will be required with respect to the coolant corrosion of the secondary heat exchanger, especially in diffusion bonding and welding.

The molten salt FLiNaK (LiF-NaF-KF) is considered the best candidate of the eleven that were compared, for use as the coolant in the FHR intermediate loop. It exhibits the best thermal performance, a reasonable coolant cost among the fluoride salts, and controllable corrosion effect by careful alloy selection (Hastelloy N) and chemistry control (reductants and redox buffer).

The basic setup for the selection of the secondary heat exchanger has been established with evaluation goals, alternatives, and criteria. However, without sufficient information and knowledge, it is difficult to make a right decision. Therefore, a current priority is to collect information to aid in decision making. Feasibility studies will be conducted in near future to provide sufficient information to aid in the evaluation and decision making process. 


\section{REFERENCES}

Anderson, M., et al., 2010, "University of Wisconsin-Madison Molten Salt Program- Experiments and Lessons Learned," March 2010.

Baade, William F., Uday N. Parekh, and Venkat S. Raman (Air Products and Chemicals, Inc.), 2001, "Hydrogen," Kirk-Othmer Encyclopedia of Chemical Technology, John Wiley \& Sons.

Bejan, A., Tsatsaronis, G., Moran, M., Thermal Design and Optimization, John Wiley \& Sons, 1996.

Bhushan, Navneet, and Kanwal Rai, 2004, Strategic Decision Making: Applying the Analytic Hierarchy Process, London: Springer-Verlag. ISBN 1-8523375-6-7.

Bonilla, C. F., 1958, “Comparisons of Coolants,” Section 9-3, Chapter 6.5, Nuclear Engineering Handbook, Ed. H. Etherington, McGraw-Hill, NY.

Dewson, S. J., and B. Thonon, 2003, "The Development of High Efficiency Heat Exchangers for Helium Gas Cooled Reactors," Report No. 3213, International Conference on Advanced Nuclear Power Plants (ICAP), Cordoba, Spain.

Dostal, V., M. J. Driscoll, and P. Heizlar, 2004, A Supercritical Carbon Dioxide Cycle for Next Generation Nuclear Plants, MIT-ANP-TR-100200. Boston: Massachusetts Institute of Technology.

Elshout, Ray, 2010, "Hydrogen Production By Steam Reforming," Chemical Engineering, May 2010, pp. 34-38.

Fisher, D. L., and R. L. Sindelar, 2008, "Compact Heat Exchanger Manufacturing Technology Evaluation,” Savannah River Nuclear Solutions, SRNS-STI-2008-00014, Savannah River Site, Aiken, South Carolina.

Forman, Ernest H., Saul I. Gass, 2001-07, “The analytical hierarchy process — an exposition," Operations Research, Vol. 49, Issue 4, pp. 469-487.

Grimes, W. R., E. G. Bohlmann, A. S. Meyer, and J. M. Dale, 1972, "Fuel can Coolant Chemistry," Chapter 5 in M. W. Rosenthal, P. N. Haubenreich, and R. B. Briggs, The Development Status of Molten-Salt Breeder Reactors, Oak Ridge National Laboratory Report ORNL-4812.

Hallowell, David L., 2005, “Analytical Hierarchy Process (AHP) - Getting Oriented,” SixSigma.com. Retrieved 2007-08-21.

Hesselgreaves, J. E., 2001, Compact Heat Exchangers, Selection, Design and Operation, First edition, Pergamon.

Holcomb, D. E., S. M. Cetiner, G. F. Flanagan, F. J. Pertz, and G. L. Yoder, 2009, An Analysis of Testing Requirements for Fluoride Salt-Cooled High Temperature Reactor Components, ORNL/TM2009/297, November 2009.

Ingersoll, D. T et al., 2004, Status of Preconceptual Design of the Advanced High Temperature Reactor (AHTR), Oak Ridge National Laboratory Report ORNL/TM-2004/104.

Ingersoll, D. T., C. W. Forsberg, and P. E. MacDonald, 2007, Trade Studies on the Liquid-Salt-Cooled Very High-Temperature Reactor: Fiscal Year 2006 Progress Report, Oak Ridge National Laboratory Report ORNL/TM-2006/140.

Kitto, J. B., and S. C. Stultz, 2005, "Thermodynamics of Steam," Steam: Its Generation and Use, Edition 41 (p. 16). Barberton, Ohio, The Babcock and Wilcox Company.

Latzko, D. G. H., 1970, “Sodium-Cooled Fast Reactor Engineering," Proceeding of a Symposium on Progress in Sodium-Cooled Fast Reactor Engineering held by the IAEA in Monaco, IAEA-SM$130 / 20$. 
LeBlanc, D., 2010a, "Molten Salt Reactors: A New Beginning for an Old Idea," Nuclear Engineering and Design, Vol. 240, pp. 1644-1656.

LeBlanc, D., 2010b, "Too Good to Leave on the Shelf," available at http://memagazine.asme.org/Articles/2010/May/Too_Good_Leave_Shelf.cfm Accessed on Aug $27^{\text {th }} 2010$.

O. Benes, C. Cabet, S. Delpech, P. Hosnedl, V. Ignatiev, R. Konings, D. Lecarpentier, O. Matal, E. Merle-Lucotte, C. Renault, J. Uhlir (2009) "Assessment of Liquid Salts for Innovative Applications," available at ftp://ftp.cordis.europa.eu/pub/fp6-euratom/docs/alisia-deliverable-d50v4 en.pdf, accessed on September $7^{\text {th }} 2010$

Renault, C., M. Hron, R. Konings, and D. E. Holcomb. 2009, "The Molten Salt Reactor (MSR) in Generation IV: Overview and Perspectives," GIF Symposium-Paris (France), September 9 and 10, 2009.

Saaty, T. L., 1996, The Analytic Hierarchy Process, New York, N.Y., McGraw Hill, 1980, reprinted by RWS Publication, Pittsburgh.

Sabharwall, P., M. Ebner, M. Sohal, P. Sharpe, M. Anderson, K. Sridharan, J. Ambrosek, L. Olson, and P. Brooks, 2010a, Molten Salts for High Temperature Reactors: University of Wisconsin Molten Salt Corrosion and Flow Loop Experiments - Issues Identified and Path Forward, Idaho National Laboratory report INL/EXT-10-18090.

Sabharwall, P., M. Patterson, V. Utgikar, and F. Gunnerson, 2010b, "Phase change heat transfer device for process heat applications," Nuclear Engineering and Design, In Press.

Sabharwall, P., 2009, Engineering Design Elements of a Two-Phase Thermosyphon to Transfer NGNP Thermal Energy to a Hydrogen Plant," Idaho National Laboratory report INL/EXT-09-15383.

Sabharwall, P., and F. Gunnerson, 2009, "Engineering Design Elements of a Two-Phase Thermosyphon to Transfer NGNP Thermal Energy to a Hydrogen Plant," Nuclear Engineering and Design, Vol. 239, Issue 11, pp. 2293-2301.

Sabharwall, P., and E. S. Kim, 2011, "Fluoride High Temperature Reactor Integration with Industrial Process Applications," Idaho National Laboratory, TEV-1160

Sanders, J. P., A review of possible choices for secondary coolants for molten salt reactors, ORNL CF71-8-10, Oak Ridge National Laboratory, Oak Ridge, TN, 1971.

Shah, R. K., and S. P. Sekulic, 2003, Fundamentals of Heat Exchanger Design, John Wiley and Sons, 2003.

Shah, R. K., 2003, Fundamentals of Heat Exchanger Design, John Wiley and Sons.

Sherman, S. R., and Y. Chen, 2008, Heat Exchanger Testing Requirements and Facility Needs for the NHI/NGNP Project, WSRC-STI-2008-00152, April 2008.

Snead, L. L., T. Nozawa, Y. Katoh, T. S. Byun, S. Kondo, and D. A. Petti, 2007, "Handbook of SiC Properties for Fuel Performance Modeling,” Journal of Nuclear Materials, Vol. 371, pp. 329-377.

Sohal, M., M. Ebner, P. Sabharwall, and P. Sharpe, March 2010, Engineering Database of Liquid Salt Thermophysical and Thermochemical Properties, Idaho National Laboratory report INL/EXT-1018297.

Sohal, M. S., M. Ebner, P. Sabharwall, and P. Sharpe, 2010, Engineering Database of Liquid Salt Thermophysical and Thermochemical Properties, Idaho National Laboratory report INL/EXT-1018297. 
Taborek, J., G. F. Hewitt, and N. Afgan, 1983, Heat Exchangers Theory and Practice, Hemisphere Publishing Corporation.

Tatara, R., 1997, "Heat Exchangers: An Overview of Maintenance and Operations," Duke Engineering and Services, EPRI.

Van Wylen, G., and R. Sonntag, 1973, Chapter 9: “Some Power and Refrigeration Cycles.” In G. Van Wylen, and R. Sonntag, Fundamentals of Classical Thermodynamics (pp. 302-322; 340-352). New York: John Wiley and Sons, Inc.

Vinegar, H., 2006, “Shell's In-situ Conversion Process," 26th Oil Shale Symposium, Golden, Colorado, October 16-18, 2006.

Williams, D. F., 2006, “Assessment of Candidate Molten Salt Coolants for the NGNP/NHI Heat-Transfer Loop,” Oak Ridge National Laboratory Report ORNL/TM-2006/69.

Williams, D. F., L. M. Toch, and K. T. Clarno, Assessment of Candidates Molten Salt Coolants for the Advanced High Temperature Reactor, ORNL/TM-2006/12, 2006a. 
Appendix A

Development of Figures of Merit for Coolant ThermalHydraulic Performance 


\section{Appendix A-Development of Figures of Merit for Coolant Thermal-Hydraulic Performance}

\section{A-1. INTRODUCTION}

If a certain coolant is superior to the other coolant for all properties, the selection of the coolant becomes straight forward. However, each coolant is generally good in some respect (properties) but poor in the other. Therefore, it is useful to compare some key parameters that determine coolant thermal performance in the system of interest. This section discusses only coolant thermal-hydraulic characteristics; the other characteristics will be discussed later.

Figures of merits (FOMs) were used for evaluating the thermal performance of the coolants. Bonilla (1958) has provided the FOMs based on minimal pumping power for a given coolant temperature rise as follows:

$$
F O M=\mu^{0.2} /\left(\rho^{2} C_{P}^{2.8}\right)
$$

where

$$
\begin{aligned}
\mu & =\text { viscosity } \\
\rho & =\text { density } \\
C_{p} & =\text { heat capacity } .
\end{aligned}
$$

Sanders (1971) proposed the following FOM based on the heat exchanger surface area:

$$
F O M=\mu^{0.2} /\left(\rho^{0.3} C_{p}^{0.6} k^{0.6}\right)
$$

Williams (2006) used the above FOMs for comparing heat transfer performance of the molten salt coolants for a Next Generation Nuclear Plant/Nuclear Hydrogen Initiative heat transfer loop.

The above two parameters are very useful for comparing overall coolant heat transfer performance at the early stages of research. However, they are still not complete for evaluating all the important thermal performance parameters in the system of interest. Figure A-1 shows the general thermal-hydraulic requirements for the intermediate coolant in the FHR systems.

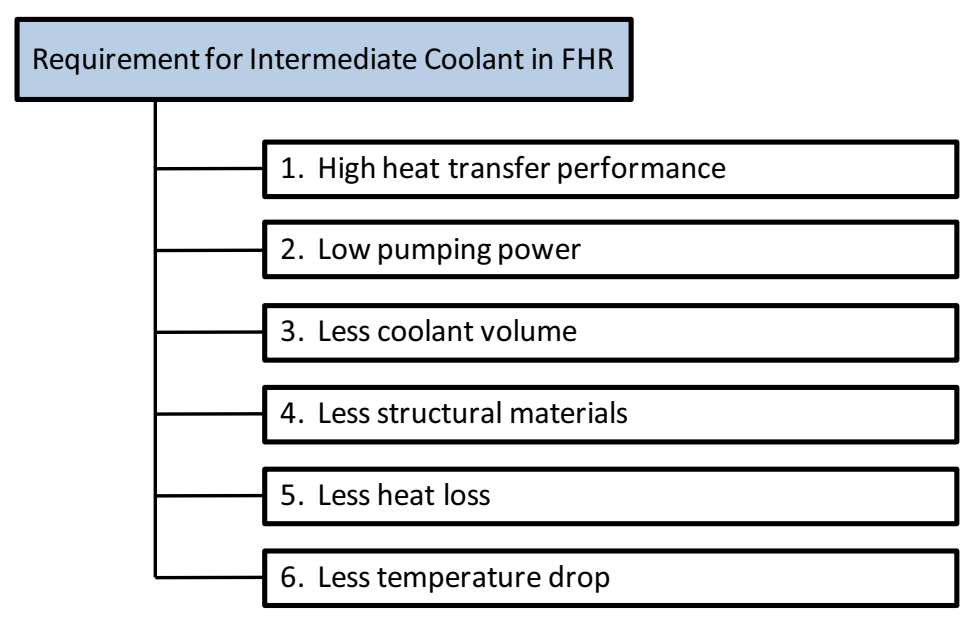

Figure A-1. General thermal-hydraulic requirements for the intermediate coolant in the FHR systems. 
The following are general thermal-hydraulic requirements for the coolant in the FHRs:

- High heat transfer performance: Coolant should transfer heat efficiently. Good heat transfer performance leads to efficient heat transfer between the primary and the secondary sides.

- Low pumping power: Coolant should require low pumping power to minimize efficiency loss and economic loss.

- Less coolant volume: Small volume of coolant is preferred for economic reasons.

- Less structural materials for containing coolant: Small amount of structural materials for the coolant containment is preferred for economic reasons.

- Less heat loss: Heat loss of the coolant should be minimized when transferring heat long distances for a more efficient system.

- Less temperature drop: The coolant temperature drop should be minimized when transferring heat to long distances for a more efficient system.

The above five requirements are associated with the thermal-hydraulic properties including thermal conductivity, density, heat capacity, and viscosity. In this study, five different FOMs were developed that can represent each requirement.

Figure A-2 shows the basic configuration of the general intermediate heat transfer loop. Heat $(Q)$ is transferred to the coolant system through heat exchangers, increasing coolant temperature. This coolant is driven by pumps or circulators to transport the heat to several areas for use in electricity generation, chemical process, etc. Therefore, the operating temperature and pressure of this system are generally determined and optimized by how the energy is used. However, detailed heat transfer performance, system size, and major component specifications are significantly affected by types of coolants.

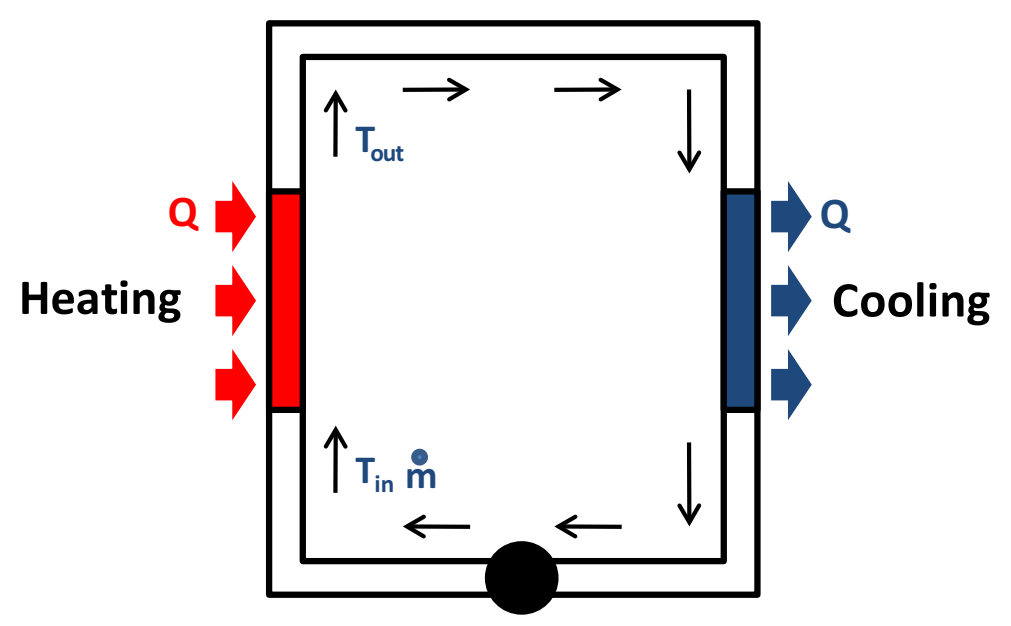

Figure A-2. General configuration of intermediate heat transfer loop.

\section{A-2. HEAT TRANSFER PERFORMANCE FACTOR: FOM FOR HEAT TRANSFER PERFORMANCE (FOM $\left.{ }_{\mathrm{HT}}\right)$}

The heat transfer is the major role of the coolant. Therefore, heat transfer performance is one of the most important factors for considering coolant options. Heat transfer performance of the coolants can be compared by calculating the heat transfer at the same pumping power for the given geometry. If a certain coolant has the highest heat transfer coefficient, the coolant can be considered as having the best heat transfer performance. 
The FOM for the heat transfer performance can be derived as Equation A-3. Figure A-3 shows a circular pipe with diameter, $\mathrm{D}$ and length, $\mathrm{L}$. In this derivation, the pumping power was assumed to be the same for the different fluids. The pumping power is expressed as follows:

$$
P_{\text {pump }}=\frac{\Delta P \cdot G}{\eta}
$$

where

$$
\begin{array}{ll}
P_{\text {pump }} & =\text { pumping power }(\mathrm{W}) \\
\Delta P & =\text { pressure drop }(\mathrm{Pa}) \\
G & =\text { volumetric flow rate } \\
\eta & =\text { pump efficiency. }
\end{array}
$$

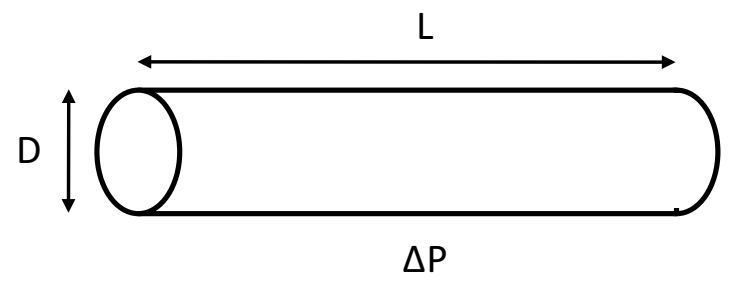

Figure A-3. Geometry and input parameters for FOM development (heat transfer performance).

The cooling system is generally operated in the turbulent flow regime. Therefore, the pressure drop is expressed by

$$
\Delta P=f \cdot \frac{1}{2} \rho \cdot U^{2} \cdot \frac{L}{D}
$$

where

$f=$ friction factor (constant for the high Reynolds number),

$\rho=$ density,

$L=$ channel length,

$D=$ channel diameter,

$U=$ flow velocity.

The friction factor (f) can be calculated by the Blasius formula for a smooth pipe as follows:

$f=0.316 \cdot \mathrm{Re}^{-0.25}$

where

$$
\operatorname{Re}=\frac{\rho \cdot U \cdot D}{\mu} .
$$


The volumetric flow rate can be expressed by

$$
\bar{Q}=U \cdot A=U \cdot\left(\frac{\pi}{4} D^{2}\right)
$$

where

$$
A=\text { channel cross-sectional area. }
$$

By inserting Eqs. (A-4), (A-5), (A-6), and (A-7) in Eq. (A-3), the following expression can be obtained:

$$
\begin{aligned}
P_{\text {pump }} & =\frac{\left(f \cdot \frac{1}{2} \rho \cdot U^{2} \cdot \frac{L}{D}\right) \cdot U \cdot\left(\frac{\pi}{4} D^{2}\right)}{\eta}=\frac{\left(0.316 \cdot\left(\frac{\rho \cdot U \cdot D}{\mu}\right)^{-0.25} \cdot \frac{\pi}{8} \rho \cdot U^{3} \cdot L \cdot D\right)}{\eta} \\
& =\frac{\left(\frac{0.316 \cdot \pi}{8} \rho^{0.75} \cdot U^{2.75} \cdot L \cdot D^{0.75} \cdot \mu^{0.25}\right)}{\eta} .
\end{aligned}
$$

Therefore, the flow velocity can be derived by

$$
U=\left(\frac{\eta \cdot P_{\text {pump }}}{\left(\frac{0.316 \cdot \pi}{8} L \cdot D^{0.75}\right)}\right)^{0.36} \cdot(\rho)^{-0.27} \cdot(\mu)^{-0.09}=C_{1} \cdot(\rho)^{-0.27} \cdot(\mu)^{-0.09}
$$

For the given conditions, the variable $C_{l}$ can be considered as constant. Therefore, the flow velocity is determined by only coolant density and viscosity.

General convective heat transfer is expressed as follows:

$Q=h \cdot S \cdot \Delta T$.

where

$$
\begin{aligned}
Q & =\text { heat } \\
h & =\text { heat transfer coefficient }, \\
S & =\text { heat transfer surface area, } \\
\Delta T & =\text { temperature differences between bulk fluid and wall. }
\end{aligned}
$$

In the given condition, surface area $(S)$ and temperature difference $(\Delta T)$ are fixed. Therefore, the heat transfer is proportional to the heat transfer coefficient $(h)$. The heat transfer coefficient for the turbulent flow is generally expressed by the Dittus-Boelter correlation:

$$
h=\frac{k}{D} \cdot N u=\frac{k}{D} \cdot\left(0.023 \operatorname{Re}^{0.8} \operatorname{Pr}^{0.4}\right) .
$$


where

$$
\begin{aligned}
& k=\text { thermal conductivity, } \\
& N u \text { = Nusselt number, } \\
& \operatorname{Re}=\text { Reynolds number, } \\
& \operatorname{Pr}=\text { Prandtl number. }
\end{aligned}
$$

The Prandtl number $(\mathrm{Pr})$ is defined as follows:

$$
\operatorname{Pr}=\frac{C_{p} \cdot \mu}{k} .
$$

By inserting Eqs (A-6) and (A-12) in Eq. (A-11), the heat transfer coefficient $(h)$ can be written as

$$
h=\frac{k}{D} \cdot\left(0.023\left(\frac{\rho \cdot U \cdot D}{\mu}\right)^{0.8}\left(\frac{C_{p} \cdot \mu}{k}\right)^{0.4}\right)
$$

The velocity in Eq. (A-13) can be replaced by Eq. (A-9).

$$
h=\frac{k}{D} \cdot\left(0.023\left(\frac{\rho \cdot D}{\mu}\right)^{0.8} \cdot\left(C_{1} \cdot(\rho)^{-0.27} \cdot(\mu)^{-0.09}\right)^{0.8} \cdot\left(\frac{C_{p} \cdot \mu}{k}\right)^{0.4}\right)
$$

therefore,

$$
\begin{aligned}
& h=\left(\frac{0.023 \cdot\left(C_{1}\right)^{0.8}}{D^{0.2}}\right) \cdot(k)^{0.6} \cdot(\rho)^{0.58} \cdot\left(C_{p}\right)^{0.4} \cdot(\mu)^{-0.47} . \\
& h \sim(k)^{0.6} \cdot(\rho)^{0.58} \cdot\left(C_{p}\right)^{0.4} \cdot(\mu)^{-0.47} .
\end{aligned}
$$

The figure of merit (FOM) for the heat transfer performance is here defined by normalization as follows:

$$
F O M_{h t}=\frac{h}{h_{0}} .
$$

where

$$
\begin{aligned}
& h=\text { heat transfer coefficient for a certain coolant, } \\
& h_{0}=\text { heat transfer coefficient for a reference coolant. }
\end{aligned}
$$

Therefore,

$$
F O M_{h t}=\frac{(k)^{0.6} \cdot(\rho)^{0.58} \cdot\left(C_{p}\right)^{0.4} \cdot(\mu)^{-0.47}}{R_{h t, 0}} .
$$




$$
R_{h t, 0}=\left(k_{0}\right)^{0.6} \cdot\left(\rho_{0}\right)^{0.58} \cdot\left(C_{p, 0}\right)^{0.4} \cdot\left(\mu_{0}\right)^{-0.47} .
$$

According to Eq. (A-16), the coolant shows better heat transfer performance if it has higher thermal conductivity, higher density, higher heat capacity, and lower viscosity. The sensitivity of each property for the heat transfer performance factor $\left(F O M_{h t}\right)$ can be calculated by normalized form as follows:

$$
\begin{gathered}
S_{k, h t}=\frac{\partial F O M_{h t} / F O M_{h t}}{\partial k / k}=0.6 \\
S_{\rho, h t}=\frac{\partial F O M_{h t} / F O M_{h t}}{\partial \rho / \rho}=0.58 \\
S_{C_{p}, h t}=\frac{\partial F O M_{h t} / F O M_{h t}}{\partial C_{p} / C_{p}}=0.4 \\
S_{\mu, h t}=\frac{\partial F O M_{h t} / F O M_{h t}}{\partial \mu / \mu}=-0.47 .
\end{gathered}
$$

The above results show that the thermal conductivity is the most sensitive property that affects heat transfer performance, following by coolant density, viscosity and heat capacity, respectively.

\section{A-3. PUMPING FACTOR: FOM FOR PUMPING POWER (FOMP)}

To operate a heat transfer loop, the coolant is pumped though the system to make it flow. Less pumping power is highly preferred for the coolant. This study proposes the same figure of merit provided by Bonilla (1958), in the normalized form, which is based on minimal pumping power for a given coolant temperature rise as

$$
\text { FOM }_{p}=\frac{\mu^{0.2} /\left(\rho^{2} \cdot C_{P}^{2.8}\right)}{R_{p, 0}}
$$

where

$R_{p, 0}=\mu_{0}^{0.2} /\left(\rho_{0}^{2} \cdot C_{P, 0}^{2.8}\right)$ (for the reference coolant).

According to Eq. (A-25), the coolant needs less pumping power if it has higher density, higher heat capacity, and lower viscosity. The sensitivity of each property for the pumping power required factor $\left(F O M_{p}\right)$ can be calculated by normalized form as follows:

$$
\begin{gathered}
S_{k, p}=\frac{\partial F O M_{p} / F O M_{p}}{\partial k / k}=0.0 \\
S_{\rho, 0}=\frac{\partial F O M_{p} / F O M_{p}}{\partial \rho / \rho}=-2 \\
S_{C_{p} . p}=\frac{\partial F O M_{p} / F O M_{p}}{\partial C_{p} / C_{p}}=-2.8
\end{gathered}
$$


$S_{\mu, p}=\frac{\partial F O M_{p} / F O M_{p}}{\partial \mu / \mu}=0.2$.

The above results show that the heat capacity is the most important property that affects required pumping power, followed by coolant density and viscosity. Relatively, the viscosity effect is small because the friction loss in the coolant is dominated by turbulent mixing not by viscous friction. Thermal conductivity does not affect the required pumping power.

\section{A-4. COOLANT VOLUME FACTOR: FOM FOR COOLANT VOLUME $\left(F O M_{C v}\right)$}

Since each coolant has different thermal properties, the volumes required for the coolant loops are also different, depending on the coolant types. Smaller coolant volume is usually preferred for economic reasons. The volume of the coolant is generally determined based on the given heat transfer duty and the pumping power (or friction loss). Therefore, the volumes of the coolants in the heat transfer loop can be compared by calculating the channel diameter for the same heat duty, pumping power, and pipe length.

Heat transfer in the heat transfer loop is expressed by

$Q=\dot{m} \cdot C_{p} \cdot \Delta T=\left(\frac{\pi}{4} D^{2} \cdot \rho \cdot U\right) \cdot C_{p} \cdot \Delta T$

Therefore, the velocity $(U)$ can be expressed by

$U=\frac{Q}{\left(\frac{\pi}{4} D^{2} \cdot \Delta T\right) \cdot C_{p} \cdot \rho}=\left(\frac{Q}{\left(\frac{\pi}{4} D^{2} \cdot \Delta T\right)}\right) \cdot C_{p}^{-1} \cdot \rho^{-1}$.

The pumping power is expressed as

$P_{\text {pump }}=\frac{\left(f \cdot \frac{1}{2} \rho \cdot U^{2} \cdot \frac{L}{D}\right) \cdot U \cdot\left(\frac{\pi}{4} D^{2}\right)}{\eta}=\frac{\left(\frac{0.316 \cdot \pi}{8} \rho^{0.75} \cdot L \cdot D^{0.75} \cdot \mu^{0.25}\right)}{\eta} \cdot U^{2.75}$

Therefore,

$$
\begin{aligned}
P_{\text {pump }} & =\frac{\left(\frac{0.316 \cdot \pi}{8} \rho^{0.75} \cdot L \cdot D^{0.75} \cdot \mu^{0.25}\right)}{\eta} \cdot\left(\left(\frac{Q}{\left(\frac{\pi}{4} D^{2} \cdot \Delta T\right)}\right) \cdot C_{p}^{-1} \cdot \rho^{-1}\right)^{2.75} \\
= & \frac{Q^{2.75} \cdot\left(\frac{0.316 \cdot \pi}{8} L\right)}{\eta \cdot\left(\frac{\pi}{4} \Delta T\right)^{2.75}} \cdot(\rho)^{-2} \cdot\left(C_{p}\right)^{-2.75} \cdot(D)^{-4.75} \cdot(\mu)^{0.25}
\end{aligned}
$$


Therefore, the channel diameter $(D)$ can be calculated as

$$
D=\left(\frac{Q^{2.75} \cdot\left(\frac{0.316 \cdot \pi}{8} L\right)}{P_{\text {pump }} \cdot \eta \cdot\left(\frac{\pi}{4} \Delta T\right)^{2.75}}\right)^{0.21} \cdot(\rho)^{-0.42} \cdot\left(C_{p}\right)^{-0.58} \cdot(\mu)^{0.05}
$$

Thus, the volume of the coolant is

$$
V=\frac{\pi}{4} D^{2} L=\left(\frac{\pi}{4} L \cdot\left(\frac{Q^{2.75} \cdot\left(\frac{0.316 \cdot \pi}{8} L\right)}{P_{\text {pump }} \cdot \eta \cdot\left(\frac{\pi}{4} \Delta T\right)^{2.75}}\right)^{0.42}\right) \cdot(\rho)^{-0.84} \cdot\left(C_{p}\right)^{-1.16} \cdot(\mu)^{0.1}
$$

The FOM for the coolant volume is here defined by normalization as

$$
F O M_{c v}=\frac{V}{V_{0}}
$$

where:

$$
\begin{aligned}
& V=\text { volume required for a certain coolant } \\
& V_{0}=\text { volume required for a reference coolant. }
\end{aligned}
$$

Therefore,

$F O M_{c v}=\frac{(\rho)^{-0.84} \cdot\left(C_{p}\right)^{-1.16} \cdot(\mu)^{0.1}}{R_{c v, 0}}$

where

$$
R_{c v, 0}=\left(\rho_{0}\right)^{-0.84} \cdot\left(C_{p, 0}\right)^{-1.16} \cdot\left(\mu_{0}\right)^{0.1} .
$$

According to Eq. (A-37), the coolant needs higher density and higher heat capacity to have smaller volume. This is because more heat can be stored and transferred per unit volume with a higher density and heat capacity. The sensitivity of each property for the required coolant volume factor $\left(F O M_{c v}\right)$ can be calculated by normalized form as follows:

$$
\begin{aligned}
& S_{k, c v}=\frac{\partial F O M_{c v} / F O M_{c v}}{\partial k / k}=0.0 \\
& S_{\rho, c v}=\frac{\partial F O M_{c v} / F O M_{c v}}{\partial \rho / \rho}=-0.84 \\
& S_{C_{p} . c v}=\frac{\partial F O M_{c v} / F O M_{c v}}{\partial C_{p} / C_{p}}=-1.16
\end{aligned}
$$


$S_{\mu, c v}=\frac{\partial F O M_{c v} / F O M_{c v}}{\partial \mu / \mu}=0.1$.

The above results show that the heat capacity is the most important property that affects required coolant volume, followed by coolant density and viscosity, respectively.

\section{A-5. PIPE MATERIAL VOLUME FACTOR: FOM FOR COOLANT CONTAINMENT VOLUME (FOM CCV $_{\text {) }}$}

Depending on flow conditions (temperature and pressure), the heat transfer structure requires different pipe sizes and thickness. A larger pipe size and thickness requires more volume of structural materials leading to increased cost. In comparing required pipe material volumes for the coolant and the operating conditions, pipe size and thickness were calculated for the same heat duty and pumping power.

Pipe diameter was already estimated in Eq. (A-34) for the given heat duty and pumping power as follows:

$$
D=\left(\frac{Q^{2.75} \cdot\left(\frac{0.316 \cdot \pi}{8} L\right)}{P_{\text {pump }} \cdot \eta \cdot\left(\frac{\pi}{4} \Delta T\right)^{2.75}}\right)^{0.21} \cdot(\rho)^{-0.42} \cdot\left(C_{p}\right)^{-0.58} \cdot(\mu)^{0.05} .
$$

In the heat transfer loop, the pipe thickness is determined based on the mechanical stress. Mechanical stresses in the thin-walled cylindrical shaped pipe (the vessel must have a wall thickness of no more than about one-tenth (Bejan et al. 1996) are estimated as follows:

$\sigma_{\theta}=\frac{P \cdot r}{t}$ (hoop stress),

$\sigma_{z}=\frac{P \cdot D^{2}}{(D+2 t)^{2}-D^{2}}($ axial stress $)$

$\sigma_{r}=-\frac{P}{2}$ (radial stress).

where:

$$
\begin{aligned}
P & =\text { internal pressure } \\
r & =\text { pipe radius } \\
D & =\text { pipe diameter } \\
t & =\text { pipe thickness }
\end{aligned}
$$


Generally, axial stress and radial stress are less than hoop stress. Thus, hoop stress becomes the limiting factor for determining pipe thickness. For the same material that has the same stress criteria, the thickness of the pipe can be calculated by Eq. (A-44) as

$$
t=\frac{P \cdot D}{2 \cdot \sigma_{\theta}}=\left(\frac{1}{2 \cdot \sigma_{\theta}} \cdot\left(\frac{Q^{2.75} \cdot\left(\frac{0.316 \cdot \pi}{8} L\right)}{P_{\text {pump }} \cdot \eta \cdot\left(\frac{\pi}{4} \Delta T\right)^{2.75}}\right) \cdot(P) \cdot(\rho)^{-0.42} \cdot\left(C_{p}\right)^{-0.58} \cdot(\mu)^{0.05} .\right.
$$

The volume of the pipe materials per unit length can be estimated for the thin walled pipe as

$$
V_{p}=\pi \cdot D \cdot t \cdot 1=\pi \cdot\left(\frac{P}{2 \cdot \sigma_{\theta}}\right) \cdot D^{2} .
$$

Therefore,

$$
V_{p}=\left(\pi \cdot\left(\frac{1}{2 \cdot \sigma_{\theta}}\right) \cdot\left(\frac{Q^{2.75} \cdot\left(\frac{0.316 \cdot \pi}{8} L\right)}{P_{\text {pump }} \cdot \eta \cdot\left(\frac{\pi}{4} \Delta T\right)^{2.75}}\right)^{0.42}\right) \cdot(P) \cdot(\rho)^{-0.84} \cdot\left(C_{p}\right)^{-1.16} \cdot(\mu)^{0.1}
$$

The FOM for the coolant volume is here defined by normalization as

$$
F O M_{c c v}=\frac{V_{p}}{V_{p, 0}}
$$

where:

$V_{p}=$ volume required for a pipe materials

$V_{p, 0}=$ volume required for the reference pipe materials.

Therefore,

$F O M_{c c v}=\frac{(P) \cdot(\rho)^{-0.84} \cdot\left(C_{p}\right)^{-1.16} \cdot(\mu)^{0.1}}{R_{c c v, 0}}$

where

$$
R_{c c v, 0}=\left(P_{o}\right) \cdot\left(\rho_{0}\right)^{-0.84} \cdot\left(C_{p, 0}\right)^{-1.16} \cdot\left(\mu_{0}\right)^{0.1}
$$

According to Eq. (A-51), the coolant needs higher density, higher heat capacity, and lower operating pressure to have smaller material volume. The sensitivity of each property for the required material volume factor $\left(F O M_{c c v}\right)$ can be calculated by

$$
S_{k, c c v}=\frac{\partial F O M_{c c v} / F O M_{c c v}}{\partial k / k}=0.0
$$




$$
\begin{aligned}
& S_{\rho, c c v}=\frac{\partial F O M_{c c v} / F O M_{c c v}}{\partial \rho / \rho}=-0.84 \\
& S_{C_{p} . c c v}=\frac{\partial F O M_{c c v} / F O M_{c c v}}{\partial C_{p} / C_{p}}=-1.16 \\
& S_{\mu, c c v}=\frac{\partial F O M_{c c v} / F O M_{c c v}}{\partial \mu / \mu}=0.1 \\
& S_{P, c c v}=\frac{\partial F O M_{c c v} / F O M_{c c v}}{\partial P / P}=1.0
\end{aligned}
$$

The above results show that the heat capacity is the most important property that affects required material volume. Coolant pressure and density are the next most important properties. Effects of viscosity and thermal conductivity are negligible.

\section{A-6. HEAT LOSS FACTOR: FOM FOR HEAT LOSS (FOM $\left.{ }_{\mathrm{HL}}\right)$}

A heat transfer loop is sometimes required to transfer heat very long distances. Heat loss should thus be minimized to keep high system efficiency. The heat loss for different coolants can be compared for the same heat duty and pumping power as shown in the above sections. The overall heat transfer in the heat transfer loop can be expressed by

$$
Q=\dot{m} \cdot C_{p} \cdot \Delta T=\left(\rho \cdot U \cdot \frac{\pi}{4} D^{2}\right) \cdot C_{p} \cdot \Delta T .
$$

Therefore, the velocity of the coolant can be expressed by

$$
U=\frac{Q}{\left(\frac{\pi}{4} \cdot D^{2} \cdot \Delta T\right) \cdot \rho \cdot C_{p}}
$$

The heat loss at a certain location can be defined by

$$
d Q=h \cdot(\pi \cdot D \cdot d x) \cdot\left(T-T_{w}\right)
$$

where

$$
\begin{aligned}
\mathrm{d} Q & =\text { heat loss at the surface } \\
T & =\text { coolant temperature } \\
T_{w} & =\text { pipe inner wall temperature. }
\end{aligned}
$$

Therefore,

$$
q_{\text {loss }}=\frac{d Q}{d x}=h \cdot(\pi \cdot D) \cdot\left(T-T_{w}\right) .
$$


By inserting Eq. (A-13) in Eq. (A-61),

$$
\begin{aligned}
q_{\text {loss }} & =\frac{k}{D} \cdot\left(0.023\left(\frac{\rho \cdot U \cdot D}{\mu}\right)^{0.8}\left(\frac{C_{p} \cdot \mu}{k}\right)^{0.4}\right) \cdot(\pi \cdot D) \cdot\left(T-T_{w}\right) \\
& =\left(0.023 \pi \cdot\left(T-T_{w}\right)\right) \cdot k^{0.6} \cdot C_{p}^{0.4} \cdot \rho^{0.8} \cdot \mu^{-0.4} \cdot U^{0.8} \cdot D^{0.8}
\end{aligned}
$$

By inserting Eq. (A-59) in Eq. (A-62), the following equation can be obtained

$$
\begin{aligned}
q_{\text {loss }} & =\left(0.023 \pi \cdot\left(T-T_{w}\right)\right) \cdot k^{0.6} \cdot C_{p}^{0.4} \cdot \rho^{0.8} \cdot \mu^{-0.4} \cdot\left(\frac{Q}{\left(\frac{\pi}{4} \cdot D^{2} \cdot \Delta T\right) \cdot \rho \cdot C_{p}}\right)^{0.8} \cdot D^{0.8} \\
& =\left(\left(0.023 \pi \cdot\left(T-T_{w}\right)\right) \cdot\left(\frac{Q}{\left(\frac{\pi}{4} \cdot \Delta T\right)}\right)^{0.8}\right) \cdot k^{0.6} \cdot C_{p}^{-0.4} \cdot \mu^{-0.4} \cdot D^{-0.8} \cdot
\end{aligned}
$$

For the same heat duty and pumping power, Eq. (A-43) can be replaced with $D$ in Eq. (A-63) as

$$
\begin{aligned}
q_{\text {loss }} & =\left(\left(0.023 \pi \cdot\left(T-T_{w}\right)\right) \cdot\left(\frac{Q}{\left(\frac{\pi}{4} \cdot \Delta T\right)}\right)^{0.8} \cdot\left(\frac{Q^{2.75} \cdot\left(\frac{0.316 \cdot \pi}{8} L\right)}{P_{p u m p} \cdot \eta \cdot\left(\frac{\pi}{4} \Delta T\right)^{2.75}}\right)^{-0.17}\right) \cdot(k)^{0.6} \cdot(\mu)^{-0.44} \cdot(\rho)^{0.34} \cdot\left(C_{p}\right)^{0.06} \\
& =C_{2} \cdot(k)^{0.6} \cdot(\mu)^{-0.44} \cdot(\rho)^{0.34} \cdot\left(C_{p}\right)^{0.06} .
\end{aligned}
$$

The FOM for the heat loss is here defined by normalization as

$$
F O M_{h l}=\frac{q_{\text {loss }}}{q_{\text {loss }, 0}}
$$

where

$$
\begin{aligned}
& q_{\text {loss }}=\text { heat loss for a certain coolant, } \\
& q_{\text {loss }, 0}=\text { heat loss for a reference coolant. }
\end{aligned}
$$

Therefore,

$F O M_{h l}=\frac{(k)^{0.6} \cdot(\mu)^{-0.44} \cdot(\rho)^{0.34} \cdot\left(C_{p}\right)^{0.06}}{R_{h l, 0}}$. 
where

$$
R_{h l, 0}=\left(k_{0}\right)^{0.6} \cdot\left(\mu_{0}\right)^{-0.44} \cdot\left(\rho_{0}\right)^{0.34} \cdot\left(C_{p, 0}\right)^{0.06}
$$

According to Eq. (A-66), the coolant heat loss increases with thermal conductivity and decreases with heat capacity, density, and viscosity. The sensitivity of each property for the heat loss factor $\left(F O M_{h l}\right)$ can be calculated by normalized form as

$$
\begin{gathered}
S_{k, h l}=\frac{\partial F O M_{h l} / F O M_{h l}}{\partial k / k}=0.6 \\
S_{\rho, h l}=\frac{\partial F O M_{h l} / F O M_{h l}}{\partial \rho / \rho}=0.34 \\
S_{C_{p}, h l}=\frac{\partial F O M_{h l} / F O M_{h l}}{\partial C_{p} / C_{p}}=0.06 \\
S_{\mu, h l}=\frac{\partial F O M_{h l} / F O M_{h l}}{\partial \mu / \mu}=-0.44 .
\end{gathered}
$$

The above results show that the thermal conductivity is the most important property that affects the heat loss of the coolant followed by viscosity and coolant density. The effect of heat capacity is negligible.

\section{A-7. TEMPERATURE DROP FACTOR: FOM FOR TEMPERATURE DROP (FOM $\left.{ }_{D T}\right)$}

A heat transfer loop is required to transfer heat a very long distance with little temperature drop in order to minimize efficiency loss. The temperature drop of the coolants can be compared at the same heat duty and pumping power as shown in the above section. The temperature drop of the coolant originates from heat loss. Therefore, starting from Eq. (A-61) and rearranging as follows:

$$
q_{\text {loss }}=\frac{d Q}{d x}=\dot{m} \cdot C_{p} \cdot \frac{d T}{d x}=h \cdot(\pi \cdot D) \cdot\left(T-T_{w}\right) .
$$

Therefore,

$$
\frac{d T}{d x}=\frac{h \cdot(\pi \cdot D) \cdot\left(T-T_{w}\right)}{\dot{m} \cdot C_{p}}=\frac{h \cdot(\pi \cdot D) \cdot\left(T-T_{w}\right)}{Q / \Delta T} .
$$

where,

$$
\dot{m} \cdot C_{p}=\frac{Q}{\Delta T} .
$$

For the same heat duty and operating conditions, Eq. (A-74) is fixed. Therefore, the temperature drop equation (Eq. (A-74)) has the same form as the heat loss equation (Eq. (A-61)) except it is constant. 
The figure of merit (FOM) for the temperature drop is here defined by normalization as

$$
F O M_{d t}=\frac{(d T / d x)}{(d T / d x)_{0}}
$$

where

$d T / d x=$ temperature drop per unit length for a certain coolant,

$(d T / d T)_{0} \quad=$ temperature drop per unit length for the reference coolant.

Therefore,

$F O M_{d t}=\frac{(k)^{0.6} \cdot(\mu)^{-0.44} \cdot(\rho)^{0.34} \cdot\left(C_{p}\right)^{0.06}}{R_{d t, 0}}$.

where

$$
R_{d t, 0}=\left(k_{0}\right)^{0.6} \cdot\left(\mu_{0}\right)^{-0.44} \cdot\left(\rho_{0}\right)^{0.34} \cdot\left(C_{p, 0}\right)^{0.06}
$$

According to Eq. (A-77), the coolant temperature drop increases with thermal conductivity and decreases with heat capacity, density, and viscosity. The sensitivity of each property for the temperature drop factor $\left(F O M_{d t}\right)$ can be calculated by normalized form as

$$
\begin{gathered}
S_{k, d t}=\frac{\partial F O M_{d t} / F O M_{d t}}{\partial k / k}=0.6 \\
S_{\rho, d t}=\frac{\partial F O M_{d t} / F O M_{d t}}{\partial \rho / \rho}=0.34 \\
S_{C_{p} . d t}=\frac{\partial F O M_{d t} / F O M_{d t}}{\partial C_{p} / C_{p}}=0.06 \\
S_{\mu, d t}=\frac{\partial F O M_{d t} / F O M_{d t}}{\partial \mu / \mu}=-0.44 .
\end{gathered}
$$

The above results show that the thermal conductivity is the most important property that affects the temperature drop followed by viscosity and coolant density, respectively. The effect of heat capacity is negligible.

\section{A-8. SUMMARY OF FOMS FOR HEAT TRANSFER COOLANT}

Table A-1 summarizes all of the FOMs derived and proposed for the intermediate heat transfer coolants. This table lists six FOMs and sensitivities for various coolant properties. Based on the FOMs summarized, heat transfer performance, pumping power, coolant volume, pipe material volume, coolant heat loss, and coolant temperature drop can be compared easily and quantitatively for the same heat duty and pumping power requirements. A plus $(+)$ sign of a sensitivity indicates that the FOM increases with the properties while minus (-) sign indicates that the FOM decreases with the properties. The values of the sensitivities show how much the FOMs are affected by the properties. If the sensitivity is higher, the 
FOM is more significantly affected by that property. From this table, the effects of properties on the thermal-hydraulic performance of the coolants can be interpreted as follows:

- Increasing thermal conductivity can increase heat transfer performance by an order of 0.6 , but it also increases the heat loss and temperature drop of the coolant at the same rate.

- Increasing coolant density can increase heat transfer performance and reduce coolant volume by orders of 0.58 and 0.84 respectively. It also decreases pumping power by an order of 2 .

- Increasing heat capacity can increase heat transfer performance and significantly reduce coolant/material volume by orders of 0.4 and 1.16 respectively. Increases of heat loss and temperature drop are negligible (order $=0.06$ ). It also decreases pumping power by an order of 2.8 .

- Increasing viscosity increases pumping power slightly $(0.2)$ and significantly reduces heat transfer performance (0.47). It also slightly increases coolant volume (0.1).

Table A-1. Summary of FOMs for Heat Transfer Coolant.

\begin{tabular}{|c|c|c|c|c|c|}
\hline \multirow{2}{*}{ Figure of Merits } & \multicolumn{5}{|c|}{ Sensitivity of Properties } \\
\hline & $S_{k}$ & $S_{\rho}$ & $S_{C p}$ & $S_{\mu}$ & $S_{P}$ \\
\hline $\begin{array}{l}\text { Heat transfer performance factor }\left(F O M_{h t}\right) \text { : } \\
F O M_{h t}=\frac{(k)^{0.6} \cdot(\rho)^{0.58} \cdot\left(C_{p}\right)^{0.4} \cdot(\mu)^{-0.47}}{R_{h t, 0}}\end{array}$ & 0.6 & 0.58 & 0.4 & -0.47 & 0.0 \\
\hline $\begin{array}{l}\text { Pumping factor }\left(F O M_{p}\right) \text { : } \\
F O M_{p}=\frac{\rho^{-2} \cdot C_{P}^{-2.8} \cdot \mu^{0.2}}{R_{p, 0}}\end{array}$ & 0.0 & -2 & -2.8 & 0.2 & 0.0 \\
\hline $\begin{array}{l}\text { Coolant volume factor }\left(F O M_{c v}\right) \text { : } \\
F O M_{c v}=\frac{(\rho)^{-0.84} \cdot\left(C_{p}\right)^{-1.16} \cdot(\mu)^{0.1}}{R_{c v, 0}}\end{array}$ & 0.0 & -0.84 & -1.16 & 0.1 & 0.0 \\
\hline $\begin{array}{l}\text { Material Volume factor }\left(F O M_{c c v}\right) \text { : } \\
F O M_{c c v}=\frac{(P) \cdot(\rho)^{-0.84} \cdot\left(C_{p}\right)^{-1.16} \cdot(\mu)^{0.1}}{R_{c c v, 0}}\end{array}$ & 0.0 & -0.84 & -1.16 & 0.1 & 1.0 \\
\hline $\begin{array}{l}\text { Heat loss factor }\left(F O M_{h l}\right): \\
F O M_{h l}=\frac{(k)^{0.6} \cdot(\rho)^{0.34} \cdot\left(C_{p}\right)^{0.06} \cdot(\mu)^{-0.44}}{R_{h l, 0}}\end{array}$ & 0.6 & 0.34 & 0.06 & -0.44 & 0.0 \\
\hline $\begin{array}{l}\text { Temperature drop factor }\left(F O M_{d t}\right) \text { : } \\
F O M_{d t}=\frac{(k)^{0.6} \cdot(\rho)^{0.34} \cdot\left(C_{p}\right)^{0.06} \cdot(\mu)^{-0.44}}{R_{d t, 0}}\end{array}$ & 0.6 & 0.34 & 0.06 & -0.44 & 0.0 \\
\hline
\end{tabular}

